\title{
Simulating Occupancy in the NIST Net-Zero Energy Residential Test Facility
}

Farhad Omar

Steven T. Bushby 


\title{
Simulating Occupancy in the NIST Net-Zero Energy Residential Test Facility
}

\author{
Farhad Omar \\ Steven T. Bushby \\ Energy and Environment Division \\ Engineering Laboratory
}

http://dx.doi.org/10.6028/NIST.TN.1817

November 2013

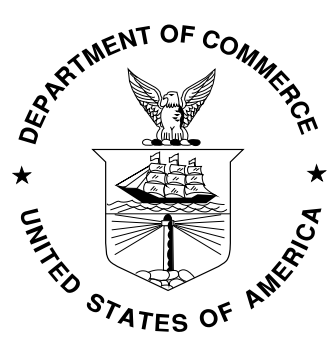

U.S. Department of Commerce

Penny Pritzker, Secretary

National Institute of Standards and Technology Patrick D. Gallagher, Under Secretary of Commerce for Standards and Technology and Director 


\section{Disclaimer}

Certain commercial entities, equipment, or materials may be identified in this document in order to describe an experimental procedure or concept adequately. Such identification is not intended to imply recommendation or endorsement by the National Institute of Standards and Technology, nor is it intended to imply that the entities, materials, or equipment are necessarily the best available for the purpose.

National Institute of Standards and Technology Technical Note 1817 Natl. Inst. Stand. Technol. Tech. Note 1817, 65 pages (November 2013) 


\begin{abstract}
The Net-Zero Energy Residential Test Facility (NZERTF), at the National Institute of Standards and Technology (NIST) in Gaithersburg, Maryland, is a research house that is comparable in size and aesthetic to the houses in the greater Washington DC metro area. The purpose of the NZERTF is to demonstrate the feasibility of achieving net zero energy over the course a year (i.e., energy generated using photovoltaic modules and a solar hot water system equals energy consumed). The lifestyle choices of the occupants can have a substantial effect on the overall energy consumption of the house. As a laboratory facility, a methodology was needed to simulate the occupants' behavior. The occupancy in the NZERTF is emulated by a virtual family of four whose behavior and activities are based on recommendations published by the U.S. Department of Energy. In order to attempt to realistically emulate the daily activities of the virtual family it is necessary to replicate their occupancy profiles, water usage, lighting usage, miscellaneous electric plug loads, cooking loads, appliances loads, and sensible and latent loads. This paper discusses the methodology, strategy, and hardware behind emulating the occupancy in the NZERTF.
\end{abstract}

\title{
Keywords
}

Net zero energy house; net zero energy residential test facility; occupancy profile; occupancy schedule; occupancy emulation; daily occupancy emulation schedule 


\section{Acknowledgments}

The authors wish to thank everyone involved in the Net Zero Residential Test Facility project. Special thanks to Mark Davis, William Healy, Hunter Fanney, Piotr Domanski, Vance Payne, Harrison Skye, Mark Kedzierski, Tania Ullah, Andy Persily, Lisa Ng, Glen Glaeser, John Wamsley, David Yashar, Sandra Heckman, Monyelle Mingo, and Joshua Kneifel of Engineering Laboratory. The authors also wish to thank Michael J. Vanderploey, Vincent P. Anderson, and Alan R. Frank of Whirlpool Corporation, Charlie Smith of GE Appliances, and Benjamin King of BSH Home Appliances.

\section{Authors Information}

Farhad Omar

Electrical Engineer

National Institute of Standards and Technology

100 Bureau Drive, Mailstop 8631

Gaithersburg, MD, 20899

Tel: $301-975-4008$

Email: farhad.omar@nist.gov

Steven T. Bushby

Mechanical Engineer, Leader of Mechanical Systems \& Controls Group

National Institute of Standards and Technology

100 Bureau Drive, Mailstop 8631

Gaithersburg, MD, 20899

Tel: $301-975-5873$

Email: steven.bushby@nist.gov 


\section{Contents}

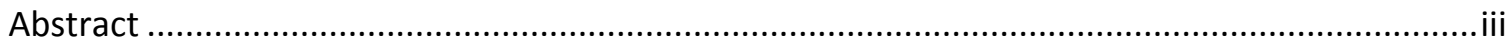

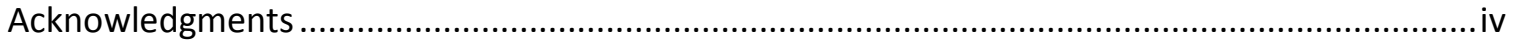

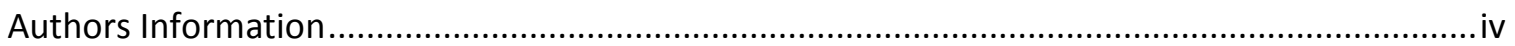

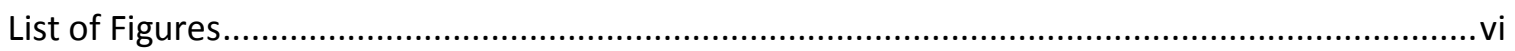

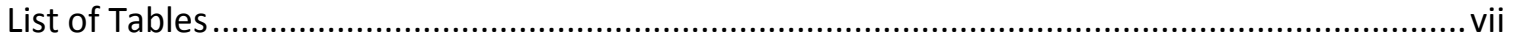

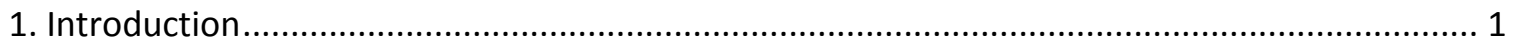

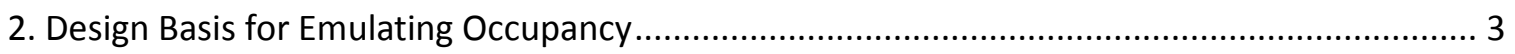

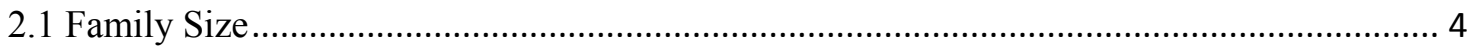

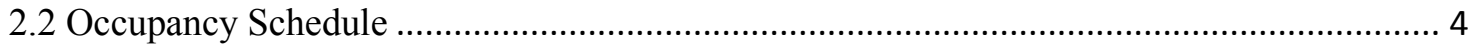

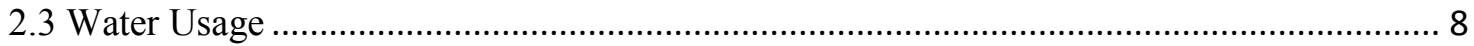

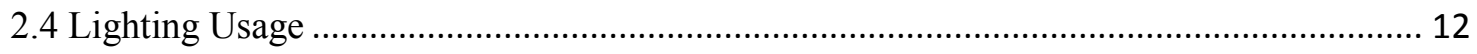

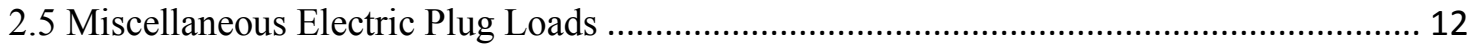

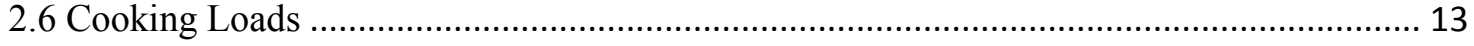

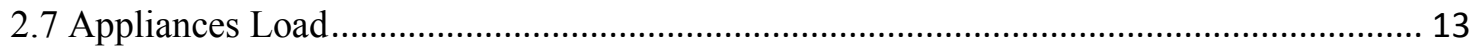

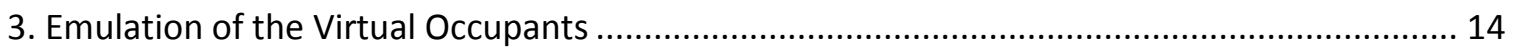

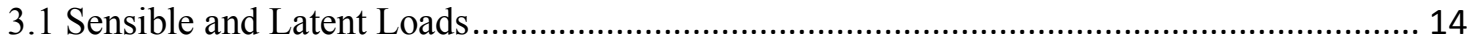

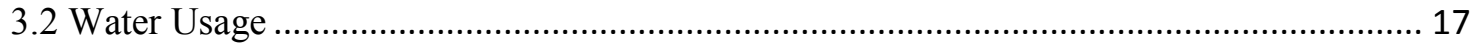

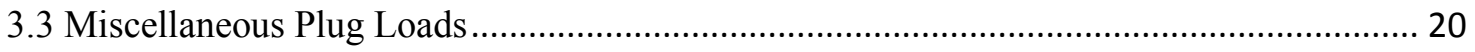

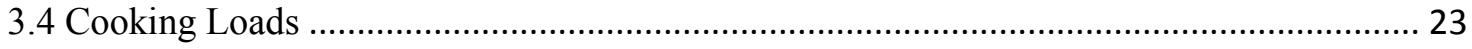

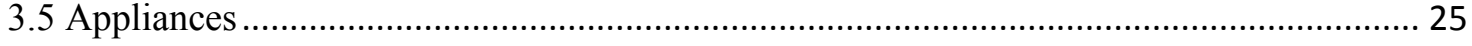

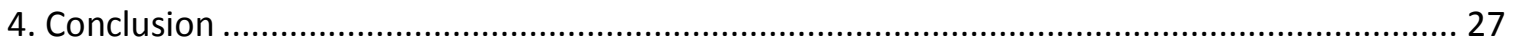

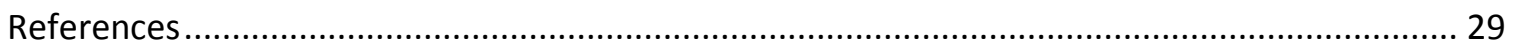




\section{List of Figures}

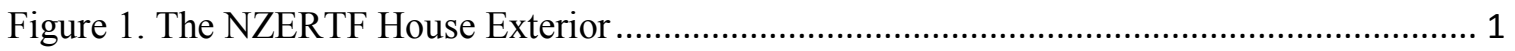

Figure 2. The NZERTF first floor plan ............................................................................... 2

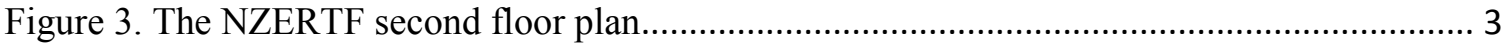

Figure 4. Build America benchmark occupancy profile by day type and space type Occ-WD

(occupancy week days) and Occ-WE (occupancy weekends) - ................................................. 4

Figure 5. NZERTF occupancy profile for Mondays and Wednesdays ........................................ 5

Figure 6. NZERTF occupancy profile for Tuesdays and Thursdays............................................ 6

Figure 7. NZERTF occupancy profile for Fridays ............................................................ 6

Figure 8. NZERTF occupancy profile for Saturdays .............................................................. 7

Figure 9. The occupancy profile for Sundays....................................................................... 7

Figure 10. Median number of draws and variation for households at various levels of occupancy,

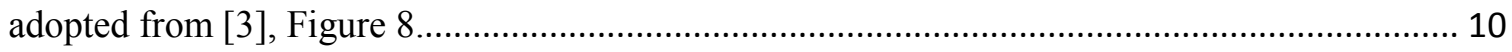

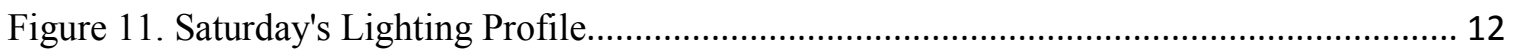

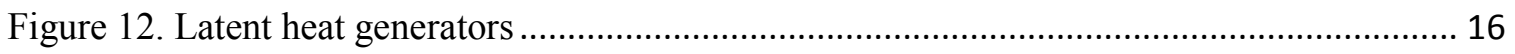

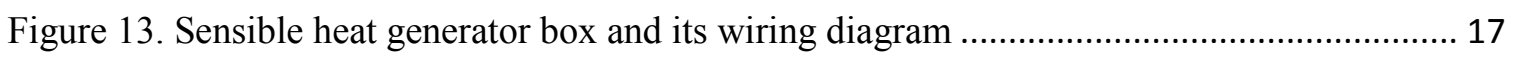

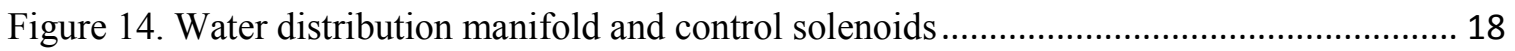

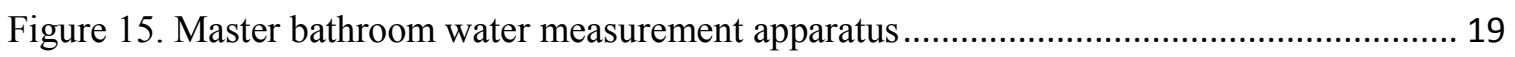

Figure 16. Kitchen sink water measurement apparatus ........................................................ 19

Figure 17. The heating elements for plug loads with larger than $200 \mathrm{~W}$ power requirement

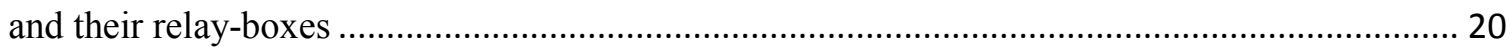

Figure 18. The relay-box, its wiring diagram, and a toaster plugged into it ................................ 21

Figure 19. The electric two-burner portable hot plate, the range hood, and the relay-box ........... 24

Figure 20. The oven Controller-box and its wiring schematic .................................................. 25

Figure 21. The dryer, modified misting nozzle, and the washer .............................................. 26 


\section{List of Tables}

Table 1. Total volume of water consumption from showers, baths, and sinks for 4 bedrooms $\left(\mathrm{N}_{\mathrm{br}}=4\right)$. (Equations adapted from [2], Table 10.)* ........................................... 8

Table 2 . The total daily water consumption per person per event and the remaining water volume

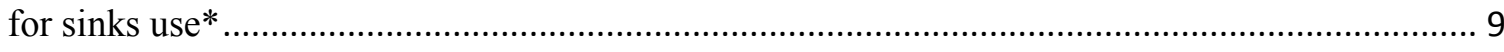

Table 3. The daily number of kitchen and bathroom sink draws ............................................. 11

Table 4 . The daily distribution of water consumption by the kitchen and bathroom sinks*........ 11

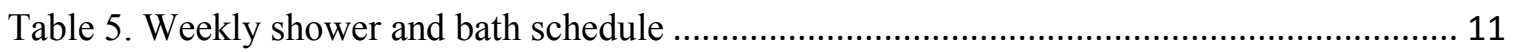

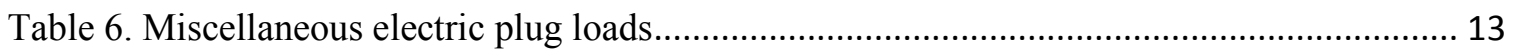

Table 7. Daily cycles for clothes washer, clothes dryer, and dishwasher .................................... 14

Table 8. Estimated volume of moisture during cooking events, adapted from [9],

Table labeled Household moisture sources* ......................................................................... 15

Table 9. Total daily moisture generated by cooking events and the NZERTF occupants ............ 15

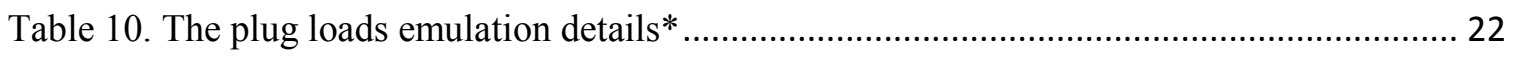

Table 11. Cooking appliances emulation details ................................................................... 23 


\section{Introduction}

The Net-Zero Energy Residential Test Facility (NZERTF), at the National Institute of Standards and Technology (NIST) in Gaithersburg, Maryland, is a research house that is comparable in size and aesthetics to the houses in the greater Washington DC metro area. The NZERTF serves two purposes: the first is to demonstrate the feasibility of achieving net zero energy operation energy generated using photovoltaic modules and solar hot water heaters equals the total energy consumed - over the course of one year. Second, the facility will be used to test existing and new energy efficient and smart grid technologies, and develop test methods that better reflect how those technologies will perform in a real home, rather than in a laboratory. The NZERTF construction was funded by the American Recovery and Reinvestment Act (ARRA). The exterior of the NZERTF is shown in Figure 1.

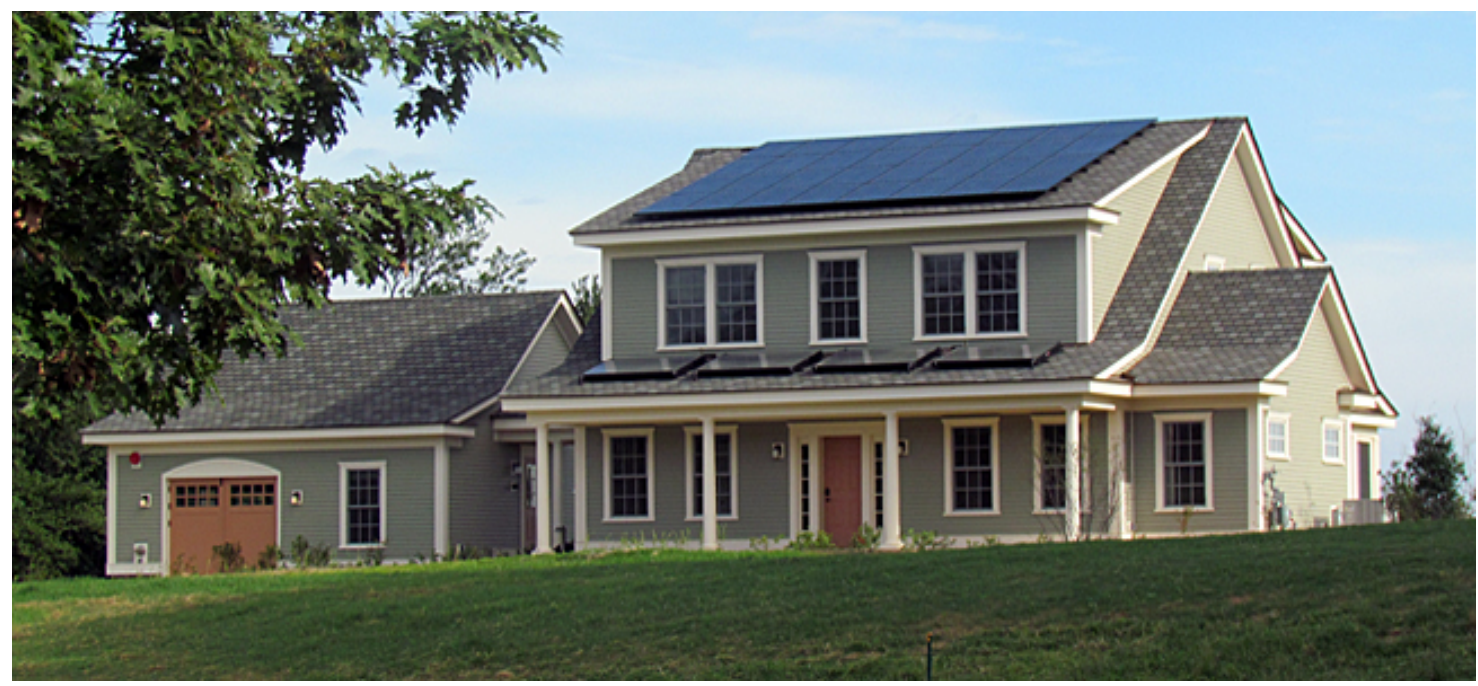

Figure 1. The NZERTF House Exterior

The NZERTF is a $251 \mathrm{~m}^{2}\left(2700 \mathrm{ft}^{2}\right)$, four bedroom house with a detached garage built entirely with commercially available products. Figure 2 shows the floor plan for the first floor that includes a living room, dining room, kitchen, a bedroom/office, a bathroom, and an unconditioned porch. Figure 3 shows the floor plan for the second floor containing a master bedroom, master bathroom, two other bedrooms, and a bathroom. The detached garage houses the control and measurement equipment used to operate the house. The energy used by the control and measurement equipment and to space condition the garage is not considered part of home's energy consumption.

The activities and habits of the occupants have a major impact on the energy consumption of a home. However, the NZERTF is not occupied by people. Instead the daily activities of the NZERTF occupants are emulated by hardware and software. In the initial year of operation, a virtual family of four is prescribed as the occupants of the facility. The software activates major appliances, plug loads such as entertainment systems, and specially designed devices built to represent the latent and sensible heat generated by the activities of the virtual human occupants. 
This report describes in detail the assumptions made about the virtual family's activities and how the resultant energy loads are imposed upon the house in order to provide a realistic approximation of a family living in the facility.

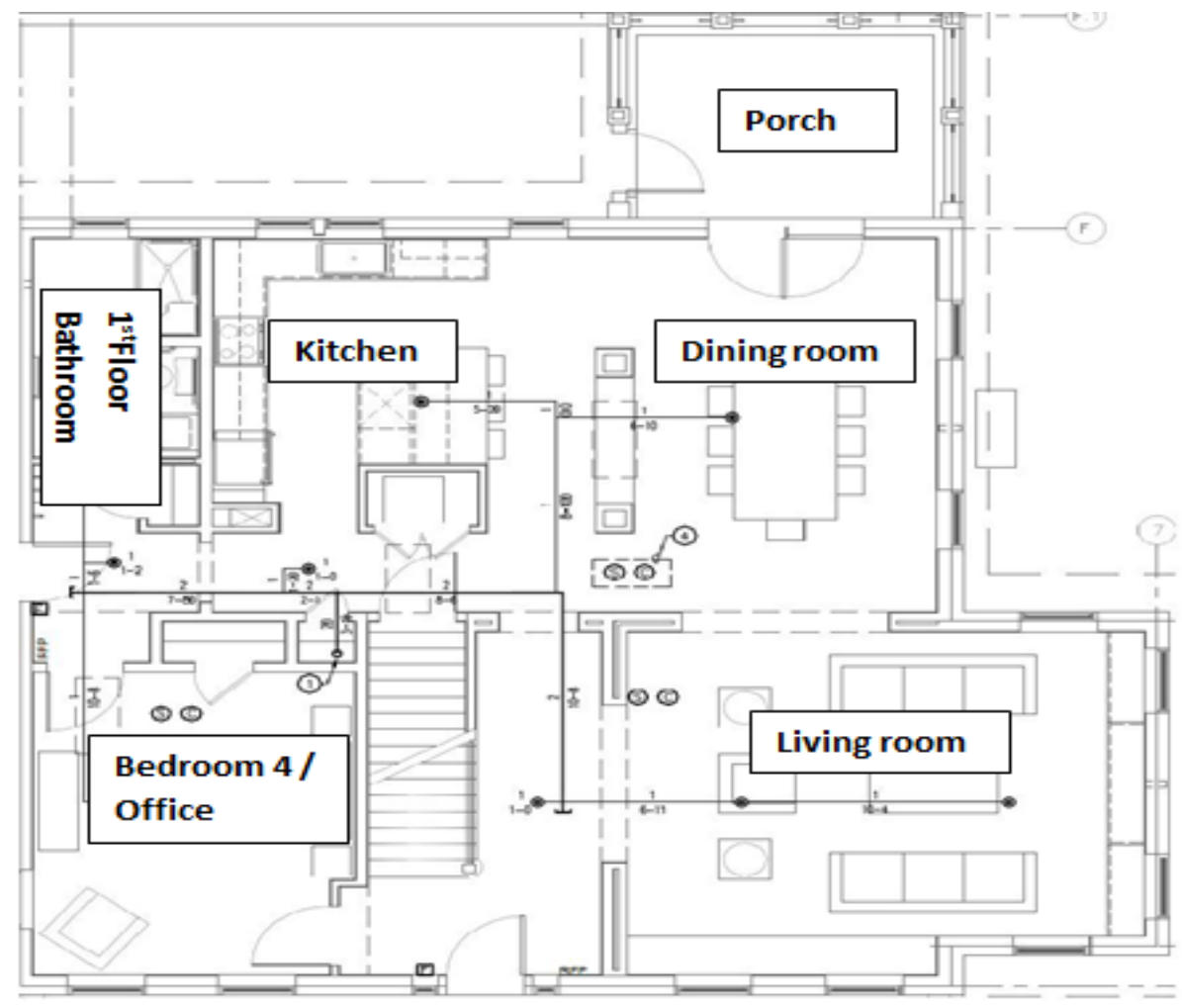

Figure 2. The NZERTF first floor plan 


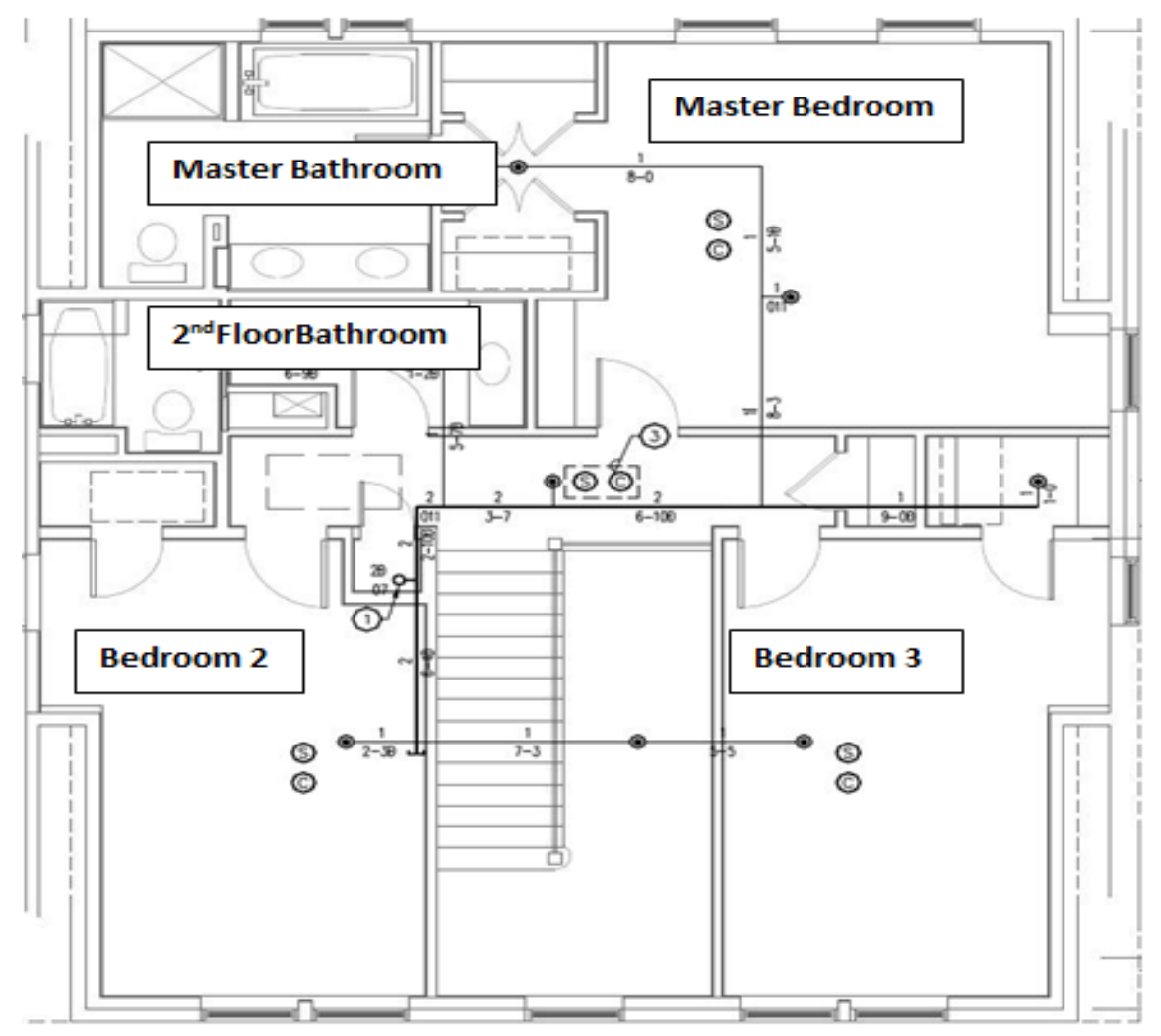

Figure 3. The NZERTF second floor plan

\section{Design Basis for Emulating Occupancy}

A myriad of detailed choices must be made to realistically emulate the daily activities of a family and the resulting energy impacts. These lifestyle choices can have a substantial effect on energy consumption [1]. Although the NZERTF was designed to have very energy efficient heating, ventilating, and air-conditioning (HVAC) systems, lighting, and appliances, it was assumed that the lifestyle of the occupants would not be substantially different from families living in a conventional house.

Rather than just make an extensive set of arbitrary choices and assumptions about the lifestyle of the virtual NZERTF occupants, the approach taken was to make use of user profiles developed for the U.S. Department of Energy (DOE) Building America program. The Building America program is a multi-year collaboration between DOE national laboratories and top U.S. home builders intended to substantially improve the energy efficiency of homes. In order to measure progress in improving the energy efficiency of homes, the Building America program has established a benchmark intended to be consistent with mid-1990s standard practices [2]. This benchmark includes a series of user profiles intended to represent occupant behavior. The Building America user profiles were used where applicable as the basis for determining all of the details needed to simulate occupancy in the NZERTF. 


\subsection{Family Size}

The first key decision to make is the number of people in the virtual family. According to the survey data reported in [2], the number of occupants in a single-family house can be estimated by Equation 1.

Number of occupants $=0.59 \times \mathrm{N}_{\mathrm{br}}+0.87$

Where, $\mathrm{N}_{\mathrm{br}}$ is the number of bedrooms.

Applying this equation to the four bedroom NZERTF would indicate that the average number of occupants over a large population would be 3.23 people. Since we cannot have fractions of people it was decided that the virtual family would consist of two adults and two children. The ages of the children are arbitrarily selected to be fourteen (middle school age) and eight years old (elementary school age). School attendance factors into the family's daily routines. In this report, the fourteen year old is identified as ChildA and the eight year old is identified as ChildB.

\subsection{Occupancy Schedule}

The occupancy schedule drives many of the energy loads in the house. To determine the schedule for appliance usage and to account for the sensible and latent load from the people, it is necessary to determine when the occupants are home and when they are in various parts of the house.

Figure 4 shows normalized occupancy patterns for weekdays and weekends that are used in the Building America benchmark [2]. Two space types are considered in this profile; bedrooms and living room.

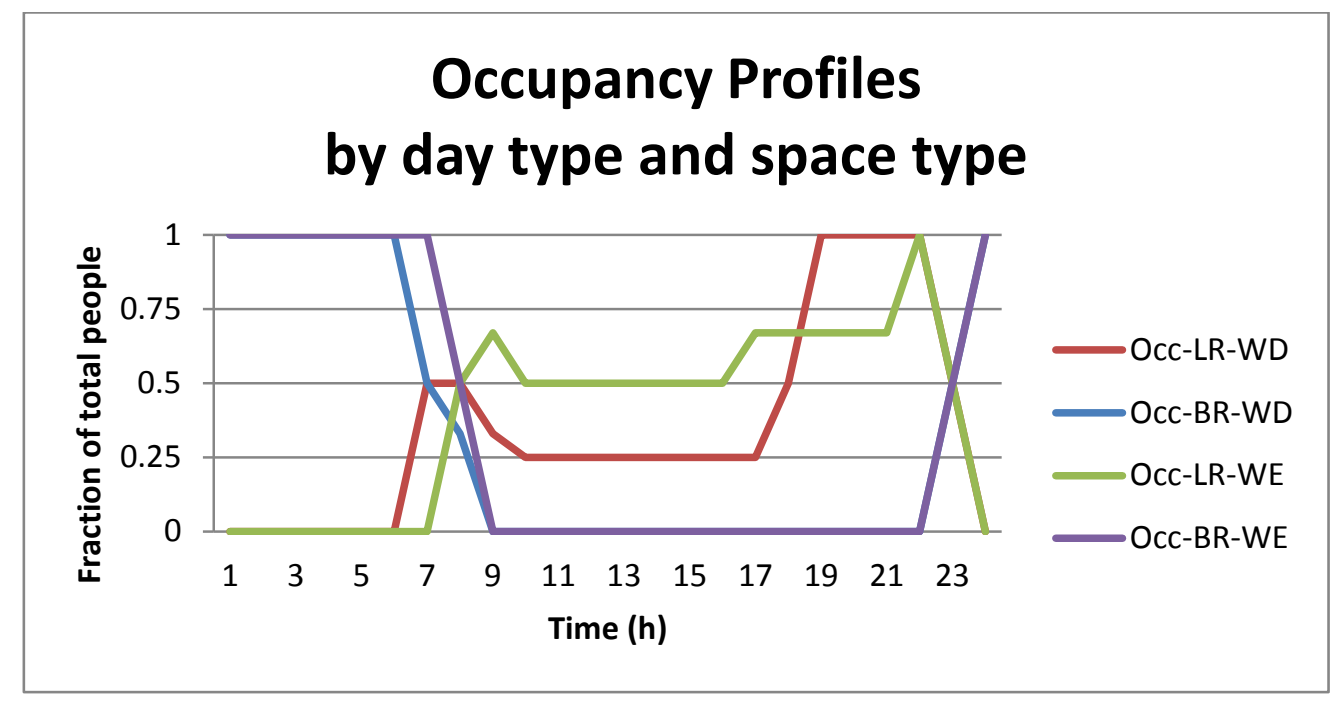

Figure 4. Build America benchmark occupancy profile by day type and space type Occ-WD (occupancy week days) and Occ-WE (occupancy weekends) LR (living room) - BR (bedroom), Adapted from [1] Figure 24. 
The occupancy profile, in Figure 4, was used as a guide to develop the occupancy profile details for the NZERTF. Additional details about the virtual family must be assumed to help fill in the daily routine details. It is assumed that both parents work outside the home leaving the house at 8:30 a.m. and returning home at 6:00 p.m. As previously noted, ChildA is a fourteen year old middle school student and ChildB is an eight year old elementary school student. It is assumed that both the middle school and the elementary school start at 8:30 a.m. and end at 3:30 p.m. Arrangements have been made for after school care for ChildB every week day. ChildA has a variable schedule that depends on the day of the week. Both children leave the house at 8:00 a.m. ChildB returns home every day at 6:00 p.m. ChildA returns home at 6:00 p.m. on Mondays, Wednesdays and Fridays, and 4:00 p.m. on Tuesdays and Thursdays. During the summer, it is assumed that the children attend day care or camp outside of the home and, thus, follow the same schedule.

The net result is that on Mondays, Wednesdays, and Fridays the house is unoccupied from 8:30 a.m. to 6:00 p.m. On Tuesdays and Thursdays, the house is unoccupied from 8:30 a.m. to 4:00 p.m. when ChildA returns home. On weekends it was assumed that at least two members of the family are at home at any given time. The family does not take vacations or host large parties such as birthday gatherings.

Figures 5 through Figure 9 represent the daily occupancy profiles of the NZERTF developed by applying these additional constraints to the profile shown in Figure 4. For the NZERTF, occupancy of the living room is taken to mean occupancy anywhere that is not in a bedroom. For simplicity and repeatability, the same weekly schedule is used for 52 weeks, irrespective of the seasons or holidays.

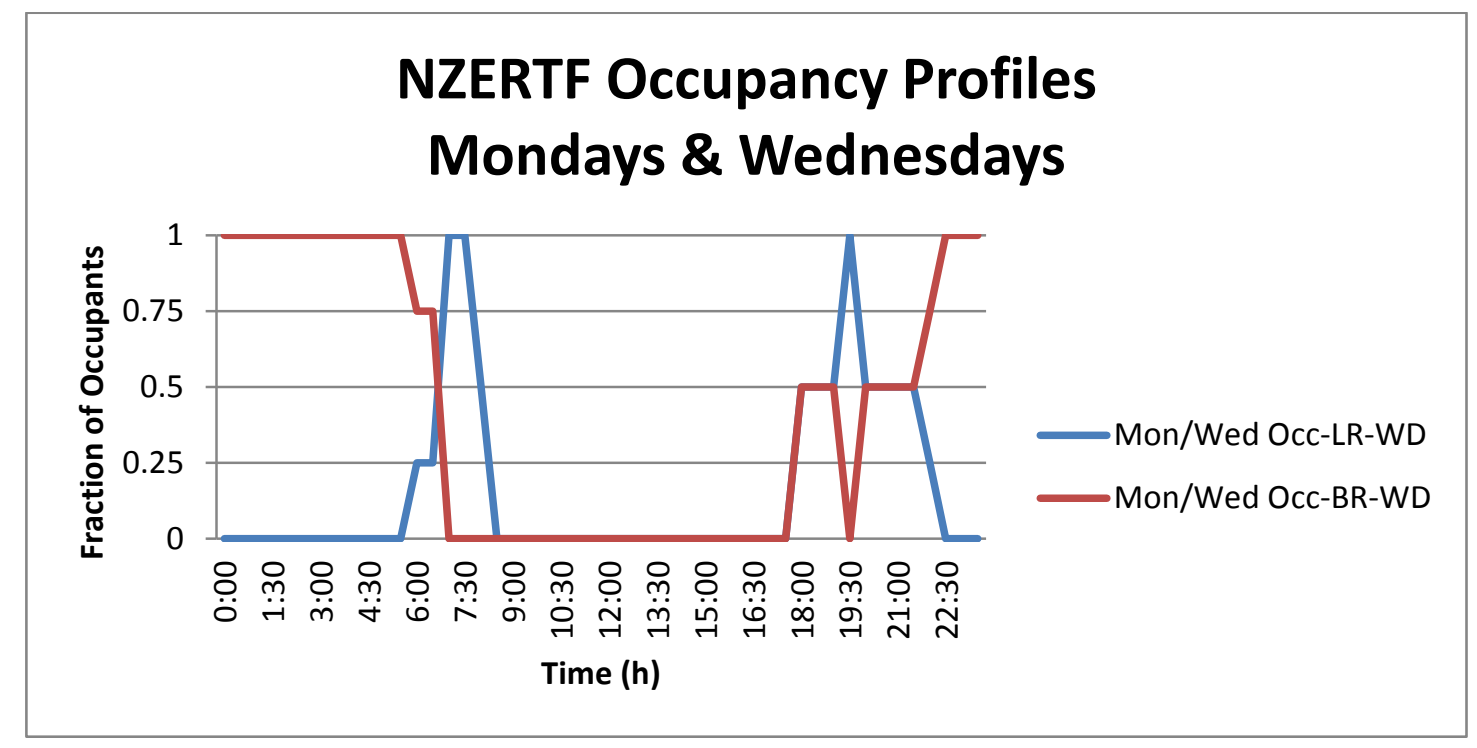

Figure 5. NZERTF occupancy profile for Mondays and Wednesdays 


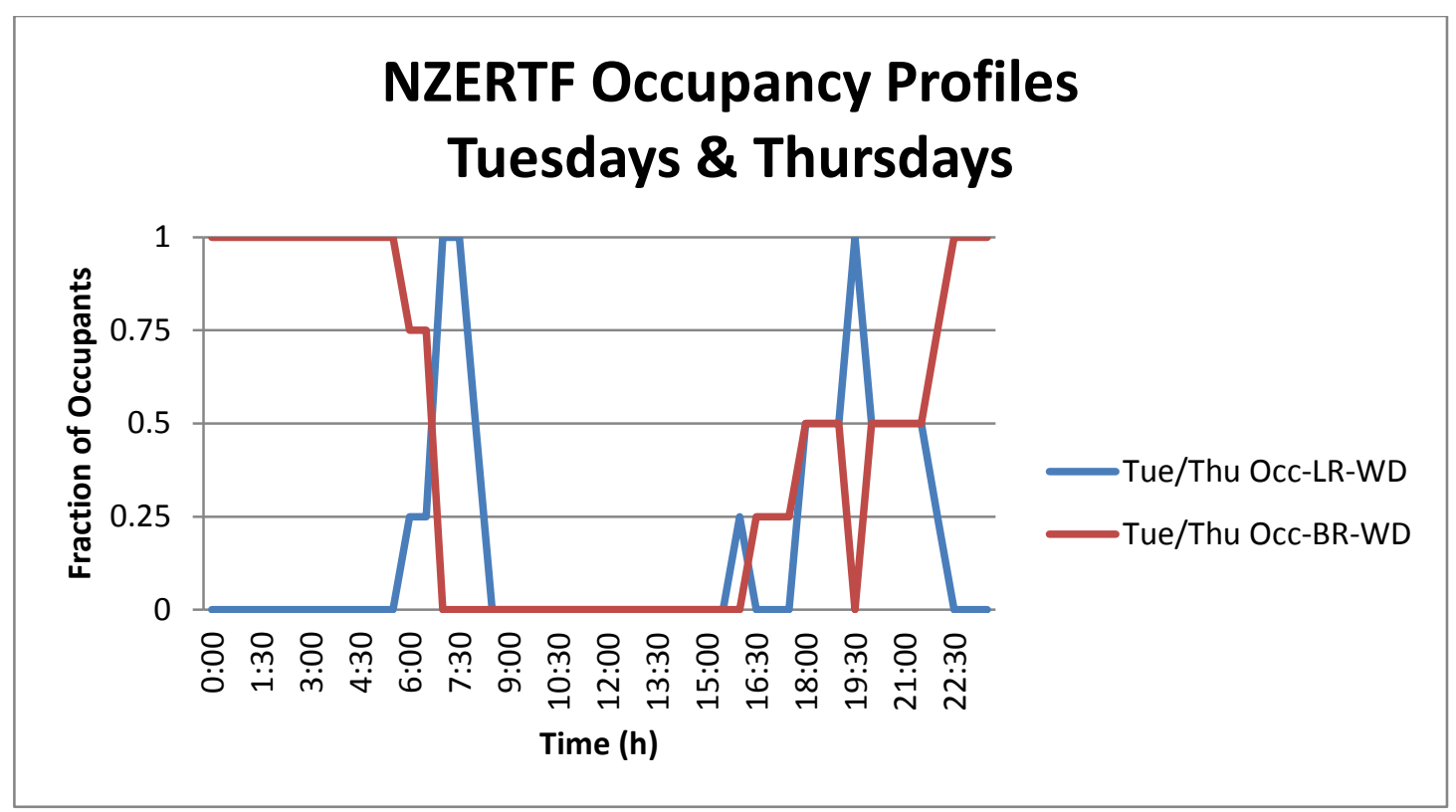

Figure 6. NZERTF occupancy profile for Tuesdays and Thursdays

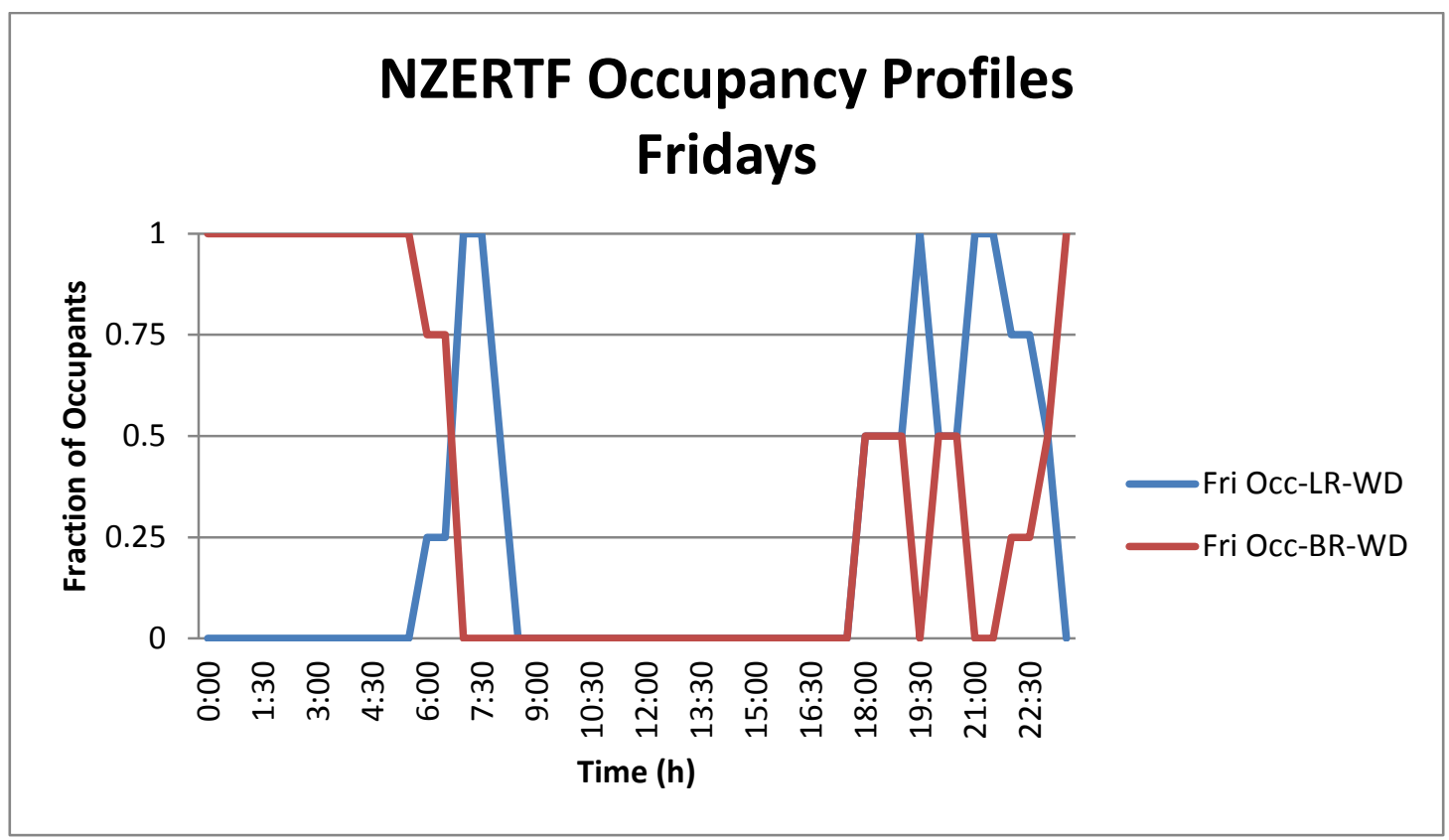

Figure 7. NZERTF occupancy profile for Fridays 


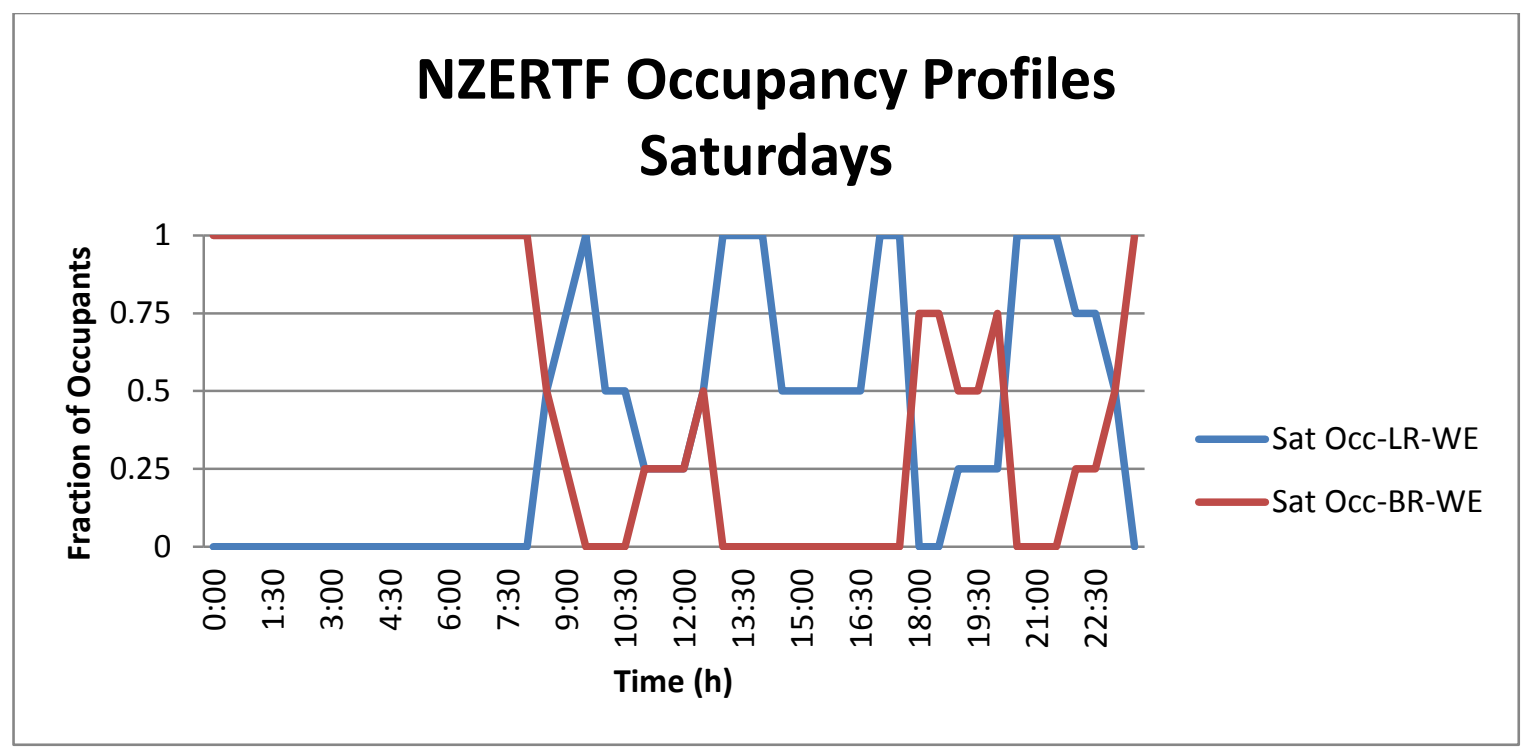

Figure 8. NZERTF occupancy profile for Saturdays

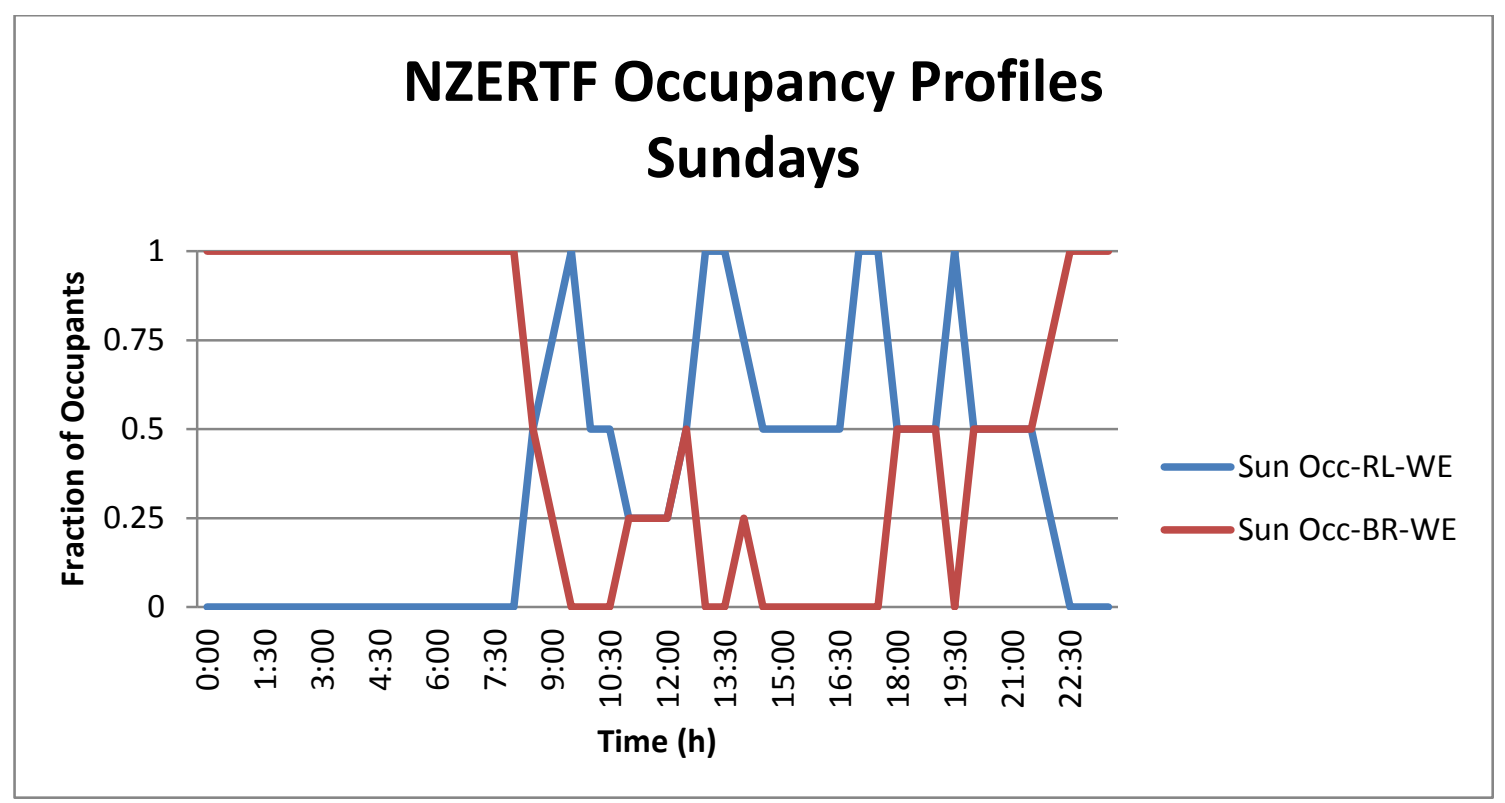

Figure 9. The occupancy profile for Sundays

Establishing the house occupancy pattern enables the development of detailed schedules for other energy consuming activities because occupant initiated activities must take place when the house is occupied. 


\subsection{Water Usage}

Water consumption is an important aspect of the daily activities of the NZERTF occupants. To simulate the water draw activities, it was necessary to identify the total daily volume of water use and identify the mechanisms (i.e., shower and sink use) by which the water is used. As the focus of the facility is on energy use, those end uses that use purely cold water (e.g., toilets) are not simulated. Table 1 summarizes the average daily water consumption from showers, baths, and sinks for a family of four was calculated from the average of three domestic hot-water studies reported in [2].

Table 1. Total volume of water consumption from showers, baths, and sinks for 4 bedrooms $\left(\mathrm{N}_{\mathrm{br}}=4\right)$. (Equations adapted from [2], Table 10.)*

\begin{tabular}{|l|l|l|c|}
\hline \multicolumn{1}{|c|}{ End Use } & $\begin{array}{c}\text { End-Use } \\
\text { Water } \\
\text { Temp. }\end{array}$ & $\begin{array}{c}\text { Water Usage } \\
\text { (gallons/day) }\end{array}$ & $\begin{array}{c}\text { Daily Water } \\
\text { Usage for Four } \\
\text { Bedrooms } \\
\text { (liters/gallons) }\end{array}$ \\
\hline Shower & $\begin{array}{l}40.6^{\circ} \mathrm{C} \\
\left(105^{\circ} \mathrm{F}\right)\end{array}$ & $\begin{array}{l}14.0+4.67 \times \mathrm{N} \mathrm{N}_{\mathrm{br}} \\
(\mathrm{Hot}+\mathrm{Cold})\end{array}$ & $123.7 / 32.7$ \\
\hline Bath & $\begin{array}{l}40.6^{\circ} \mathrm{C} \\
\left(105^{\circ} \mathrm{F}\right)\end{array}$ & $\begin{array}{l}3.5+1.17 \times \mathrm{N} \mathrm{br} \\
(\mathrm{Hot}+\mathrm{Cold})\end{array}$ & $31.0 / 8.2$ \\
\hline Sinks & $\begin{array}{l}40.6^{\circ} \mathrm{C} \\
\left(105^{\circ} \mathrm{F}\right)\end{array}$ & $\begin{array}{l}12.5+4.16 \times \mathrm{N}_{\mathrm{br}} \\
(\mathrm{Hot}+\mathrm{Cold})\end{array}$ & $110.3 / 29.1$ \\
\hline Total Daily Volume & & & $\mathbf{2 6 5 . 0} / \mathbf{7 0 . 0}$ \\
\hline
\end{tabular}

*The numbers are calculations used for target set-point and do not reflect the measurement accuracy

According to Table 1, the total daily water usage for showers, baths, and sinks is 265 liters (70 gallons); this number does not include the water consumption by the dishwasher or clothes washer. The dishwasher and clothes washer water usage are determined by their internal mechanisms and we do not restrict their normal operation.

To develop the water draw schedule, we assumed that each occupant bathes once per day. Both parents and ChildA always shower, while ChildB sometimes showers and sometimes takes a bath. Even though some daily variation in bathing was considered desirable, we determined that the weekly volume of water usage must comply with the 1855 liters/week (490 gallons/week) derived from Table 1. Table 2 shows the details of the bathing water consumption assumed throughout the week in order to meet these assumptions. 
Table 2. The total daily water consumption per person per event and the remaining water volume for sinks use*

\begin{tabular}{|c|c|c|c|c|c|c|}
\hline Days & $\begin{array}{c}\text { ParentA + } \\
\text { ParentB } \\
\text { Showers } \\
\text { (liters/gallons) }\end{array}$ & $\begin{array}{c}\text { ChildA } \\
\text { Showers } \\
\text { (liters/gallons) }\end{array}$ & $\begin{array}{c}\text { ChildB } \\
\text { Showers or } \\
\text { Baths } \\
\text { (liters/gallons) }\end{array}$ & $\begin{array}{c}\text { Total Showers } \\
\text { \& Baths } \\
\text { (liters/gallons) }\end{array}$ & $\begin{array}{c}\text { Remaining } \\
\text { for Sink } \\
\text { (liters/gallons) }\end{array}$ & $\begin{array}{c}\text { Total Daily } \\
\text { Volume } \\
\text { (liters/gallons) }\end{array}$ \\
\hline Monday & $66.24 / 17.50$ & $53.00 / 14.00$ & $33.12 / 8.75$ & $152.36 / 40.25$ & $95.32 / 25.18$ & $247.68 / 65.43$ \\
\hline Tuesday & $66.24 / 17.50$ & $53.00 / 14.00$ & $33.12 / 8.75$ & $152.36 / 40.25$ & $95.32 / 25.18$ & $247.68 / 65.43$ \\
\hline Wednesday & $66.24 / 17.50$ & $33.12 / 8.75$ & $113.56 / 30.00$ & $212.93 / 56.25$ & $95.32 / 25.18$ & $308.25 / 81.43$ \\
\hline Thursday & $66.24 / 17.50$ & $53.00 / 14.00$ & $33.12 / 8.75$ & $152.36 / 40.25$ & $95.32 / 25.18$ & $247.68 / 65.43$ \\
\hline Friday & $66.24 / 17.50$ & $53.00 / 14.00$ & $33.12 / 8.75$ & $152.36 / 40.25$ & $95.32 / 25.18$ & $247.68 / 65.43$ \\
\hline Saturday & $66.24 / 17.50$ & $33.12 / 8.75$ & $113.56 / 30.00$ & $212.93 / 56.25$ & $95.32 / 25.18$ & $308.25 / 81.43$ \\
\hline Sunday & $66.24 / 17.50$ & $53.00 / 14.00$ & $33.12 / 8.75$ & $152.36 / 40.25$ & $95.32 / 25.18$ & $247.68 / 65.43$ \\
\hline
\end{tabular}

* The numbers are calculations used for target set-points and do not reflect the measurement accuracy

The column labeled as "Remaining for Sink" shows the total daily volume of water to be consumed by sink draws. The total weekly volume of water consumption is 1855 liters (490 gallons), of which 1188 liters (314 gallons) are allocated for showers and baths. The remaining volume of 667 liters (176 gallons) is allocated for the sink draws. The weekly sink volume (667 liters) was equally divided over seven days to compute the daily water consumption for sink events. Recall that the weekly volume of 1855 liters does not include the water consumption by the dishwasher or clothes washer.

The NZERTF sink draws are separated into two categories, bathrooms' sink draws and kitchen sink draws. According to Hot Water Draw Patterns in Single-Family Houses: Findings from Field Studies, the median number of hot water draws for most households ranged between 25 to 100 draws [3].The report in [3] is the result of work sponsored by the California Energy Commission and describes hot water draw patterns that the Lawrence Berkeley National Laboratory obtained from ten studies. Figure 10 shows the variation of median number of daily hot water draws by the number of occupant. 


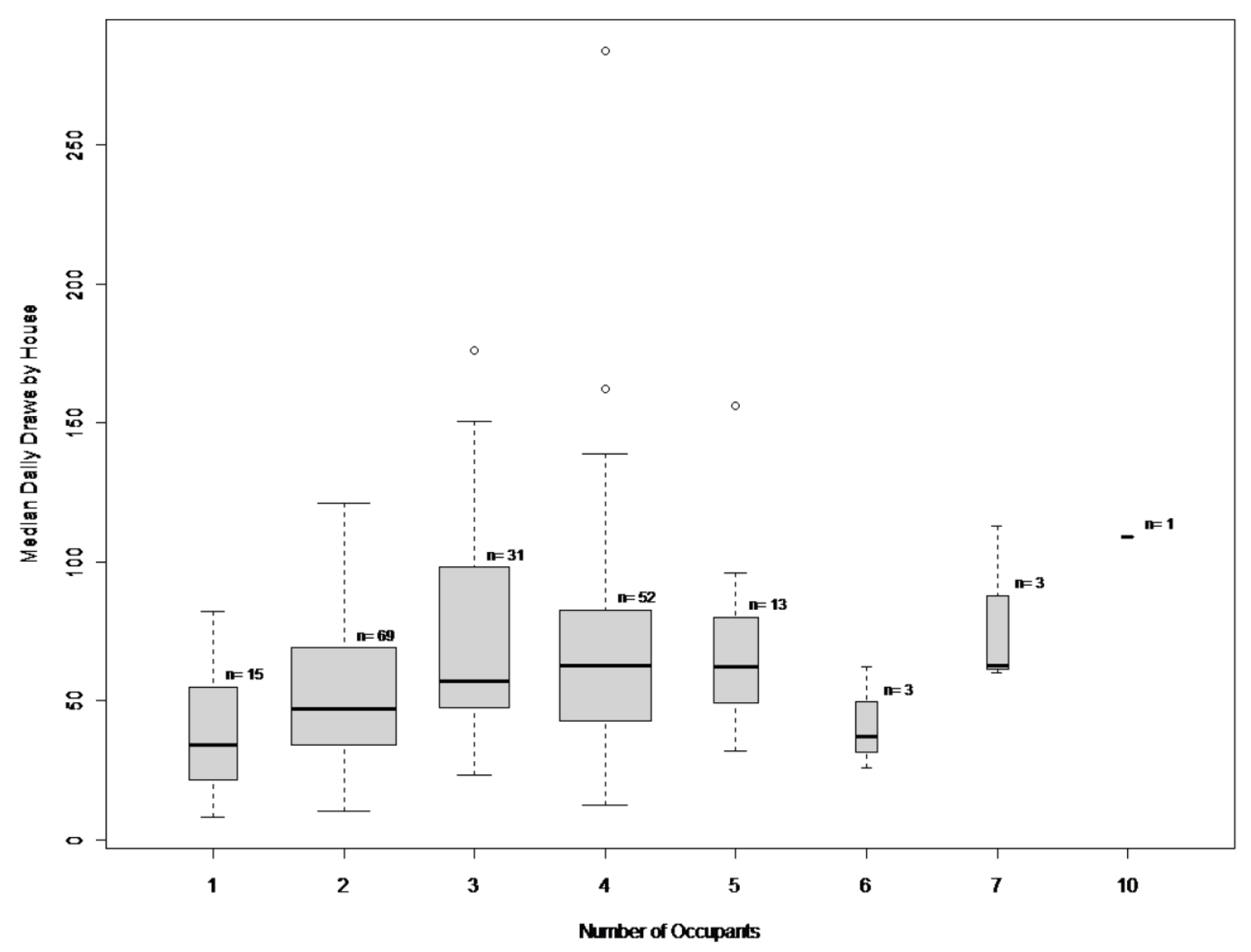

Figure 10. Median number of draws and variation for households at various levels of occupancy, adopted from [3], Figure 8.

In the NZERTF, the goal was to obtain a representative number of water draws that remain within the median range described above. A representative number of draws for the kitchen and bathroom sinks, was obtained from the Standardized Domestic Hot Water (DHW) Event Schedules for Residential Buildings developed by the National Renewable Energy Laboratory (NREL) [4]. The standardized event schedule generator, in spreadsheet format, provides a detailed daily schedule of DHW usage for a year. The methodology used in [4] takes into account the fact that the water main temperature effects the mixture of hot and cold water used. The number of draws for sinks, based on a user-selected typical meteorological year (TMY) site, can be extracted from the schedule. In this case, the TMY for Baltimore-Washington International Airport in Maryland was selected According to the event generator, there are 10367 kitchen sink and 4439 bathroom sink draws [4]. To obtain the total daily number of draws, the total kitchen and bathroom sink draws were divided by 365 days. Table 3 shows the number of kitchen and bathroom sink draws obtained from the event generator. 
Table 3. The daily number of kitchen and bathroom sink draws

\begin{tabular}{|l|c|}
\hline Number of Kitchen Sink Draws/Year & 10367 \\
\hline Daily Kitchen Sink Draws & 28 \\
\hline Number of Bathroom Sinks Draws/Year & 4439 \\
\hline Daily Bathroom Sink Draws & 12 \\
\hline
\end{tabular}

The number of draws shown in Table 3 combined with the total sink draw volumes shown in Table 2 was used to compute the volume of water drawn by each sink event. Table 4 shows the daily water consumption by the bathroom and kitchen sink fixtures.

Table 4. The daily distribution of water consumption by the kitchen and bathroom sinks*

\begin{tabular}{|c|c|c|c|c|c|}
\hline Days & $\begin{array}{c}\text { Remaining } \\
\text { for Sinks } \\
\text { (liters/gallons) }\end{array}$ & $\begin{array}{c}\text { Number } \\
\text { of } \\
\text { Draws } \\
\text { Kitchen + } \\
\text { Bathroom } \\
\text { Sinks }\end{array}$ & $\begin{array}{c}\text { Volume/Draw } \\
\text { (liters/gallons) }\end{array}$ & $\begin{array}{c}\text { Total Volume } \\
\text { Drawn by the } \\
\text { Kitchen Sink } \\
\text { (liters/gallons) }\end{array}$ & $\begin{array}{c}\text { Total Volume } \\
\text { Drawn by the } \\
\text { Bathroom Sinks } \\
\text { (liters/gallons) }\end{array}$ \\
\hline Monday & $95.32 / 25.18$ & 40 & $2.38 / 0.63$ & $66.72 / 17.63$ & $28.59 / 7.55$ \\
\hline Tuesday & $95.32 / 25.18$ & 40 & $2.38 / 0.63$ & $66.72 / 17.63$ & $28.59 / 7.55$ \\
\hline Wednesday & $95.32 / 25.18$ & 40 & $2.38 / 0.63$ & $66.72 / 17.63$ & $28.59 / 7.55$ \\
\hline Thursday & $95.32 / 25.18$ & 40 & $2.38 / 0.63$ & $66.72 / 17.63$ & $28.59 / 7.55$ \\
\hline Friday & $95.32 / 25.18$ & 40 & $2.38 / 0.63$ & $66.72 / 17.63$ & $28.59 / 7.55$ \\
\hline Saturday & $95.32 / 25.18$ & 40 & $2.38 / 0.63$ & $66.72 / 17.63$ & $28.59 / 7.55$ \\
\hline Sunday & $95.32 / 25.18$ & 40 & $2.38 / 0.63$ & $66.72 / 17.63$ & $28.59 / 7.55$ \\
\hline
\end{tabular}

* The numbers are calculations used for target set-points and do not reflect the measurement accuracy

To create the NZERTF water consumption schedule we also needed to identify the time at which the shower and bath events are to take place. The a.m. and p.m. shower/bath schedules follow the occupancy profile discussed in Section 2.2. Table 5 shows the distribution of bathing events.

Table 5. Weekly shower and bath schedule

\begin{tabular}{|l|l|l|l|l|}
\hline \multicolumn{1}{|c|}{ Days } & \multicolumn{1}{c|}{$\begin{array}{c}\text { ParentA / Event } \\
\text { Time }\end{array}$} & $\begin{array}{c}\text { ParentB / Event } \\
\text { Time }\end{array}$ & $\begin{array}{c}\text { ChildA / Event } \\
\text { Time }\end{array}$ & \multicolumn{1}{c|}{$\begin{array}{c}\text { ChildB / Event } \\
\text { Time }\end{array}$} \\
\hline Monday & Shower (a.m.) & Shower (a.m.) & Shower (E-p.m.) $^{1}$ & Shower (a.m.) \\
\hline Tuesday & Shower (a.m.) & Shower (a.m.) & Shower (L-p.m.) & Shower (a.m.) \\
\hline Wednesday & Shower (a.m.) & Shower (a.m.) & Shower (E-p.m.) & Bath (p.m.) \\
\hline Thursday & Shower (a.m.) & Shower (a.m.) & Shower (L-p.m.) & Shower (a.m.) \\
\hline Friday & Shower (a.m.) & Shower (a.m.) & Shower (E-p.m.) & Shower (a.m.) \\
\hline Saturday & Shower (L-p.m.) ${ }^{2}$ & Shower (a.m.) & Shower (a.m.) & Bath (p.m.) \\
\hline Sunday & Shower (p.m.) & Shower (a.m.) & Shower (E-p.m.) & Shower (a.m.) \\
\hline
\end{tabular}

${ }^{1}$ E-p.m. means early p.m., ${ }^{2}$ L-p.m. means late p.m. 
A more detailed schedule, that contains water draw events, is provided in the Appendix A of this document.

\subsection{Lighting Usage}

The NZERTF lighting usage follows the occupancy profile of the family and is irrespective of the seasons' daylight changes. In the evening and morning when someone occupies a space (e.g., a bedroom, living room, or the kitchen) the lights for that space are energized. No lights are energized when the family is sleeping at night except for bathroom events. Similarly, no lights are energized when the house is unoccupied during the week. On the weekends, despite having at least two family members at home at all times, the lights are not energized during the day except for bathroom events. As an example, the NZERTF lighting profile, for Saturday, is shown in Figure 11 .

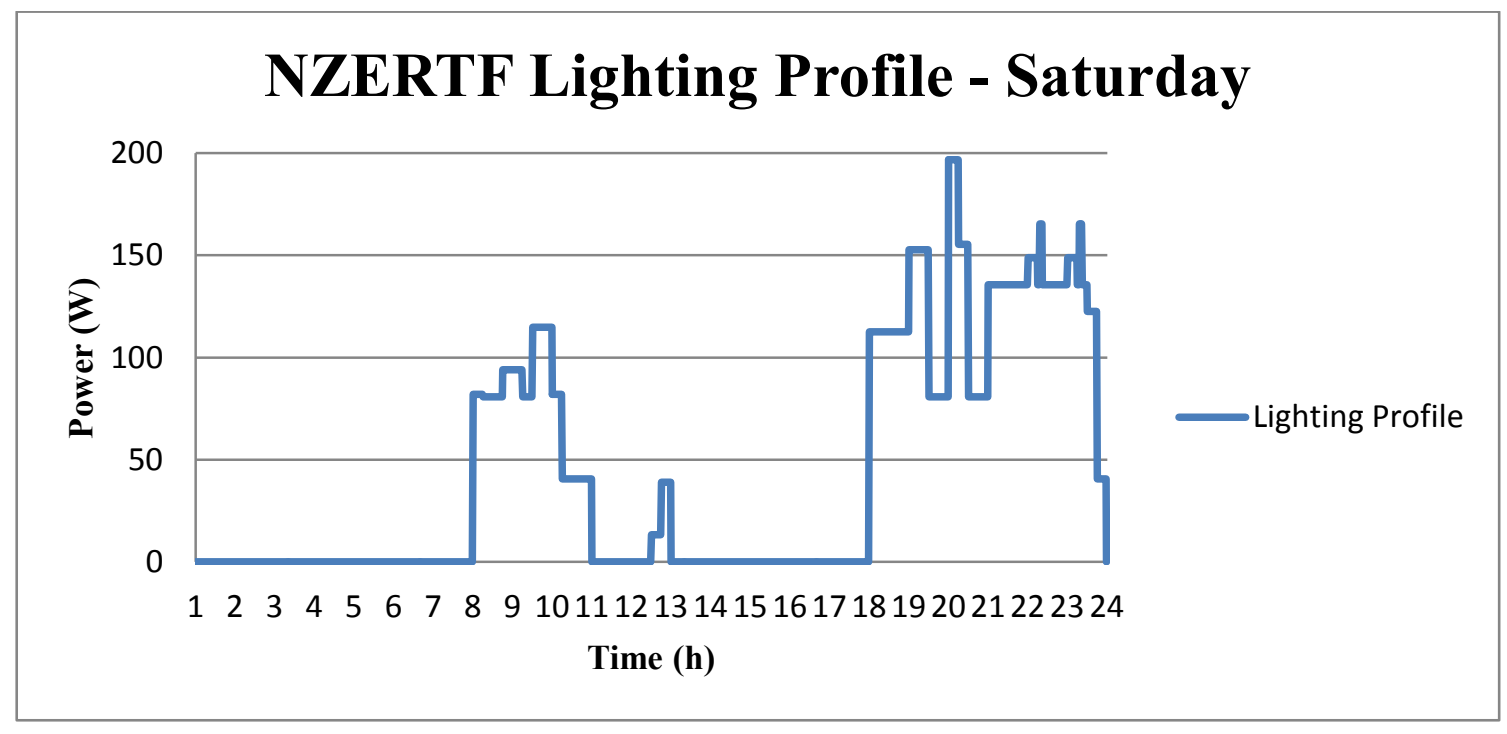

Figure 11. Saturday's Lighting Profile

\subsection{Miscellaneous Electric Plug Loads}

Simulating occupancy in the NZERTF requires operating various electric plug loads as well as cooking meals and performing laundry. The list of miscellaneous plug loads and their annual energy consumption, unless noted, is obtained from Table 17 in [2]. The criterion to select miscellaneous electric plug loads was assumed to be based on commonly used or owned by at least $50 \%$ of households. It is assumed that the annual energy consumption contains the active and standby energy usage. Table 6 shows the list of plug loads and their annual energy consumption. 
Table 6. Miscellaneous electric plug loads

\begin{tabular}{|c|c|c|c|}
\hline \multicolumn{4}{|c|}{ Miscellaneous Electric Plug Loads } \\
\hline Loads & $\begin{array}{c}\text { Annual Energy } \\
\text { (kWh) }\end{array}$ & Loads & $\begin{array}{c}\text { Annual Energy } \\
\text { (kWh) }\end{array}$ \\
\hline First Color TV & $127.3^{1}$ & Laptop PC & $72^{2}$ \\
\hline Second Color TV & $22.3^{1}$ & Desktop PC & $237^{2}$ \\
\hline DVD Player (Blu-ray) & $78^{2}$ & PC Monitor & $85^{2}$ \\
\hline Video Game System & $41^{2}$ & Printer (inkjet) & 39.0 \\
\hline Clock Radio & 14.9 & DSL/Cable Modem & 17.6 \\
\hline Boom Box/ Portable Stereo & 16.8 & Hair Dryer & 41.1 \\
\hline Component / Rack Stereo & 153.0 & Curling Iron & 1.0 \\
\hline Cable Box & 152.7 & Vacuum Cleaner & $55^{2}$ \\
\hline Microwave & 135.1 & Clock & 26.0 \\
\hline Coffee Maker (Drip) & 61.2 & Cordless Phone & 23.2 \\
\hline Toaster Oven & 32.3 & Cell Phone Charger & 77.4 \\
\hline Toaster & 45.9 & Answering Machine & 33.5 \\
\hline Blender & 7.0 & Fan (Portable) & 11.3 \\
\hline Can Opener & 3.0 & Heating Pads & 3.0 \\
\hline Hand Mixer & 2.0 & Iron & 52.7 \\
\hline Slow Cooker / Crock Pot & 16.0 & OTHER & 9.4 \\
\hline Wireless Router & $209.7^{3}$ & & \\
\hline $\begin{array}{l}\text { The annual energy consumptions } \\
\text { The First one is a } 47 \text { " LED televis } \\
\text { The annual energy consumption is } \\
\text { in the Residential Sector [5] } \\
\text { The annual energy consumption is } \\
\text { in } 52 \text { weeks ( } 8736 \text { hours) }\end{array}$ & $\begin{array}{l}\text { e First and Second } \\
\text { and the Second one } \\
\text { ained from Table } 2 .\end{array}$ & $\begin{array}{l}\text { or televisions are based on } \\
\text { 32" LED television, and } \\
6 \text { Oprating Characteristic }\end{array}$ & $\begin{array}{l}\text { he occupancy profile. } \\
\text { th are Energy Star rate } \\
\text { of Electric Appliances } \\
\text { y the number of hours }\end{array}$ \\
\hline
\end{tabular}

\subsection{Cooking Loads}

Cooking meals are emulated by an electric cooktop and an electric oven. Their annual energy consumption is obtained from Table ES.2 Energy Consumption for Cooking Products [6]. The baseline annual energy for a smooth electric cooktop is $233.4 \mathrm{kWh}$, and for a self-cleaning electric oven is $303.7 \mathrm{kWh}$. It is assumed that every time that the cooktop is used the range hood is also operated for the same length of time.

\subsection{Appliances Load}

With the exception of the HVAC, heat pump water heater, and refrigerator units, the operation of other appliances (e.g., clothes washer, clothes dryer, and dishwasher) are automated by the NZERTF's data acquisition/controller unit. The number of cycles/week for the dishwasher, clothes washer, and clothes dryer was obtained from [7] and is based on a survey conducted by Proctor and Gamble. Table 7 summarizes the daily cycles of clothes washer, clothes dryer, and dishwasher 
Table 7. Daily cycles for clothes washer, clothes dryer, and dishwasher

\begin{tabular}{|l|c|c|c|}
\hline Days & Clothes Washer & Clothes Dryer & Dishwasher \\
\hline Monday & 0 & 0 & 1 \\
\hline Tuesday & 0 & 0 & 0 \\
\hline Wednesday & 2 & 1 & 1 \\
\hline Thursday & 0 & 0 & 0 \\
\hline Friday & 0 & 0 & 1 \\
\hline Saturday & 2 & 2 & 1 \\
\hline Sunday & 2 & 2 & 1 \\
\hline
\end{tabular}

The family's interaction with the refrigerator is emulated by placing a thermal load inside the unit. A detailed analysis of this interaction is given in Section 3.5.

\section{Emulation of the Virtual Occupants}

The discussion of the emulation of the virtual family is separated into several major sections: the implementation of the sensible and latent loads, water usage, miscellaneous plug loads, cooking, laundry, and dishwashing appliances.

\subsection{Sensible and Latent Loads}

Emulating human occupancy, in a virtual environment, such as the NZERTF, requires accounting for the sensible and latent loads generated by the presence and activities of the occupants themselves. In the NZERTF, sensible loads are simulated by resistors placed in the bedrooms, kitchen, and the living room areas. Each sensible load emulator, representing a particular family member, is activated according to the schedule for that person. For example, when ParentA is in the master bedroom the sensible load emulator for ParentA is activated in the master bedroom. The same procedure is applied to all family members. In contrast, the latent loads produced by the entire family and cooking activities, which are introduced as vaporized water, are lumped together to simplify the instrumentation. This approach can be justified because the NZERTF air-handler unit recirculates the moisture, generated locally in the kitchen, to the entire house. According to Table 1 in Nonresidential Cooling and Heating Load Calculations of ASHRAE's Handbook of Fundamentals, the adjusted sensible and latent load per person, for seated and very light work in an apartment, is $70 \mathrm{~W}$ and $45 \mathrm{~W}$, respectively [8]. These adjusted values are averaged for adults and children, so a single value of $70 \mathrm{~W}$ is used for all emulators.

To emulate latent load, in the NZERTF, it is essential to determine the amount of moisture dissipated by the family through respiration, perspiration, and cooking activities. According to Latent Heat of Vaporization in Thermal Physiology, at a skin temperature of $33^{\circ} \mathrm{C}\left(91.4{ }^{\circ} \mathrm{F}\right)$ the heat needed to vaporize 1 gram of water is $2.398 \mathrm{~kJ}$ [9]. The value of latent heat of vaporization was used to convert $45 \mathrm{~W}$ to its equivalent volume in liters. The estimated moisture generated 
per person is 0.07 liters/h $(0.02$ gallons $/ \mathrm{h})$. The latent load in [8] does not include the volume of moisture generated by cooking activities. It is obtained from the Home Moisture document published by the Minnesota Department of Commerce [10]. The estimated latent load generated for each cooking event (denoted as breakfast, lunch, and dinner) is shown in Table 8.

Table 8. Estimated volume of moisture during cooking events, adapted from [9],

Table labeled Household moisture sources*

\begin{tabular}{|l|c|}
\hline Cooking Event (Family of Four, Average) & $\begin{array}{c}\text { Estimated Amount } \\
\text { per Event } \\
\text { (liters/gallons) }\end{array}$ \\
\hline Breakfast & $0.17 / 0.04$ \\
\hline Lunch & $0.25 / 0.07$ \\
\hline Dinner & $0.58 / 0.15$ \\
\hline
\end{tabular}

* The numbers are calculations used for target set-points and do not reflect the measurement accuracy

During the week, Monday through Friday, no one is home to prepare lunch so the moisture generated by cooking events only includes breakfast and dinner. The moisture generated on the weekends, however, includes all three meals. The daily moisture generated by the NZERTF family members account for the length of time that they are home. Table 9 shows the daily moisture generated by cooking meals and the occupants.

Table 9. Total daily moisture generated by cooking events and the NZERTF occupants

\begin{tabular}{|l|c|c|c|}
\hline \multicolumn{1}{|c|}{ Days } & $\begin{array}{c}\text { Daily Moisture from } \\
\text { Cooking (liters/gallons) }\end{array}$ & $\begin{array}{c}\text { Daily Moisture from } \\
\text { People (liters/gallons) }\end{array}$ & $\begin{array}{c}\text { Total Daily Moisture } \\
\text { Cooking + People } \\
\text { (liters/gallons) }\end{array}$ \\
\hline Sunday & $0.99 / 0.26$ & $5.83 / 1.54$ & $6.83 / 1.80$ \\
\hline Monday & $0.74 / 0.20$ & $3.87 / 1.02$ & $4.61 / 1.22$ \\
\hline Tuesday & $0.74 / 0.20$ & $4.0 / 1.06$ & $4.74 / 1.25$ \\
\hline Wednesday & $0.74 / 0.20$ & $3.87 / 1.02$ & $4.61 / 1.22$ \\
\hline Thursday & $0.74 / 0.20$ & $4.0 / 1.06$ & $4.74 / 1.25$ \\
\hline Friday & $0.74 / 0.20$ & $3.87 / 1.02$ & $4.61 / 1.22$ \\
\hline Saturday & $0.99 / 0.26$ & $5.63 / 1.49$ & $6.22 / 1.75$ \\
\hline
\end{tabular}

* The numbers are calculations used for target set-points and do not reflect the measurement accuracy

In order to introduce moisture into the NZERTF to represent the latent loads from cooking and the simulated human occupants, an ultrasonic humidifier is used. The approach used and the design of the apparatus are based on recommendations from Field Test Protocol: Standard Internal Load Generation for Unoccupied Test Homes [11]. The advantage of an ultrasonic humidifier is that it creates very fine water droplets as cool fog, thereby releasing a steady rate of moisture at room temperature regardless of the ambient relative humidity. 
The apparatus used in the NZERTF, shown in Figure 12, are commercially available humidifiers modified to enable long term operation without human intervention. The water reservoir is connected to a metered water supply line through a solenoid valve operated by a level switch. The solenoid valve is normally closed and the entire device is placed in a pan with a leak detector to enable remote detection of any water leaks.

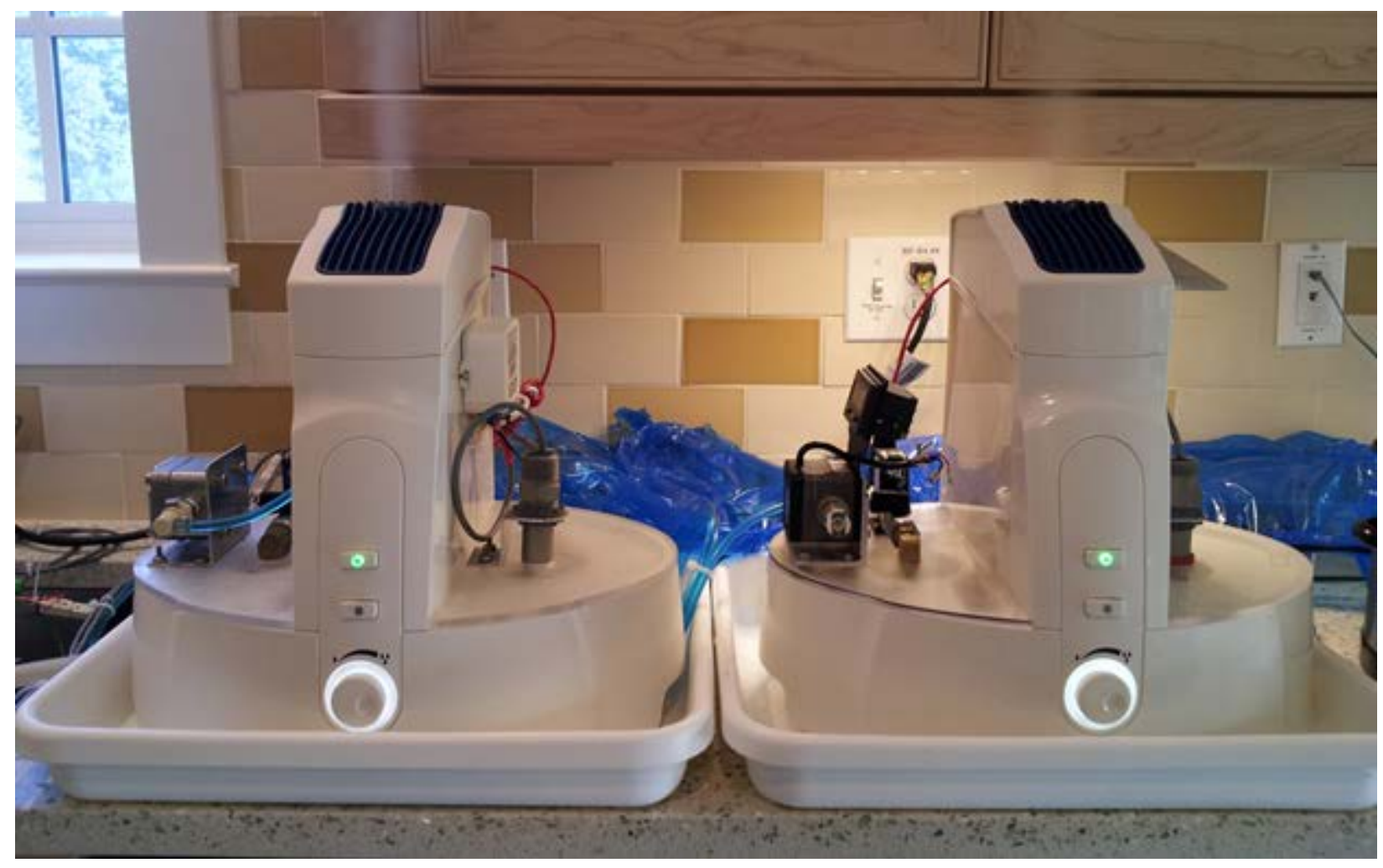

Figure 12. Latent heat generators

Laboratory tests determined that each ultrasonic humidifier's output capacity is approximately 0.27 liters/h $(0.07$ gallons/h) of moisture. Given this capacity, two ultrasonic humidifiers were installed to meet the daily required latent load as reported in Table 7 . The amount of moisture introduced into the air is controlled by time. The flow meter provides a verification of correct operation.

To emulate sensible heat, eight resistance heating boxes were designed and built. Each box represents a family member and placed in bedrooms, kitchen, living room, and dining room. The key components of a box are a bulb socket screw-in heater, a dimmer switch, a solid state relay, a safety fuse, and a fixture to mount the screw-in heater (maximum power rating is $200 \mathrm{~W}$ ). The dimmer switch controls the output power of each box, which was calibrated to $70 \mathrm{~W}$, to represent the sensible heat generated by each person. The solid state relay turns the sensible heat generator on or off upon receiving a signal from the facility's acquisition/controller unit. The safety fuse is installed in-line with the hot power line to protect the circuit against current overload. Figure 13 shows a sensible heat generator box and the wiring diagram. 

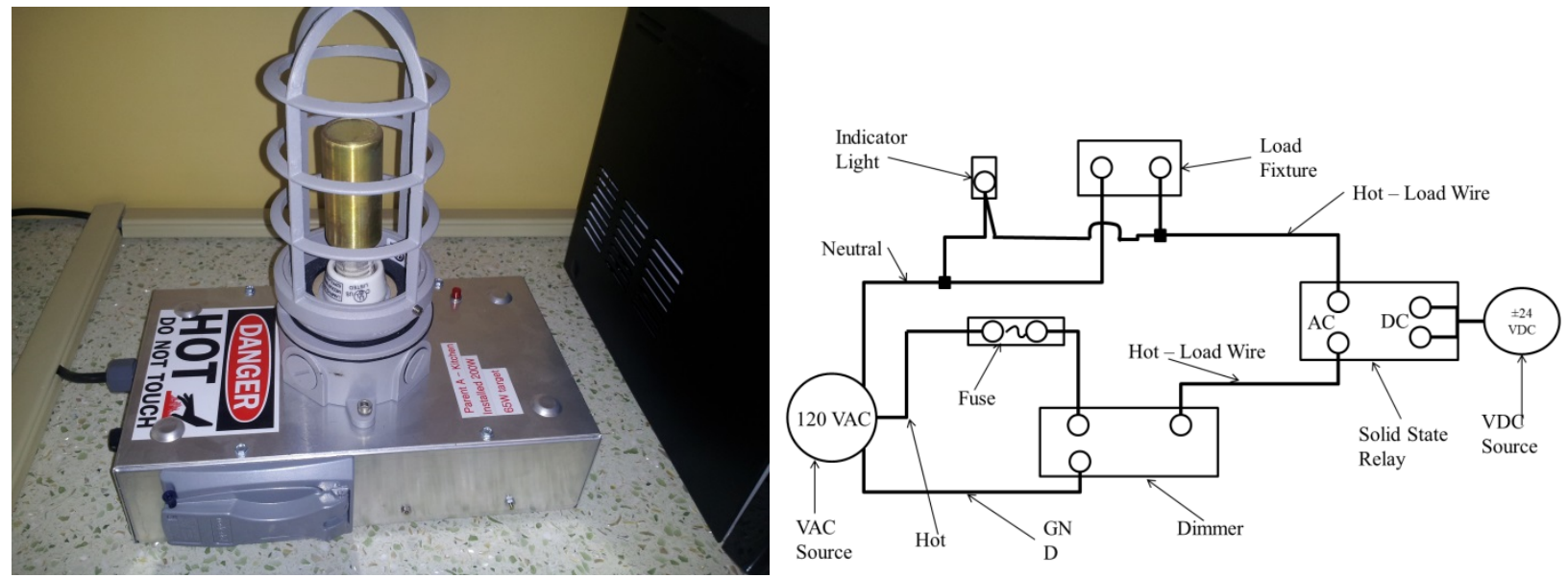

Figure 13. Sensible heat generator box and its wiring diagram

\subsection{Water Usage}

For simplicity of measurement, all first floor water draws are scheduled in the kitchen sink. No one takes a shower on the first floor, so all first floor events are bathroom and kitchen sink related. All second floor water draws, which include second bathroom and master bathroom shower and sink events, are scheduled in the master bathroom shower. The master bathroom shower is used to emulate the shower and sink events. The bathtub faucet is used to emulate the bath events. While it is acknowledged that this arrangement may not fully capture heat losses in the hot water distribution pipes, the quest to simplify the automation of water draws took precedence over any such inaccuracies.

In the NZERTF, the plumbing distribution system consists of a manifold in the basement from which cross-linked polyethylene tubing delivers hot and cold water directly to each fixture. Normally-closed solenoid valves are installed in each of these lines at the manifold, and a signal is sent to the valves on the hot and cold lines for each fixture to initiate or terminate a water draw. Figure 14 shows the manifold that delivers hot and cold water to each fixture and the control solenoids. 


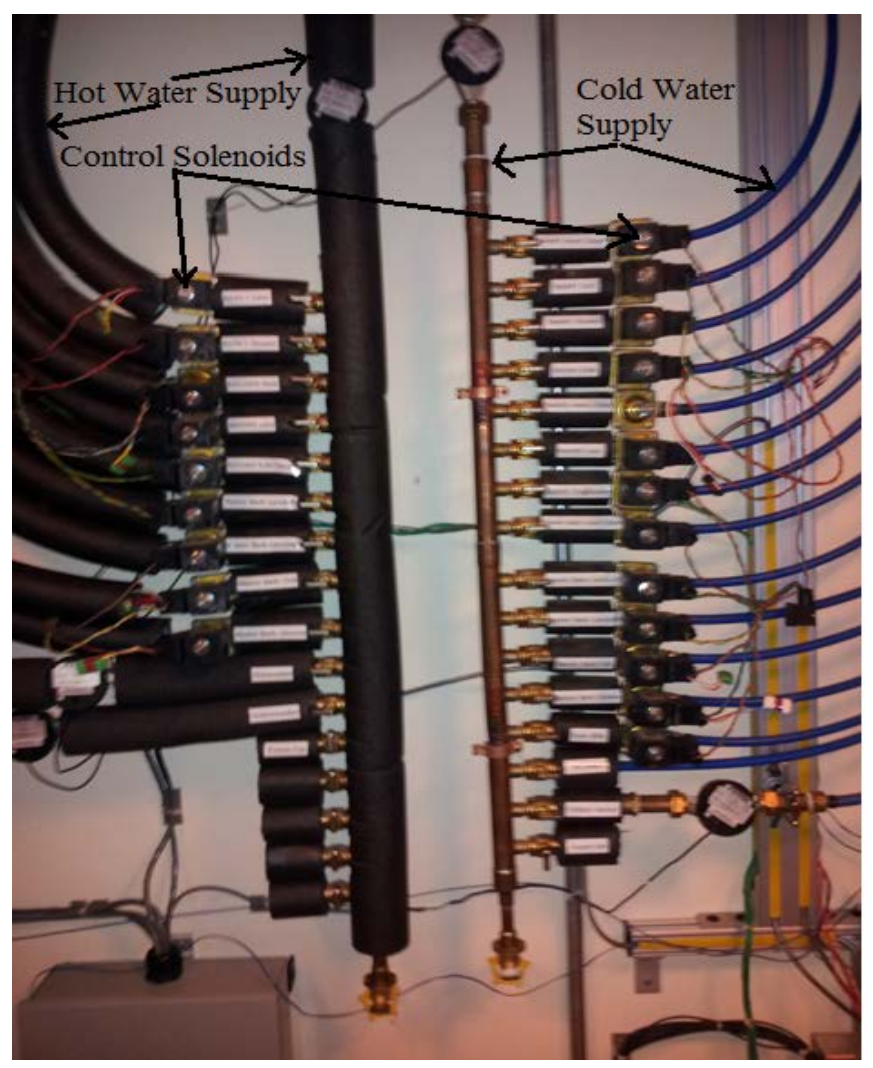

Figure 14. Water distribution manifold and control solenoids

The water from the master bathroom shower and the bathtub faucets are deposited through hoses into a tank placed on a load cell. Similarly, the kitchen sink water is deposited into a smaller tank which is also placed on top of a load cell. At the bottom of each tank, there is a drain valve that is controlled by a normally open solenoid. When a draw event is activated, the solenoid is closed to allow water accumulation in the tank. The scale measures the mass of water accumulated in the tank, with the volume removed being computed based on the density of water at the temperature measured at the fixture. The event is terminated once the threshold, set by the volume requirements for each event, is met. The solenoid is then opened to let the water drain. The same procedure takes place for all water draw events. To measure each draw correctly and terminate the event properly, the water events are scheduled such that they do not overlap. Flow meters are also used as redundant measurements. Figure 15 and Figure 16 show the water measurement apparatus in the master bathroom and the kitchen sink, respectively. 

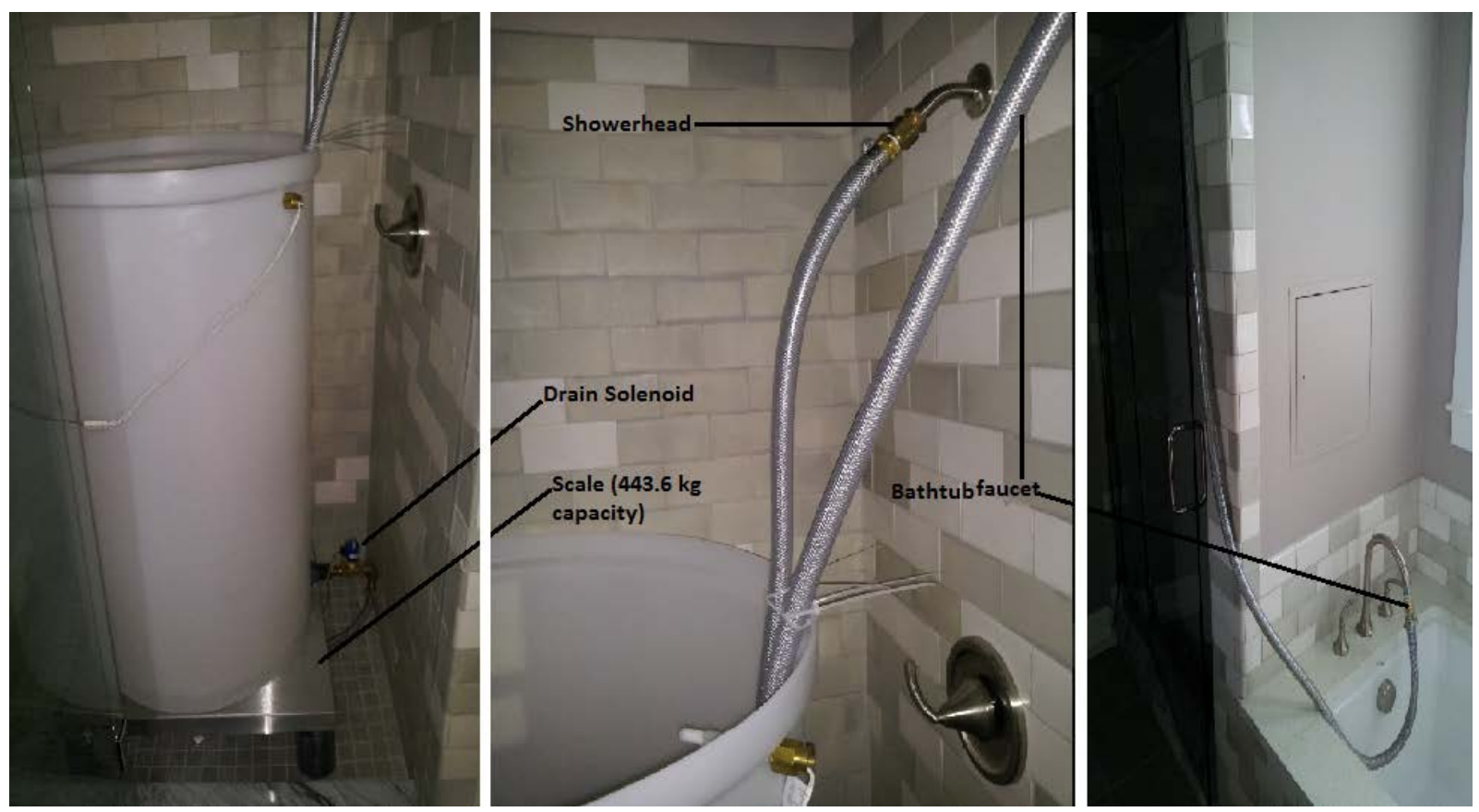

Figure 15. Master bathroom water measurement apparatus

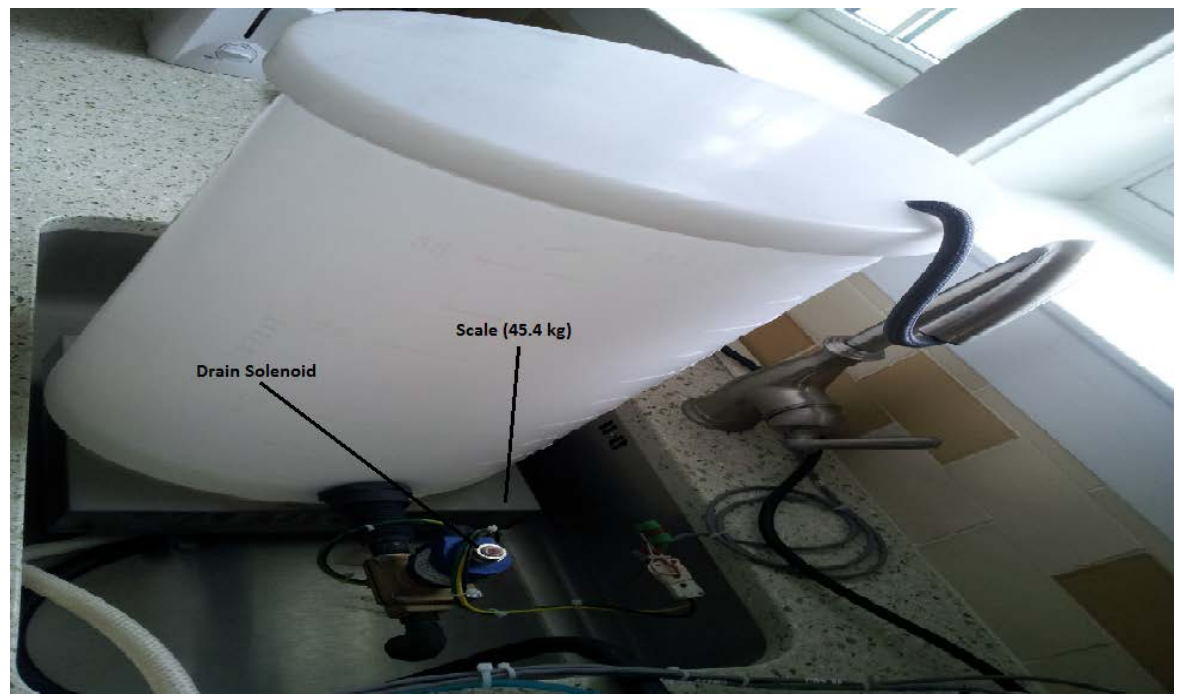

Figure 16. Kitchen sink water measurement apparatus

In order to determine the ratio of hot to cold water in each draw, the faucets were manually adjusted so that the water temperature exiting the fixtures met the ASHRAE's requirement for representative hot-water temperatures. According to Table 3 in the Service Water Heating chapter of the ASHRAE Handbook of HVAC applications, the hot water temperature for hand washing is $40.7^{\circ} \mathrm{C}\left(105^{\circ} \mathrm{F}\right)$, and $43.3^{\circ} \mathrm{C}\left(110^{\circ} \mathrm{F}\right)$ for showers and baths [12]. The heat pump water heater temperature is set to $48.9^{\circ} \mathrm{C}\left(120^{\circ} \mathrm{F}\right)$. These settings are adjusted throughout the year as the cold water temperature changes to ensure proper delivery temperature. 


\subsection{Miscellaneous Plug Loads}

All plug loads are automated according to the schedule in Appendix A. The strategy to emulate plug loads (including cooking appliances) in the NZERTF is to use their annual energy consumption as a target and create a schedule to satisfy that requirement. The assumed frequency of usage of plug loads, in a given day, is based on the occupancy profile and may change from one day to the next. Some plug loads involve real appliances and others, which are difficult or unsafe to automate, are emulated with resistive loads. For example, modern televisions require activation with a remote control that is not easily automated, and a coffee maker is difficult to safely turn on and off using a data acquisition/controller unit. All plug loads, including standby, that are rated less than $200 \mathrm{~W}$ are emulated with resistant heating boxes similar to the one shown in Figure 13. However, plug loads larger than $200 \mathrm{~W}$ are emulated with heating elements connected to a relay-box shown in Figure 17. A relay-box, which energizes and de-energizes these plug loads and the real appliances, is shown in Figure 18.

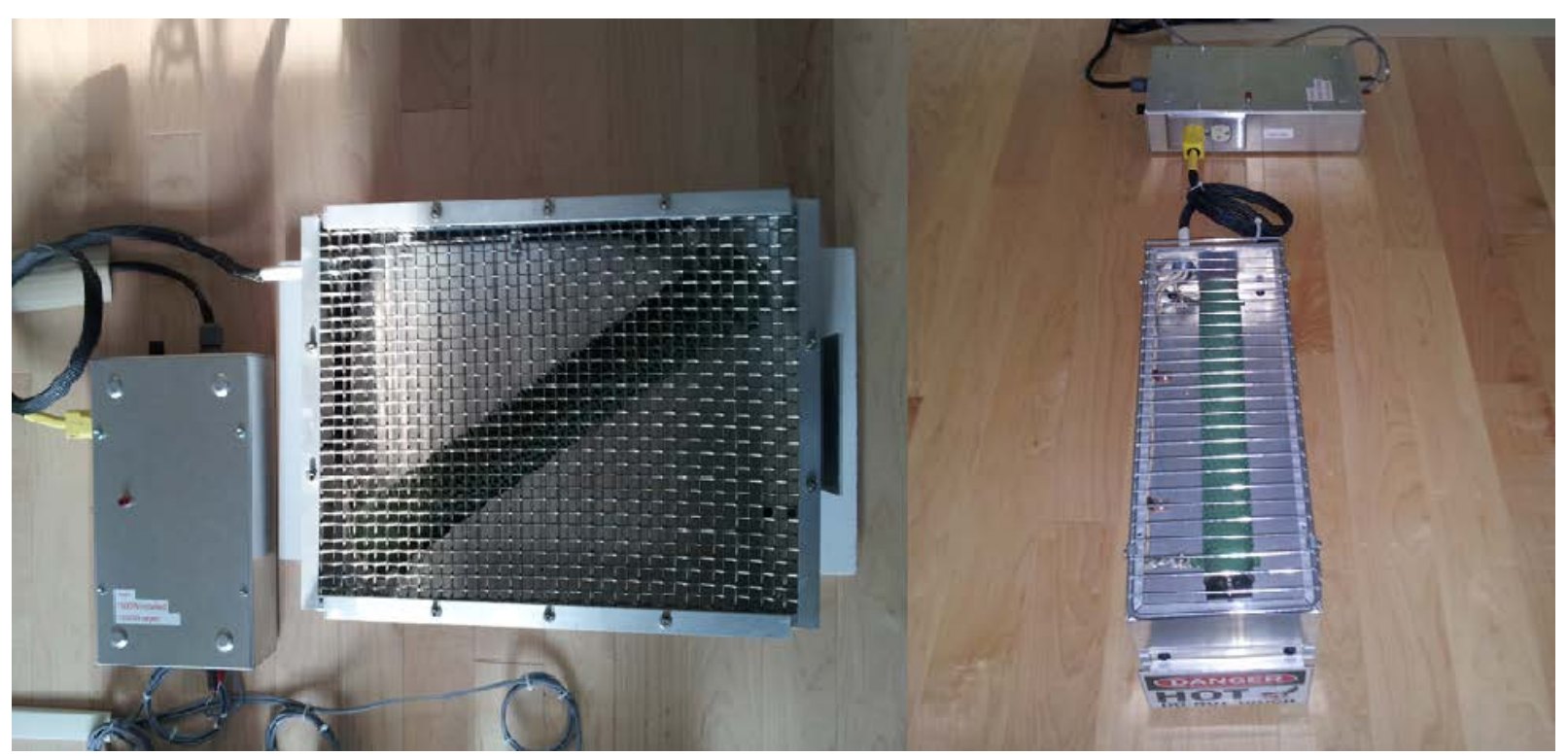

Figure 17. The heating elements for plug loads with larger than $200 \mathrm{~W}$ power requirement and their relay-boxes 


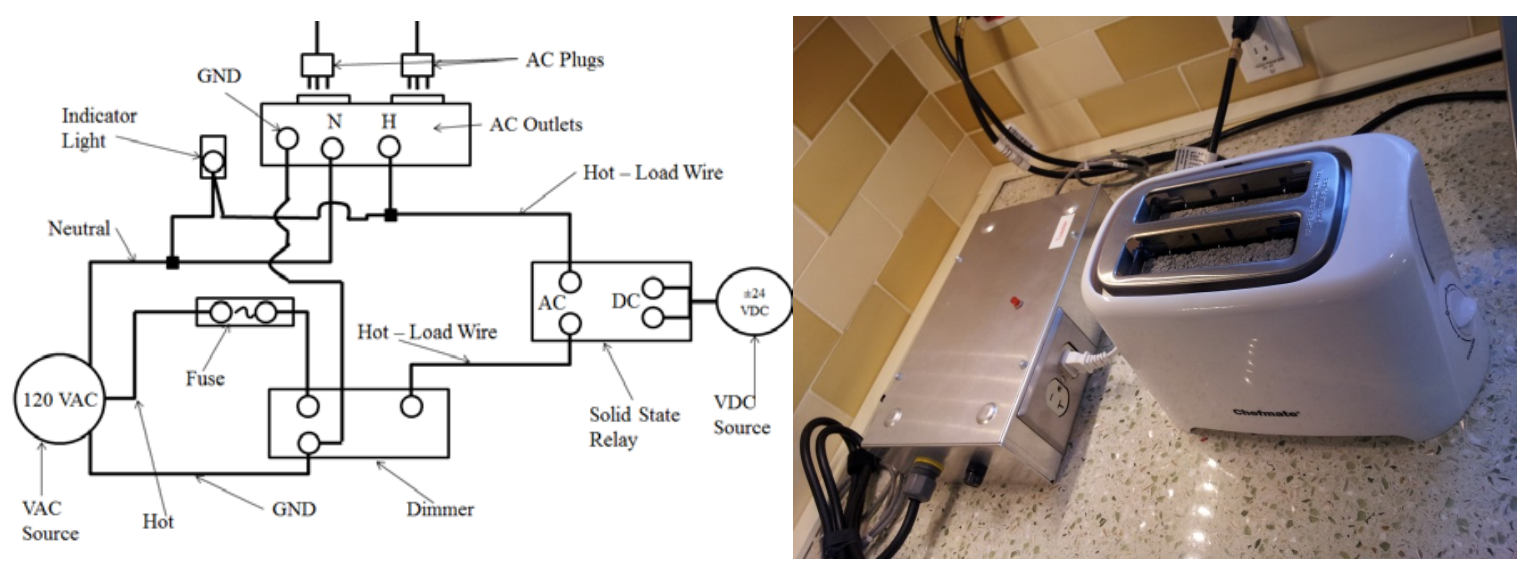

Figure 18. The relay-box, its wiring diagram, and a toaster plugged into it

The mechanisms to control all plug loads are separated into three main categories: time-based, criteria-based, and cycle-based. All plug loads, except the cycle-based loads, have a start-time and an end-time. In time-based control, the data acquisition/controller unit starts a load based on its start-time and turns it off when the end-time is reached. Similarly in criteria-based control the acquisition/controller unit starts a load based on its start-time, but it terminates the load when a certain criterion (e.g., energy consumption) has been met. For safety purposes, a timeout criterion is also applied to these loads which terminates their use if a certain elapsed time is reached. For example, when the hair dryer is energized, the data acquisition/controller unit monitors its energy consumption and terminates it when the energy consumed equals the prescribed energy. In criteria-based control, the end-time serves as a safety switch (a timeout) to prevent the loads from operating continuously in case of a malfunction beyond a predefined window. In the cycle-based control, the loads are activated based on their start-times and allowed to complete their normal cycles. The acquisition/controller unit does not terminate cycle-based loads. For implementation purposes, all plug loads are installed in various locations within the NZERTF. The location, control mechanism, emulation approach (actual appliance or heater box), active and standby power (where applicable), weekly time of use, and weekly required energy for each load are given in Table 10. 
Table 10. The plug loads emulation details*

\begin{tabular}{|c|c|c|c|c|c|c|c|}
\hline $\begin{array}{l}\mathscr{\Xi} \\
\stackrel{0}{a}\end{array}$ & $\begin{array}{l}\stackrel{0}{\tilde{E}} \\
\stackrel{\Xi}{\Theta}\end{array}$ & 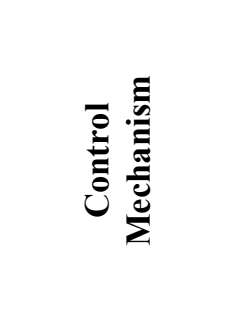 & 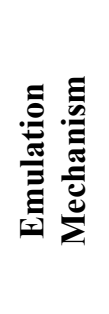 & 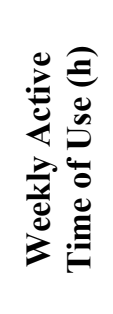 & 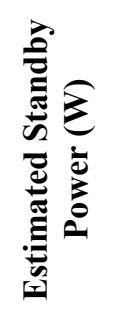 & 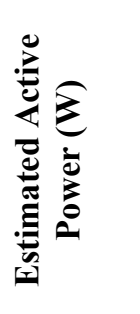 & 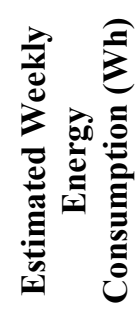 \\
\hline $\mathrm{BR}^{1}$ & Laptop & Time-based & $\mathrm{HB}^{8}$ & 25 & 3.1 & 36.9 & 1384.6 \\
\hline BR2 & Boom Box & Time-based & $\mathrm{HB}$ & 168 & $\mathrm{NA}^{10}$ & 1.9 & 323.1 \\
\hline BR2 & Cellphone Charger & Time-based & HB & 168 & NA & 8.9 & 1488.5 \\
\hline BR2 & Clock Radio & Time-based & HB & 168 & NA & 1.7 & 286.5 \\
\hline $\mathrm{BR} 3^{2}$ & Laptop & Time-based & HB & 12.75 & 5.9 & 36.9 & 1384.6 \\
\hline $\mathrm{BR}^{3}$ & Desktop Monitor + PC & Time-based & $\mathrm{HB}$ & 41 & 16.0 & 101.6 & 6192.3 \\
\hline BR4 & DSL Modem & Time-based & HB & 168 & NA & 2.0 & 338.5 \\
\hline BR4 & OTHER & Time-based & HB & 168 & NA & 1.1 & 180.8 \\
\hline BR4 & Printer & Time-based & HB & 168 & NA & 4.5 & 750.0 \\
\hline BR4 & Wireless Router & Time-based & HB & 168 & NA & 24.0 & 4032.7 \\
\hline $\mathrm{KA}^{4}$ & Can Opener & Time-based & HB & 0.82 & NA & 70.0 & 57.7 \\
\hline $\mathrm{LR}^{5}$ & Blu-ray Player (DVD) & Time-based & $\mathrm{HB}$ & 3.04 & 8.8 & 17.0 & 1500.0 \\
\hline LR & Cable Box & Time-based & HB & 168 & NA & 17.5 & 2936.5 \\
\hline LR & Clock & Time-based & HB & 168 & NA & 3.0 & 500.0 \\
\hline LR & Component Stereo & Time-based & HB & 168 & NA & 17.5 & 2942.3 \\
\hline LR & Phone/Answering Machine & Time-based & $\mathrm{HB}$ & 168 & NA & 6.5 & 1090.4 \\
\hline LR & Television & Time-based & HB & 37.25 & 1.0 & 62.2 & 2447.7 \\
\hline LR & Video Game Console & Time-based & $\mathrm{HB}$ & 3 & 4.3 & 27.0 & 788.9 \\
\hline $\mathrm{MBR}^{6}$ & Blu-ray Player & Time-based & HB & 3.04 & 8.8 & 17.0 & 1500.0 \\
\hline MBR & Heating Pad & Time-based & $\mathrm{HB}$ & 1.75 & NA & 33.0 & 57.7 \\
\hline MBR & Portable Fan & Time-based & $\mathrm{HB}$ & 11 & NA & 19.8 & 217.3 \\
\hline MBR & Television & Time-based & HB & 6.75 & 1.0 & 45.36 & 429.6 \\
\hline MBR & Cable Box & Time-based & $\mathrm{HB}$ & 168 & NA & 17.5 & 2936.5 \\
\hline MBR & Cellphone Charger & Time-based & $\mathrm{HB}$ & 168 & NA & 8.9 & 1488.5 \\
\hline MBR & Cellphone Charger & Time-based & HB & 168 & NA & 8.9 & 1488.5 \\
\hline MBR & Clock Radio & Time-based & $\mathrm{HB}$ & 168 & NA & 1.7 & 286.5 \\
\hline $\mathrm{KA}$ & Microwave & Cycle-based & $\mathrm{AA}^{9}$ & 1.5 & NA & 1850.0 & 2598.1 \\
\hline BR4 & Vacuum & Criteria-based & $\mathrm{HB}$ & 1.95 & NA & 542.0 & 1057.7 \\
\hline KA & Blender & Criteria-based & AA & 0.84 & NA & 161.0 & 134.6 \\
\hline KA & Coffee Maker & Criteria-based & HB & 2.14 & NA & 550.0 & 1176.9 \\
\hline KA & Hand Mixer & Criteria-based & AA & 0.34 & NA & 113.0 & 38.5 \\
\hline KA & Slow Cooker & Criteria-based & AA & 18.09 & NA & 17.0 & 307.7 \\
\hline KA & Toaster & Criteria-based & AA & 1.24 & NA & 712.0 & 882.7 \\
\hline KA & Toaster Oven & Criteria-based & AA & 0.67 & NA & 923.0 & 638.5 \\
\hline $\mathrm{MBA}^{7}$ & Hair Dryer + Curling Iron & Criteria-based & AA & 0.54 & NA & 1500.0 & 809.6 \\
\hline MBR & Iron & Criteria-based & AA & 0.84 & NA & 1200.0 & 1013.5 \\
\hline \multicolumn{8}{|c|}{$\begin{array}{lll}{ }^{1} \text { BR2 - Second Bedroom, } & { }^{4} \mathrm{KA} \text { - Kitchen, } & { }^{7} \mathrm{MBA} \text { - Mater Bedroom Bathroom } \\
{ }^{2} \mathrm{BR} 3 \text { - Third Bedroom, } & { }^{5} \mathrm{LR} \text { - Living Room, } & { }^{8} \mathrm{HB} \text { - Heater-Box } \\
{ }^{3} \text { BR4 - Bedroom Four, } & { }^{6} \mathrm{MBR} \text { - Master Bedroom, } & { }^{9} \mathrm{AA} \text { - Actual Appliance } \\
\end{array}$} \\
\hline
\end{tabular}


For the majority of plug loads listed in Table 10, their active power is computed using their weekly energy divided by their weekly active time of use. The weekly active time of use is based on the occupancy profile of the family, and the weekly energy consumption is derived from their annual energy divided by 52 weeks. For ease of implementation the standby power for these loads are combined with their active power. Some plug loads run continuously and some are activated intermittently; however, the goal is to meet their weekly and, ultimately, their annual energy consumption. The plug loads' active power, given in Table 10, meets that goal. The active power, for the criteria-based and the cycle-based plug loads, was determined by measurement.

For the loads with both active and standby power, given in Table 10, the sum of the standby energy and active energy consumption equals their weekly energy consumption. The active power for the laptop is computed as the average of fully-on charged (29.5 W), and fully-on charging $(44.3 \mathrm{~W})$ modes obtained from the Standby Power Summary Table of Lawrence Berkeley National Laboratory [13]. The active power for the Desktop Monitor + PC is the sum of active powers for a desktop computer and a liquid-crystal display (LCD) monitor. According to [13], the active power for an LCD display in on mode is $27.6 \mathrm{~W}$ and for a desktop computer in on/idle mode is approximately $74 \mathrm{~W}$. The active power for the Blu-ray player is obtained from [5], and active power for the Video Game console was obtained from [13]. The active power for the televisions in the master bedroom and the living room were obtained from the ENERGY STAR Television product list [14]. For these plug loads, the standby power is computed as the difference between the weekly energy and active energy consumption divided by the weekly standby time of use.

\subsection{Cooking Loads}

The control mechanism for cooking events is similar to the criteria-based control approach described in the Section 3.3. Table 11 shows the list of cooking appliances that are installed in the NZERTF. In addition to the appliances, a range hood is also activated when the electric cooktop is activated. The range hood is set to its medium level and the active power consumption is, approximately, $100 \mathrm{~W}$.

Table 11. Cooking appliances emulation details

\begin{tabular}{|c|c|c|c|c|c|}
\hline 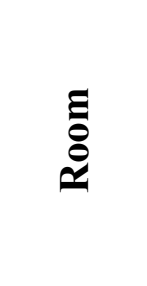 & 号 & 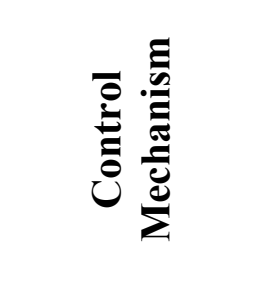 & 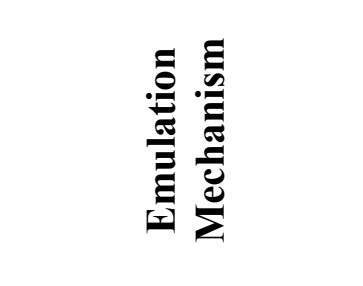 & 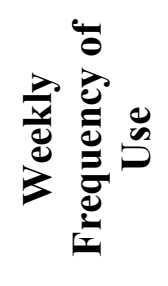 & 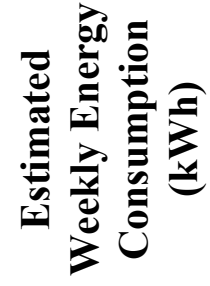 \\
\hline Kitchen & Cooktop & Criteria-based & Actual Appliance & 11 & 4.49 \\
\hline Kitchen & Oven & Criteria-based & Modified Appliance & 3 & 5.84 \\
\hline
\end{tabular}

* The estimated weekly energy in Table 11 are used for target set-points and does not reflect the measurement accuracy 
The cooktop and the range hood are energized and de-energized using relay-boxes similar to the one shown in Figure 18. Figure 19 shows the cooktop installed in the NZERTF. Because of difficulties in controlling the built-in cooktop, a two-burner portable hot plate was used instead. Pots containing water are placed on top of the burners to absorb the heat that is produced. After they are energized, the energy consumption is monitored and the relay shuts off power when the prescribed amount of energy is used by the unit.

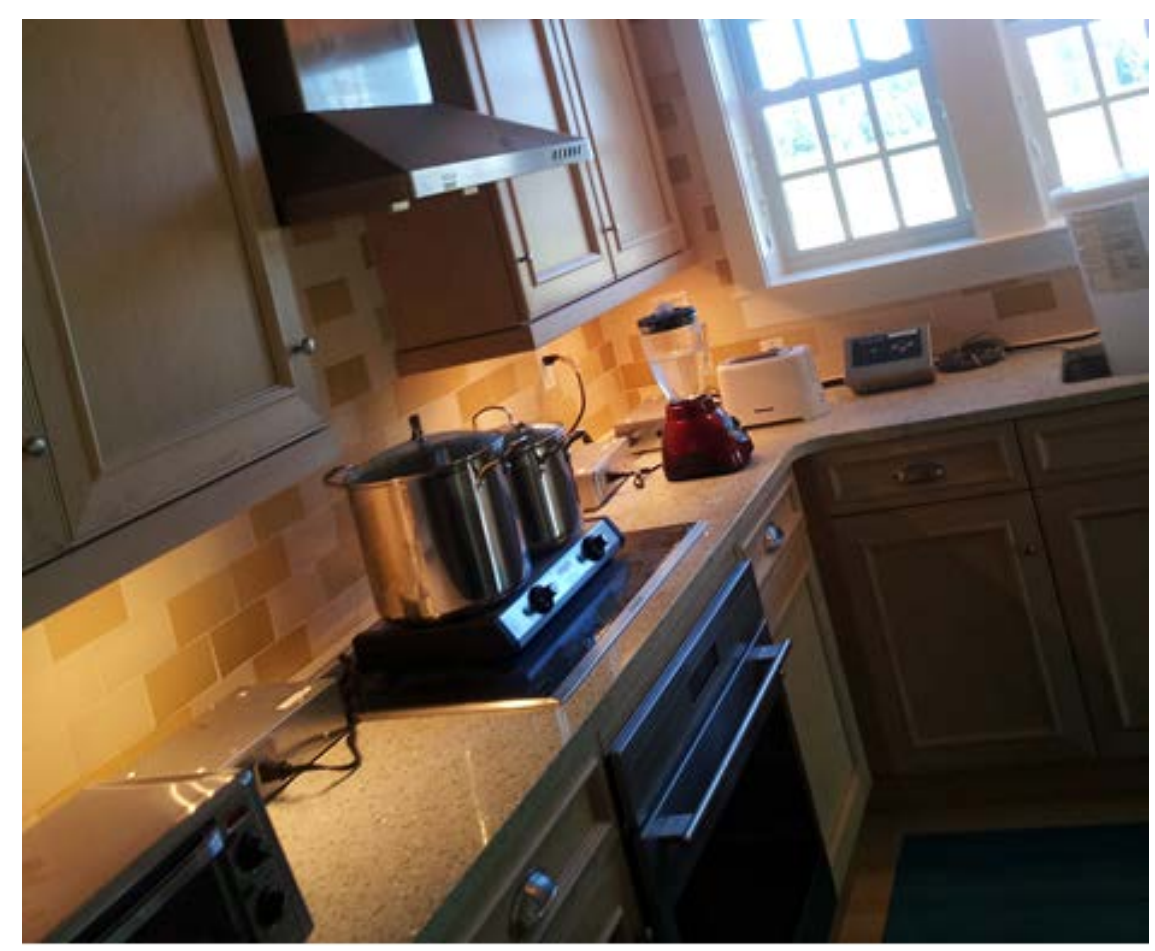

Figure 19. The electric two-burner portable hot plate, the range hood, and the relay-box

The NZERTF's oven has been modified to allow emulating cooking events. To safely operate the oven, a controller-box made of a proportional-integral-derivative controller, a limit controller switch, and relays was designed and built. The controller-box activates and de-activates the heating elements and a fan inside the oven to maintain a pre-set temperature of $176.6^{\circ} \mathrm{C}$ (approximately $350^{\circ} \mathrm{F}$ ). The limit controller switch is installed to ensure that the oven does not exceed $250^{\circ} \mathrm{C}\left(482^{\circ} \mathrm{F}\right)$. The main software turns the controller-box off once the oven meets its pre-determined prescribed energy. Figure 20 shows the controller-box and its wiring schematic. 


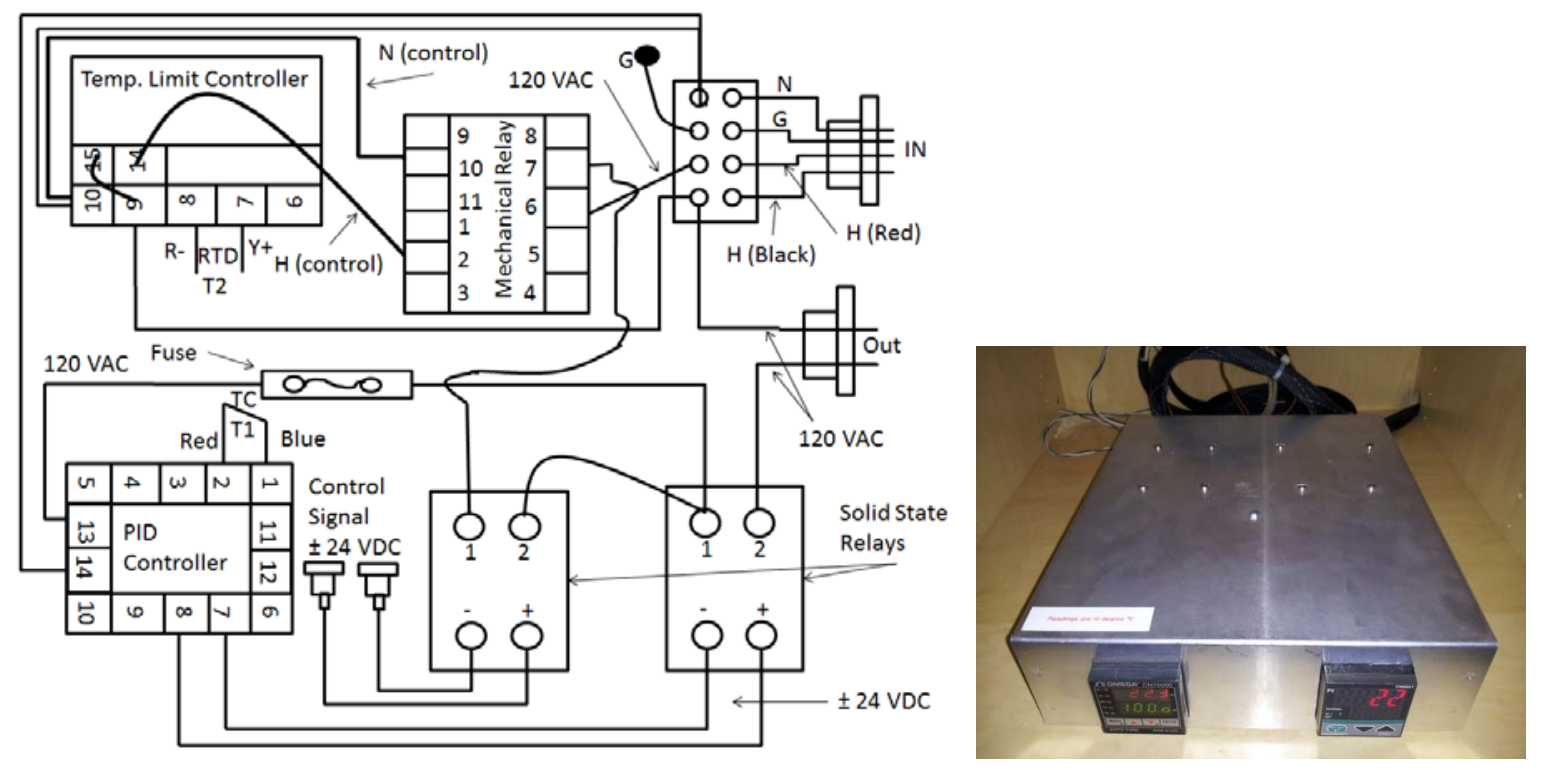

Figure 20. The oven Controller-box and its wiring schematic

\subsection{Appliances}

The clothes washer, clothes dryer, and dishwasher units were modified to allow remote activation. The clothes washer and dryer are directly controlled by the acquisition/controller unit with a dry-contact relay card, which initiates a normal cycle that automatically runs to completion. According to the Department of Energy (DOE) Table 5.1 of Section 2.8 of Appendix J2 to Subpart B of Part 430, Uniform Test Method for Measuring the Energy Consumption of Automatic and Semi-Automatic Clothes Washers, the average test load for a clothes washer container with $121.8 \mathrm{~L}(4.30 \mathrm{cu}$. $\mathrm{ft}$.) capacity is $4.63 \mathrm{~kg}(10.20 \mathrm{lbs}$.) [15]. The clothes dryer is equipped with an advanced moisture sensing system. It is also equipped with a misting nozzle inside the drum container. Since placing a dry load of laundry ends the cycle prematurely, the misting nozzle was modified to allow water to be added to the laundry load. The volume of water added to the laundry was determined by washing the average test load and measuring the weight of the test load after the wash cycle. The final weight of the test load was measured to be $6.26 \mathrm{~kg}$ ( $13.80 \mathrm{lbs}$.). The misting nozzle flow rate was determined to be 3.79 liters ( 1 gallon) per minute. It is activated soon after the dryer cycle is energized and terminated when $1.63 \mathrm{~L}(1.63 \mathrm{~kg})$ of water is dispensed inside the dryer. This procedure is applied to all clothes dryer cycles. Figure 21 shows the washer, dryer, and misting nozzle installed in the NZERTF. 


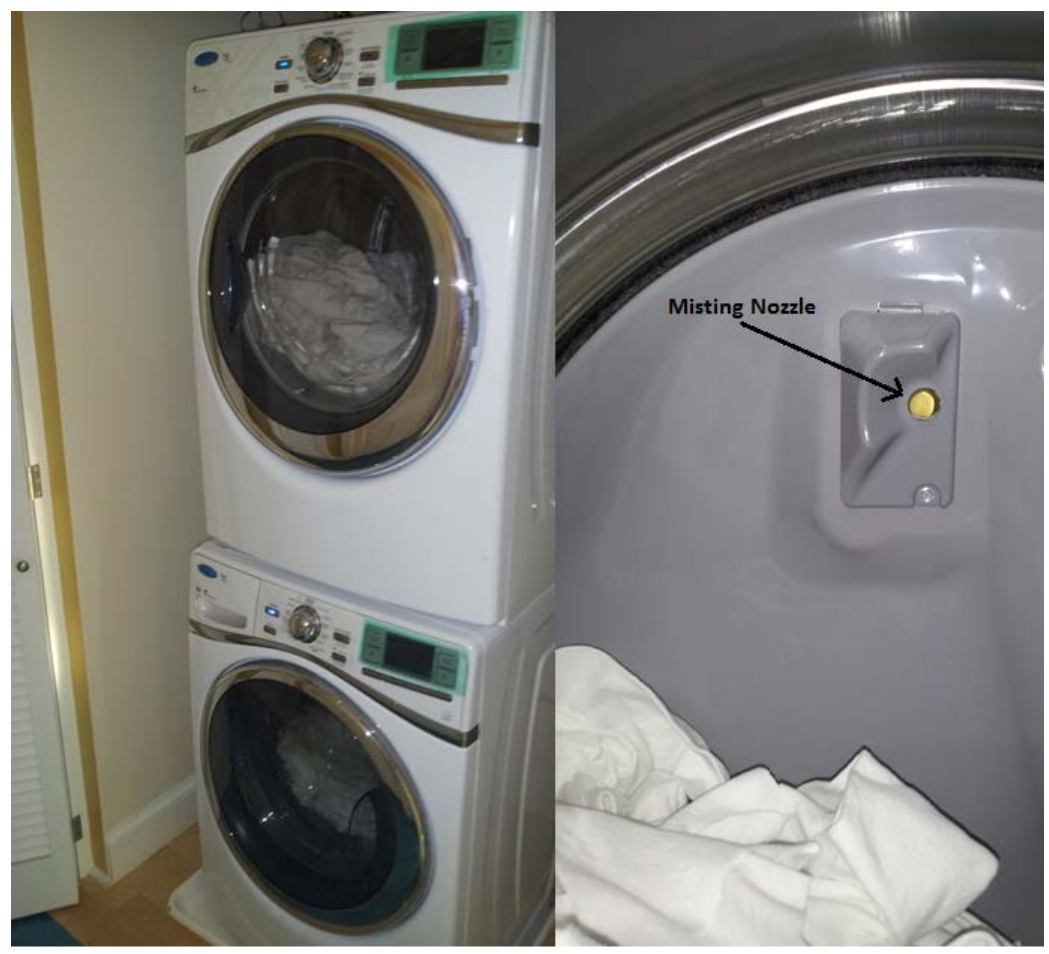

Figure 21. The dryer, modified misting nozzle, and the washer

The dishwasher control is similar to the cycle-based control of plug loads described in Section 3.3.

The refrigerator installed in the NZERTF was tested, according to the Department of Energy (DOE) test procedure, to determine the value of the thermal load inside the refrigerator [16]. The annual energy consumption of this unit, according to the energy guide label, is $335 \mathrm{kWh} /$ year and is determined by the DOE test procedure with no consumer interaction. To compensate for this, the DOE test uses elevated ambient temperature of $32.2^{\circ} \mathrm{C}\left(90^{\circ} \mathrm{F}\right)$. According to [16], approximately $5 \mathrm{kWh}$ of the $335 \mathrm{kWh}$ used per year is due to the periodic defrost cycles and the rest was used in the steady state operation of the unit. The study determined that running the thermal load (a heater) inside the refrigerator compartment at a constant ( 24 hours) value of $11.5 \mathrm{~W}$ brought the steady state back up to the annual energy consumption level (excluding the defrost). Therefore, we do not open and close the refrigerator door, except to remove ice, but instead we dissipate heat inside the refrigerator, to simulate the thermal load that people put in the refrigerator (e.g., groceries and warm food).

The energy use of the icemaker is not included in the annual energy consumption label. Operating the icemaker introduces a significant amount of moisture into the cabinet. The refrigerator has an adaptive defrost controller, so the added moisture from ice-making increases the number of the defrost cycles. It was decided that a researcher would enter the house and empty the ice bin once a week. 


\section{Conclusion}

The NZERTF utilizes a virtual family to emulate water usage, lighting usage, miscellaneous electric plug loads, cooking loads, and appliance load. The virtual family, during the first year of testing, consists of two adults and two children whose behavior and activities are based on recommendations published by the U.S. Department of Energy. A minute-by-minute device usage schedule was developed to account for electrical energy consumption, sensible and latent heat generation, and hot water consumption. Some plug loads were emulated by resistive loads while others involve real appliances (e.g., microwave, toaster oven, etc.). Sensible loads were also emulated by resistive loads while latent load was emulated by an ultrasonic humidifier modified to enable long term operation without human intervention. The mechanisms to control sensible and latent, and electrical loads were separated into three categories: time-based, criteria-based, and cycle-based control. All loads, except the cycle-based loads, have a start-time and an end-time. In time-based control, the data acquisition/controller unit starts a load based on its start-time and turns it off when the end-time is reached. In criteria-based control the acquisition/controller unit starts a load based on its start-time, but it terminates the load when a certain criterion, e.g., energy consumption, has been met. In the cycle-based control, the loads were activated based on their start-times and allowed to complete their normal cycles. Water usage was emulated by energizing and de-energizing solenoid valves on the cold and hot water supply lines. The control mechanism is similar to the criteria-based control. The NZERTF is currently being used to demonstrate the feasibility of achieving net zero energy over the course a year (e.g., energy generated using photovoltaic modules and solar hot water panels equals energy consumed). It will subsequently serve as a test bed to develop measurement science, test/performance metric, for energy efficient building technologies. The load automation techniques discussed in the report can be utilized to emulate a range of occupant behavior. 


\section{References}

[1] J. Seryak and K. Kissock, "Occupancy and Behavioral Affects on Rresidential Enery Use," Proceedings of annual conference on American solar energy society, 2000.

[2] R. Hendrom, "Building America Research Benchmark Definition Updated December 19, 2008," National Renewable Energy Laboratory, 2008.

[3] J. D. Lutz, A. Lekov, Y. Qin, and M. Melody, "Hot Water Draw Patterns in Single-Family Houses : Findings from Field Studies,” Lawrence Berkeley National Laboratory, 2011.

[4] R. Hendron and J. Burch, "Development of Standardized Domestic Hot Water Event Schedules for Residential Buildings," National Renewable Energy Laboratory, 2008.

[5] L. International, D\&R, 2009 Building Energy Data Book. U.S. Depeartment of Energy, 2009.

[6] T. and M. A. Group, "Technical Support Document: Energy Conservation Standards for Consumer Pproducts," 1998.

[7] C. Iglehart, N. Milesi_Ferretti, and M. Galler, "Consumer Use of Dishwashers, Clothes Washers , and Dryers : Data Needs and Availability,” NIST Technical Note 1696, 2011.

[8] ASHRAE, 2013 ASHRAE Handbook - Fundamentals. 2013.

[9] J. L. Monteith, "Latent Heat of Vaporization in Thermal Physiology.," Nature: New biology, vol. 236, no. 64. p. 96, 22-Mar-1972.

[10] R. Barnhart, "Home Moisture," Minnesota Department of Commerce, Last Modified August 2nd, 2012.

[11] X. Fang, D. Christensen, G. Barker, and E. Hancock, "Field Test Protocol : Standard Internal Load Generation for Unoccupied Test Homes," Building Technologies Program, U.S. Department of ENERGY, 2011.

[12] ASHRAE, 2011 ASHRAE Handbook - HVAC Applications. 2011.

[13] LBNL, "Standby Power Summary Table.” Lawrence Berkeley National Laboratory, http://standby.lbl.gov/summary-table.html.

[14] “ENERGY STAR Television Product List.” ENERGY STAR, http://downloads.energystar.gov/bi/qplist/tv_prod_list.pdf, 2013.

[15] "Uniform Test Method for Measuring the Energy Consumption of Automatic and Semi-Automatic Clothes Washers.” 10 CFR 430. APPENDIX J2. SUBPART B, 2013.

[16] D. Yashar, "Refrigerator's Thermal Load," Private Communications, National Institute of Standards and Technology, MD, 2012. 


\section{Appendix A}

For the loads that are time-based controlled (see Section 3.3 for details), the start-time and endtime are given but the corresponding entries in columns labeled as (Target Volume / Draw) and (Target Energy / Event) are left blank. For the loads that are criteria-based controlled (e.g., a sink use or a blender use) start-time, end-time, target volume, and target energy are given in columns labeled Target Volume / Draw and Target Energy / Event. The end-time is a safety timeout mechanism. For the loads that are cycle-based controlled only the start-time has been given, and all other corresponding entries are left blank. The numbers (e.g., target volume and energy) throughout the schedule are calculations used for target set-points and do not reflect the measurement accuracy.

\section{Mondays}

\begin{tabular}{|c|c|c|c|c|c|c|}
\hline Start time & End time & FixtureID & Description & $\begin{array}{c}\text { Target } \\
\text { Volume / } \\
\text { Draw } \\
\text { (liters) } \\
\end{array}$ & $\begin{array}{c}\text { Target } \\
\text { Volume / } \\
\text { Draw } \\
\text { (gallons) }\end{array}$ & $\begin{array}{c}\text { Target } \\
\text { Energy / } \\
\text { Day } \\
\text { (Wh) } \\
\end{array}$ \\
\hline 12:05:00 AM & 6:00:00 AM & SHparentBMBR & $\begin{array}{l}\text { Sensible Heat ParentB Master } \\
\text { Bedroom }\end{array}$ & & & \\
\hline 12:05:00 AM & 6:30:00 AM & SHparentAMBR & $\begin{array}{l}\text { Sensible Heat ParentA Master } \\
\text { Bedroom }\end{array}$ & & & \\
\hline 12:05:00 AM & 7:00:00 AM & SHchildABR2 & Sensible Heat ChildA Bedroom \# 2 & & & \\
\hline 12:05:00 AM & 7:00:00 AM & SHchildBBR3 & Sensible Heat ChildB Bedroom \# 3 & & & \\
\hline 12:05:00 AM & 8:30:00 AM & Latent Load & Latent Load & & & \\
\hline $3: 31: 00 \mathrm{AM}$ & $3: 34: 00 \mathrm{AM}$ & LightMastBath & Master Bathroom Lights & & & \\
\hline 3:33:00 AM & 3:34:00 AM & SinkMastBathH & $\begin{array}{l}\text { Sink event - Master Bathroom hot } \\
\text { water }\end{array}$ & 2.38 & 0.63 & \\
\hline 4:00:00 AM & 4:03:00 AM & LightMastBath & Master Bathroom Lights & & & \\
\hline 4:02:00 AM & 4:03:00 AM & SinkMastBathH & $\begin{array}{l}\text { Sink event - Master Bathroom hot } \\
\text { water }\end{array}$ & 2.38 & 0.63 & \\
\hline 6:00:00 AM & 6:01:00 AM & KitchenSinkH & Kitchen Sink hot water & 2.38 & 0.63 & \\
\hline 6:00:00 AM & 6:15:00 AM & LightMastBath & Master Bathroom Lights & & & \\
\hline 6:00:00 AM & 6:30:00 AM & SHparentBDR & Sensible Heat ParentB Dining Room & & & \\
\hline 6:00:00 AM & $8: 25: 00 \mathrm{AM}$ & KitchenLights & Kitchen Lights & & & \\
\hline 6:00:00 AM & & MicrowaveCLR & $\begin{array}{l}\text { Clear Microwave (equivalent to } \\
\text { opening and closing the door) }\end{array}$ & & & \\
\hline 6:01:00 AM & & MicrowaveON & Turn Microwave ON & & & \\
\hline 6:04:00 AM & 6:19:00 AM & ShowerMastBathH & $\begin{array}{l}\text { Shower even - Master Bathroom hot } \\
\text { water }\end{array}$ & 53.00 & 14.00 & \\
\hline 6:05:00 AM & 6:15:00 AM & Blender & Blender & & & 19.20 \\
\hline $6: 10: 00 \mathrm{AM}$ & $6: 28: 20 \mathrm{AM}$ & CoffeeMaker & Coffee Maker & & & 168.12 \\
\hline $6: 15: 00 \mathrm{AM}$ & $6: 25: 00 \mathrm{AM}$ & ToasterOven & Toaster Oven & & & 88.80 \\
\hline 6:15:00 AM & 6:30:00 AM & LightMastBed & Master Bedroom Lights & & & \\
\hline $6: 15: 00 \mathrm{AM}$ & 7:00:00 AM & MastBedATV & Master Bedroom Active TV & & & \\
\hline
\end{tabular}




\begin{tabular}{|c|c|c|c|c|c|c|}
\hline 6:20:00 AM & 6:21:00 AM & SinkMastBathH & $\begin{array}{l}\text { Sink event - Master Bathroom hot } \\
\text { water }\end{array}$ & 2.38 & 0.63 & \\
\hline $6: 20: 00 \mathrm{AM}$ & $6: 35: 00 \mathrm{AM}$ & Toaster & Toaster & & & 126.00 \\
\hline $6: 25: 00 \mathrm{AM}$ & $6: 26: 00 \mathrm{AM}$ & KitchenSinkH & Kitchen Sink hot water & 2.38 & 0.63 & \\
\hline $6: 30: 00 \mathrm{AM}$ & $6: 45: 00 \mathrm{AM}$ & LightMastBath & Master Bathroom Lights & & & \\
\hline 6:30:00 AM & 6:50:00 AM & Light2ndBath & 2nd Bathroom Lights & & & \\
\hline 6:30:00 AM & 7:00:00 AM & SHparentBMBR & $\begin{array}{l}\text { Sensible Heat ParentB Master } \\
\text { Bedroom }\end{array}$ & & & \\
\hline 6:30:00 AM & 8:25:00 AM & LivingRATV & Living room - Active TV & & & \\
\hline 6:30:00 AM & 8:30:00 AM & SHparentAK & Sensible Heat ParentA Kitchen & & & \\
\hline 6:32:00 AM & 6:42:00 AM & ShowerMastBathH & $\begin{array}{l}\text { Shower even - Master Bathroom hot } \\
\text { water }\end{array}$ & 33.12 & 8.75 & \\
\hline 6:40:00 AM & 6:50:00 AM & HairDryer & Hair Dryer & & & 115.70 \\
\hline $6: 40: 00$ AM & 7:00:00 AM & Light2ndBed & 2nd Bedroom Lights & & & \\
\hline $6: 43: 00 \mathrm{AM}$ & $6: 44: 00 \mathrm{AM}$ & SinkMastBathH & $\begin{array}{l}\text { Sink event - Master Bathroom hot } \\
\text { water }\end{array}$ & 2.38 & 0.63 & \\
\hline $6: 45: 00 \mathrm{AM}$ & $6: 55: 00 \mathrm{AM}$ & ShowerMastBathH & $\begin{array}{l}\text { Shower even - Master Bathroom hot } \\
\text { water }\end{array}$ & 33.12 & 8.75 & \\
\hline $6: 45: 00 \mathrm{AM}$ & 7:00:00 AM & LightMastBed & Master Bedroom Lights & & & \\
\hline $6: 50: 00 \mathrm{AM}$ & 7:00:00 AM & Light3rdBed & 3rd Bedroom Lights & & & \\
\hline $6: 56: 00 \mathrm{AM}$ & $6: 57: 00 \mathrm{AM}$ & SinkMastBathH & $\begin{array}{l}\text { Sink event - Master Bathroom hot } \\
\text { water }\end{array}$ & 2.38 & 0.63 & \\
\hline $6: 58: 00 \mathrm{AM}$ & 6:59:00 AM & SinkMastBathH & $\begin{array}{l}\text { Sink event - Master Bathroom hot } \\
\text { water }\end{array}$ & 2.38 & 0.63 & \\
\hline 7:00:00 AM & 8:00:00 AM & DiningRLights & Dining Room Lights & & & \\
\hline 7:00:00 AM & 8:00:00 AM & SHchildALR & Sensible Heat ChildA Living Room & & & \\
\hline 7:00:00 AM & 8:00:00 AM & SHchildBDR & Sensible Heat ChildB Dining Room & & & \\
\hline 7:00:00 AM & 8:30:00 AM & SHparentBDR & Sensible Heat ParentB Dining Room & & & \\
\hline 7:05:00 AM & 7:06:00 AM & KitchenSinkH & Kitchen Sink hot water & 2.38 & 0.63 & \\
\hline 7:30:00 AM & 7:31:00 AM & KitchenSinkH & Kitchen Sink hot water & 2.38 & 0.63 & \\
\hline 8:00:00 AM & $8: 25: 00 \mathrm{AM}$ & LivingRLights & Living room Lights & & & \\
\hline 8:02:00 AM & 8:03:00 AM & KitchenSinkH & Kitchen Sink hot water & 2.38 & 0.63 & \\
\hline 8:10:00 AM & $8: 11: 00 \mathrm{AM}$ & KitchenSinkH & Kitchen Sink hot water & 2.38 & 0.63 & \\
\hline $8: 15: 00$ AM & 8:20:00 AM & Light1stBath & 1st Bathroom Lights & & & \\
\hline 8:20:00 AM & 8:21:00 AM & KitchenSinkH & Kitchen Sink hot water & 2.38 & 0.63 & \\
\hline 8:26:00 AM & 8:27:00 AM & KitchenSinkH & Kitchen Sink hot water & 2.38 & 0.63 & \\
\hline 8:28:00 AM & 8:29:00 AM & KitchenSinkH & Kitchen Sink hot water & 2.38 & 0.63 & \\
\hline 4:00:00 PM & 11:59:00 PM & Latent Load & Latent Load & & & \\
\hline 6:00:00 PM & 6:30:00 PM & KitchenLights & Kitchen Lights & & & \\
\hline 6:00:00 PM & 6:30:00 PM & SHchildBDR & Sensible Heat ChildB Dining Room & & & \\
\hline 6:00:00 PM & 6:30:00 PM & SHparentAMBR & $\begin{array}{l}\text { Sensible Heat ParentA Master } \\
\text { Bedroom }\end{array}$ & & & \\
\hline 6:00:00 PM & 7:30:00 PM & SHchildABR2 & Sensible Heat ChildA Bedroom \# 2 & & & \\
\hline 6:00:00 PM & 10:00:00 PM & SHparentBDR & Sensible Heat ParentB Dining Room & & & \\
\hline 6:00:00 PM & 10:30:00 PM & LivingRLights & Living room Lights & & & \\
\hline 6:01:00 PM & 6:06:00 PM & LightMastBath & Master Bathroom Lights & & & \\
\hline
\end{tabular}




\begin{tabular}{|c|c|c|c|c|c|c|}
\hline 6:02:00 PM & 6:06:00 PM & Light1stBath & 1st Bathroom Lights & & & \\
\hline 6:02:00 PM & 7:02:00 PM & CookTops & Cooktops & & & 408.04 \\
\hline 6:03:00 PM & 6:04:00 PM & KitchenSinkH & Kitchen Sink hot water & 2.38 & 0.63 & \\
\hline 6:05:00 PM & 6:06:00 PM & SinkMastBathH & $\begin{array}{l}\text { Sink event - Master Bathroom hot } \\
\text { water }\end{array}$ & 2.38 & 0.63 & \\
\hline 6:07:00 PM & 6:08:00 PM & KitchenSinkH & Kitchen Sink hot water & 2.38 & 0.63 & \\
\hline 6:07:00 PM & 6:30:00 PM & LightMastBed & Master Bedroom Lights & & & \\
\hline 6:08:00 PM & 6:18:00 PM & Light2ndBath & 2nd Bathroom Lights & & & \\
\hline 6:09:00 PM & 6:19:00 PM & ShowerMastBathH & $\begin{array}{l}\text { Shower even - Master Bathroom hot } \\
\text { water }\end{array}$ & 33.12 & 8.75 & \\
\hline 6:09:00 PM & & MicrowaveCLR & $\begin{array}{l}\text { Clear Microwave (equivalent to } \\
\text { opening and closing the door) }\end{array}$ & & & \\
\hline 6:10:00 PM & 8:30:00 PM & LivingRATV & Living room - Active TV & & & \\
\hline 6:10:00 PM & & MicrowaveON & Turn Microwave ON & & & \\
\hline 6:20:00 PM & 6:21:00 PM & SinkMastBathH & $\begin{array}{l}\text { Sink event - Master Bathroom hot } \\
\text { water }\end{array}$ & 2.38 & 0.63 & \\
\hline 6:20:00 PM & 7:30:00 PM & Light2ndBed & 2nd Bedroom Lights & & & \\
\hline 6:30:00 PM & 7:30:00 PM & Light3rdBed & 3rd Bedroom Lights & & & \\
\hline 6:30:00 PM & 7:30:00 PM & SHchildBBR3 & Sensible Heat ChildB Bedroom \# 3 & & & \\
\hline 6:30:00 PM & 8:15:00 PM & ComputerACB & Bedroom \# 3 - Laptop & & & \\
\hline 6:30:00 PM & 10:00:00 PM & ComputerACA & Bedroom \# 2 - Laptop & & & \\
\hline 6:30:00 PM & 10:30:00 PM & DesktopCA & Desktop PC and Monitor & & & 342.60 \\
\hline 6:30:00 PM & 10:30:00 PM & SHparentAK & Sensible Heat ParentA Kitchen & & & \\
\hline 6:40:00 PM & $6: 41: 00 \mathrm{PM}$ & KitchenSinkH & Kitchen Sink hot water & 2.38 & 0.63 & \\
\hline 6:40:00 PM & 6:47:04 PM & CanOpener & Can Opener & & & \\
\hline 6:40:00 PM & 6:50:00 PM & HandMixer & Hand Mixer & & & 5.50 \\
\hline 6:45:00 PM & 6:46:00 PM & KitchenSinkH & Kitchen Sink hot water & 2.38 & 0.63 & \\
\hline 6:55:00 PM & 6:56:00 PM & KitchenSinkH & Kitchen Sink hot water & 2.38 & 0.63 & \\
\hline 7:00:00 PM & 7:15:00 PM & KitchenLights & Kitchen Lights & & & \\
\hline 7:05:00 PM & 7:06:00 PM & KitchenSinkH & Kitchen Sink hot water & 2.38 & 0.63 & \\
\hline 7:10:00 PM & 7:11:00 PM & KitchenSinkH & Kitchen Sink hot water & 2.38 & 0.63 & \\
\hline 7:15:00 PM & 8:30:00 PM & DiningRLights & Dining Room Lights & & & \\
\hline 7:30:00 PM & 8:15:00 PM & KitchenLights & Kitchen Lights & & & \\
\hline 7:30:00 PM & 8:15:00 PM & SHchildALR & Sensible Heat ChildA Living Room & & & \\
\hline 7:30:00 PM & 8:15:00 PM & SHchildBDR & Sensible Heat ChildB Dining Room & & & \\
\hline 7:35:00 PM & 7:36:00 PM & KitchenSinkH & Kitchen Sink hot water & 2.38 & 0.63 & \\
\hline 8:00:00 PM & 8:01:00 PM & KitchenSinkH & Kitchen Sink hot water & 2.38 & 0.63 & \\
\hline 8:15:00 PM & 8:16:00 PM & KitchenSinkH & Kitchen Sink hot water & 2.38 & 0.63 & \\
\hline 8:15:00 PM & $8: 25: 00 \mathrm{PM}$ & Light2ndBath & 2nd Bathroom Lights & & & \\
\hline 8:15:00 PM & 8:30:00 PM & Light3rdBed & 3rd Bedroom Lights & & & \\
\hline 8:15:00 PM & 9:45:00 PM & Light2ndBed & 2nd Bedroom Lights & & & \\
\hline 8:15:00 PM & 11:59:00 PM & SHchildABR2 & Sensible Heat ChildA Bedroom \# 2 & & & \\
\hline 8:15:00 PM & 11:59:00 PM & SHchildBBR3 & Sensible Heat ChildB Bedroom \# 3 & & & \\
\hline
\end{tabular}




\begin{tabular}{|c|c|c|c|c|c|}
\hline 8:20:00 PM & 8:21:00 PM & SinkMastBathH & $\begin{array}{l}\text { Sink event - Master Bathroom hot } \\
\text { water }\end{array}$ & 2.38 & 0.63 \\
\hline $8: 25: 00 \mathrm{PM}$ & 8:26:00 PM & KitchenSinkH & Kitchen Sink hot water & 2.38 & 0.63 \\
\hline 8:28:00 PM & & Dishwasher & Dishwasher & & \\
\hline 8:30:00 PM & 10:30:00 PM & KitchenLights & Kitchen Lights & & \\
\hline 8:35:00 PM & 8:36:00 PM & KitchenSinkH & Kitchen Sink hot water & 2.38 & 0.63 \\
\hline 8:50:00 PM & 8:51:00 PM & KitchenSinkH & Kitchen Sink hot water & 2.38 & 0.63 \\
\hline 9:05:00 PM & 9:06:00 PM & KitchenSinkH & Kitchen Sink hot water & 2.38 & 0.63 \\
\hline 9:10:00 PM & 9:11:00 PM & KitchenSinkH & Kitchen Sink hot water & 2.38 & 0.63 \\
\hline 9:30:00 PM & 9:31:00 PM & KitchenSinkH & Kitchen Sink hot water & 2.38 & 0.63 \\
\hline 9:35:00 PM & 9:36:00 PM & KitchenSinkH & Kitchen Sink hot water & 2.38 & 0.63 \\
\hline $9: 45: 00 \mathrm{PM}$ & 10:00:00 PM & Light2ndBath & 2nd Bathroom Lights & & \\
\hline 9:55:00 PM & 9:56:00 PM & SinkMastBathH & $\begin{array}{l}\text { Sink event - Master Bathroom hot } \\
\text { water }\end{array}$ & 2.38 & 0.63 \\
\hline 10:00:00 PM & 10:15:00 PM & HeatingPad & Heating Pad & & \\
\hline 10:00:00 PM & 11:00:00 PM & LightMastBed & Master Bedroom Lights & & \\
\hline 10:00:00 PM & 11:59:00 PM & PortableFan & Portable Fan & & \\
\hline 10:00:00 PM & 11:59:00 PM & SHparentBMBR & $\begin{array}{l}\text { Sensible Heat ParentB Master } \\
\text { Bedroom }\end{array}$ & & \\
\hline 10:05:00 PM & 10:06:00 PM & KitchenSinkH & Kitchen Sink hot water & 2.38 & 0.63 \\
\hline 10:05:00 PM & 10:25:00 PM & LightMastBath & Master Bathroom Lights & & \\
\hline 10:10:00 PM & 10:11:00 PM & KitchenSinkH & Kitchen Sink hot water & 2.38 & 0.63 \\
\hline 10:20:00 PM & 10:21:00 PM & SinkMastBathH & $\begin{array}{l}\text { Sink event - Master Bathroom hot } \\
\text { water }\end{array}$ & 2.38 & 0.63 \\
\hline 10:30:00 PM & 10:40:00 PM & LightMastBath & Master Bathroom Lights & & \\
\hline 10:30:00 PM & 11:59:00 PM & SHparentAMBR & $\begin{array}{l}\text { Sensible Heat ParentA Master } \\
\text { Bedroom }\end{array}$ & & \\
\hline 10:35:00 PM & 10:36:00 PM & SinkMastBathH & $\begin{array}{l}\text { Sink event - Master Bathroom hot } \\
\text { water }\end{array}$ & 2.38 & 0.63 \\
\hline
\end{tabular}




\section{Tuesdays}

\begin{tabular}{|c|c|c|c|c|c|c|}
\hline Start time & End time & FixtureID & Description & $\begin{array}{c}\text { Target } \\
\text { Volume } \\
\text { / Draw } \\
\text { (liters) } \\
\end{array}$ & $\begin{array}{c}\text { Target } \\
\text { Volume / } \\
\text { Draw } \\
\text { (gallons) } \\
\end{array}$ & $\begin{array}{c}\text { Target } \\
\text { Energy } \\
\text { / Event } \\
\text { (Wh) } \\
\end{array}$ \\
\hline 12:05:00 AM & 6:00:00 AM & SHparentBMBR & $\begin{array}{l}\text { Sensible Heat ParentB Master } \\
\text { Bedroom }\end{array}$ & & & \\
\hline 12:05:00 AM & 6:30:00 AM & SHparentAMBR & $\begin{array}{l}\text { Sensible Heat ParentA Master } \\
\text { Bedroom }\end{array}$ & & & \\
\hline 12:05:00 AM & 7:00:00 AM & SHchildABR2 & Sensible Heat ChildA Bedroom \# 2 & & & \\
\hline 12:05:00 AM & 7:00:00 AM & SHchildBBR3 & Sensible Heat ChildB Bedroom \# 3 & & & \\
\hline 12:05:00 AM & 8:30:00 AM & Latent Load & Latent Load & & & \\
\hline $3: 31: 00 \mathrm{AM}$ & $3: 34: 00 \mathrm{AM}$ & LightMastBath & Master Bathroom Lights & & & \\
\hline 3:33:00 AM & 3:34:00 AM & SinkMastBathH & $\begin{array}{l}\text { Sink event - Master Bathroom hot } \\
\text { water }\end{array}$ & 2.38 & 0.63 & \\
\hline 4:00:00 AM & 4:03:00 AM & LightMastBath & Master Bathroom Lights & & & \\
\hline 4:02:00 AM & 4:03:00 AM & SinkMastBathH & $\begin{array}{l}\text { Sink event - Master Bathroom hot } \\
\text { water }\end{array}$ & 2.38 & 0.63 & \\
\hline 6:00:00 AM & 6:01:00 AM & KitchenSinkH & Kitchen Sink hot water & 2.38 & 0.63 & \\
\hline 6:00:00 AM & $6: 15: 00 \mathrm{AM}$ & LightMastBath & Master Bathroom Lights & & & \\
\hline 6:00:00 AM & $6: 30: 00 \mathrm{AM}$ & SHparentBDR & $\begin{array}{l}\text { Sensible Heat ParentB Dining } \\
\text { Room }\end{array}$ & & & \\
\hline 6:00:00 AM & $8: 25: 00 \mathrm{AM}$ & KitchenLights & Kitchen Lights & & & \\
\hline 6:00:00 AM & & MicrowaveCLR & $\begin{array}{l}\text { Clear Microwave (equivalent to } \\
\text { opening and closing the door) }\end{array}$ & & & \\
\hline 6:01:00 AM & & MicrowaveON & Turn Microwave ON & & & \\
\hline 6:02:00 AM & 6:03:00 AM & KitchenSinkH & Kitchen Sink hot water & 2.38 & 0.63 & \\
\hline 6:04:00 AM & 6:14:00 AM & ShowerMastBathH & $\begin{array}{l}\text { Shower even - Master Bathroom } \\
\text { hot water }\end{array}$ & 33.12 & 8.75 & \\
\hline 6:05:00 AM & $6: 15: 00 \mathrm{AM}$ & Blender & Blender & & & 19.20 \\
\hline $6: 10: 00 \mathrm{AM}$ & $6: 40: 00 \mathrm{AM}$ & CoffeeMaker & Coffee Maker & & & 168.12 \\
\hline $6: 15: 00 \mathrm{AM}$ & 6:16:00 AM & SinkMastBathH & $\begin{array}{l}\text { Sink event - Master Bathroom hot } \\
\text { water }\end{array}$ & 2.38 & 0.63 & \\
\hline 6:15:00 AM & 6:25:00 AM & ToasterOven & Toaster Oven & & & 88.80 \\
\hline 6:15:00 AM & 6:30:00 AM & LightMastBed & Master Bedroom Lights & & & \\
\hline $6: 15: 00 \mathrm{AM}$ & 7:00:00 AM & MastBedATV & Master Bedroom Active TV & & & \\
\hline 6:20:00 AM & 6:35:00 AM & Toaster & Toaster & & & 126.00 \\
\hline $6: 25: 00 \mathrm{AM}$ & $6: 26: 00 \mathrm{AM}$ & KitchenSinkH & Kitchen Sink hot water & 2.38 & 0.63 & \\
\hline 6:30:00 AM & 6:40:00 AM & ShowerMastBathH & $\begin{array}{l}\text { Shower even - Master Bathroom } \\
\text { hot water }\end{array}$ & 33.12 & 8.75 & \\
\hline 6:30:00 AM & 6:45:00 AM & LightMastBath & Master Bathroom Lights & & & \\
\hline $6: 30: 00 \mathrm{AM}$ & $6: 50: 00 \mathrm{AM}$ & Light2ndBath & 2nd Bathroom Lights & & & \\
\hline 6:30:00 AM & 7:00:00 AM & SHparentBMBR & $\begin{array}{l}\text { Sensible Heat ParentB Master } \\
\text { Bedroom }\end{array}$ & & & \\
\hline 6:30:00 AM & 8:25:00 AM & LivingRATV & Living room - Active TV & & & \\
\hline 6:30:00 AM & 8:30:00 AM & SHparentAK & Sensible Heat ParentA Kitchen & & & \\
\hline 6:40:00 AM & 6:50:00 AM & HairDryer & Hair Dryer & & & 115.70 \\
\hline $6: 40: 00 \mathrm{AM}$ & 7:00:00 AM & Light2ndBed & 2nd Bedroom Lights & & & \\
\hline
\end{tabular}




\begin{tabular}{|c|c|c|c|c|c|c|}
\hline 6:41:00 AM & $6: 42: 00 \mathrm{AM}$ & SinkMastBathH & $\begin{array}{l}\text { Sink event - Master Bathroom hot } \\
\text { water }\end{array}$ & 2.38 & 0.63 & \\
\hline $6: 43: 00 \mathrm{AM}$ & $6: 44: 00 \mathrm{AM}$ & KitchenSinkH & Kitchen Sink hot water & 2.38 & 0.63 & \\
\hline $6: 45: 00 \mathrm{AM}$ & $6: 55: 00 \mathrm{AM}$ & ShowerMastBathH & $\begin{array}{l}\text { Shower even - Master Bathroom } \\
\text { hot water }\end{array}$ & 33.12 & 8.75 & \\
\hline $6: 45: 00 \mathrm{AM}$ & 7:00:00 AM & LightMastBed & Master Bedroom Lights & & & \\
\hline $6: 50: 00 \mathrm{AM}$ & 7:00:00 AM & Light3rdBed & 3rd Bedroom Lights & & & \\
\hline 6:56:00 AM & $6: 57: 00 \mathrm{AM}$ & SinkMastBathH & $\begin{array}{l}\text { Sink event - Master Bathroom hot } \\
\text { water }\end{array}$ & 2.38 & 0.63 & \\
\hline 6:58:00 AM & 6:59:00 AM & SinkMastBathH & $\begin{array}{l}\text { Sink event - Master Bathroom hot } \\
\text { water }\end{array}$ & 2.38 & 0.63 & \\
\hline 7:00:00 AM & 8:00:00 AM & DiningRLights & Dining Room Lights & & & \\
\hline 7:00:00 AM & 8:00:00 AM & SHchildALR & $\begin{array}{l}\text { Sensible Heat ChildA Living } \\
\text { Room }\end{array}$ & & & \\
\hline 7:00:00 AM & 8:00:00 AM & SHchildBDR & $\begin{array}{l}\text { Sensible Heat ChildB Dining } \\
\text { Room }\end{array}$ & & & \\
\hline 7:00:00 AM & 8:30:00 AM & SHparentBDR & $\begin{array}{l}\text { Sensible Heat ParentB Dining } \\
\text { Room }\end{array}$ & & & \\
\hline 7:05:00 AM & 7:06:00 AM & KitchenSinkH & Kitchen Sink hot water & 2.38 & 0.63 & \\
\hline 7:30:00 AM & 7:31:00 AM & KitchenSinkH & Kitchen Sink hot water & 2.38 & 0.63 & \\
\hline 7:35:00 AM & 7:36:00 AM & KitchenSinkH & Kitchen Sink hot water & 2.38 & 0.63 & \\
\hline 8:00:00 AM & 8:25:00 AM & LivingRLights & Living room Lights & & & \\
\hline 8:02:00 AM & 8:03:00 AM & KitchenSinkH & Kitchen Sink hot water & 2.38 & 0.63 & \\
\hline 8:10:00 AM & 8:11:00 AM & KitchenSinkH & Kitchen Sink hot water & 2.38 & 0.63 & \\
\hline 8:20:00 AM & 8:21:00 AM & KitchenSinkH & Kitchen Sink hot water & 2.38 & 0.63 & \\
\hline 8:26:00 AM & 8:27:00 AM & KitchenSinkH & Kitchen Sink hot water & 2.38 & 0.63 & \\
\hline 8:30:00 AM & 8:30:00 PM & SlowCooker & Slow Cooker & & & 153.85 \\
\hline 4:00:00 PM & 4:30:00 PM & SHchildALR & $\begin{array}{l}\text { Sensible Heat ChildA Living } \\
\text { Room }\end{array}$ & & & \\
\hline 4:00:00 PM & 11:59:00 PM & Latent Load & Latent Load & & & \\
\hline 4:01:00 PM & 4:06:00 PM & Light1stBath & 1st Bathroom Lights & & & \\
\hline 4:04:00 PM & 4:05:00 PM & KitchenSinkH & Kitchen Sink hot water & 2.38 & 0.63 & \\
\hline 4:10:00 PM & 4:11:00 PM & KitchenSinkH & Kitchen Sink hot water & 2.38 & 0.63 & \\
\hline 4:25:00 PM & 4:26:00 PM & KitchenSinkH & Kitchen Sink hot water & 2.38 & 0.63 & \\
\hline 4:30:00 PM & 6:00:00 PM & Light2ndBed & 2nd Bedroom Lights & & & \\
\hline 4:30:00 PM & 6:00:00 PM & SHchildABR2 & Sensible Heat ChildA Bedroom \# 2 & & & \\
\hline 6:00:00 PM & 6:30:00 PM & KitchenLights & Kitchen Lights & & & \\
\hline 6:00:00 PM & 6:30:00 PM & LivingRLights & Living room Lights & & & \\
\hline 6:00:00 PM & 6:30:00 PM & SHchildALR & $\begin{array}{l}\text { Sensible Heat ChildA Living } \\
\text { Room }\end{array}$ & & & \\
\hline 6:00:00 PM & 6:30:00 PM & SHchildBDR & $\begin{array}{l}\text { Sensible Heat ChildB Dining } \\
\text { Room }\end{array}$ & & & \\
\hline 6:00:00 PM & 6:30:00 PM & SHparentAMBR & $\begin{array}{l}\text { Sensible Heat ParentA Master } \\
\text { Bedroom }\end{array}$ & & & \\
\hline 6:00:00 PM & 10:00:00 PM & SHparentBDR & $\begin{array}{l}\text { Sensible Heat ParentB Dining } \\
\text { Room }\end{array}$ & & & \\
\hline 6:01:00 PM & 6:06:00 PM & LightMastBath & Master Bathroom Lights & & & \\
\hline 6:02:00 PM & 6:06:00 PM & Light1stBath & 1st Bathroom Lights & & & \\
\hline 6:02:00 PM & 7:02:00 PM & CookTops & Cooktops & & & 408.04 \\
\hline
\end{tabular}




\begin{tabular}{|c|c|c|c|c|c|c|}
\hline 6:05:00 PM & 6:06:00 PM & SinkMastBathH & $\begin{array}{l}\text { Sink event - Master Bathroom hot } \\
\text { water }\end{array}$ & 2.38 & 0.63 & \\
\hline 6:07:00 PM & 6:30:00 PM & LightMastBed & Master Bedroom Lights & & & \\
\hline 6:09:00 PM & & MicrowaveCLR & $\begin{array}{l}\text { Clear Microwave (equivalent to } \\
\text { opening and closing the door) }\end{array}$ & & & \\
\hline 6:10:00 PM & 8:30:00 PM & LivingRATV & Living room - Active TV & & & \\
\hline 6:10:00 PM & & MicrowaveON & Turn Microwave ON & & & \\
\hline 6:30:00 PM & 7:30:00 PM & SHchildABR2 & Sensible Heat ChildA Bedroom \# 2 & & & \\
\hline 6:30:00 PM & 7:30:00 PM & SHchildBBR3 & Sensible Heat ChildB Bedroom \# 3 & & & \\
\hline 6:30:00 PM & 8:15:00 PM & ComputerACB & Bedroom \# 3 - Laptop & & & \\
\hline 6:30:00 PM & 8:30:00 PM & Light3rdBed & 3rd Bedroom Lights & & & \\
\hline 6:30:00 PM & 10:00:00 PM & ComputerACA & Bedroom \# 2 - Laptop & & & \\
\hline 6:30:00 PM & 10:00:00 PM & Light2ndBed & 2nd Bedroom Lights & & & \\
\hline 6:30:00 PM & 10:30:00 PM & DesktopCA & Desktop PC and Monitor & & & 342.60 \\
\hline 6:30:00 PM & 10:30:00 PM & SHparentAK & Sensible Heat ParentA Kitchen & & & \\
\hline 6:40:00 PM & 6:41:00 PM & KitchenSinkH & Kitchen Sink hot water & 2.38 & 0.63 & \\
\hline 6:40:00 PM & 6:47:04 PM & CanOpener & Can Opener & & & \\
\hline 6:40:00 PM & 6:50:00 PM & HandMixer & Hand Mixer & & & 5.50 \\
\hline 6:45:00 PM & 6:46:00 PM & KitchenSinkH & Kitchen Sink hot water & 2.38 & 0.63 & \\
\hline 6:55:00 PM & 6:56:00 PM & KitchenSinkH & Kitchen Sink hot water & 2.38 & 0.63 & \\
\hline 7:00:00 PM & 7:15:00 PM & KitchenLights & Kitchen Lights & & & \\
\hline 7:00:00 PM & 7:15:00 PM & LivingRLights & Living room Lights & & & \\
\hline 7:10:00 PM & 7:11:00 PM & KitchenSinkH & Kitchen Sink hot water & 2.38 & 0.63 & \\
\hline 7:15:00 PM & 8:30:00 PM & DiningRLights & Dining Room Lights & & & \\
\hline 7:30:00 PM & 8:15:00 PM & KitchenLights & Kitchen Lights & & & \\
\hline 7:30:00 PM & 8:15:00 PM & SHchildALR & $\begin{array}{l}\text { Sensible Heat ChildA Living } \\
\text { Room }\end{array}$ & & & \\
\hline 7:30:00 PM & 8:15:00 PM & SHchildBDR & $\begin{array}{l}\text { Sensible Heat ChildB Dining } \\
\text { Room }\end{array}$ & & & \\
\hline 7:30:00 PM & 9:30:00 PM & LivingRLights & Living room Lights & & & \\
\hline 7:35:00 PM & 7:36:00 PM & KitchenSinkH & Kitchen Sink hot water & 2.38 & 0.63 & \\
\hline 8:00:00 PM & 8:01:00 PM & KitchenSinkH & Kitchen Sink hot water & 2.38 & 0.63 & \\
\hline 8:15:00 PM & 8:16:00 PM & KitchenSinkH & Kitchen Sink hot water & 2.38 & 0.63 & \\
\hline 8:15:00 PM & 8:25:00 PM & Light2ndBath & 2nd Bathroom Lights & & & \\
\hline 8:15:00 PM & 11:59:00 PM & SHchildABR2 & Sensible Heat ChildA Bedroom \# 2 & & & \\
\hline 8:15:00 PM & 11:59:00 PM & SHchildBBR3 & Sensible Heat ChildB Bedroom \# 3 & & & \\
\hline 8:20:00 PM & 8:21:00 PM & SinkMastBathH & $\begin{array}{l}\text { Sink event - Master Bathroom hot } \\
\text { water }\end{array}$ & 2.38 & 0.63 & \\
\hline 8:25:00 PM & 8:26:00 PM & KitchenSinkH & Kitchen Sink hot water & 2.38 & 0.63 & \\
\hline 8:30:00 PM & 10:30:00 PM & KitchenLights & Kitchen Lights & & & \\
\hline 8:35:00 PM & 8:36:00 PM & KitchenSinkH & Kitchen Sink hot water & 2.38 & 0.63 & \\
\hline 8:50:00 PM & 8:51:00 PM & KitchenSinkH & Kitchen Sink hot water & 2.38 & 0.63 & \\
\hline 9:05:00 PM & 9:06:00 PM & KitchenSinkH & Kitchen Sink hot water & 2.38 & 0.63 & \\
\hline 9:10:00 PM & 9:11:00 PM & KitchenSinkH & Kitchen Sink hot water & 2.38 & 0.63 & \\
\hline
\end{tabular}




\begin{tabular}{|c|c|c|c|c|c|}
\hline 9:30:00 PM & 9:31:00 PM & KitchenSinkH & Kitchen Sink hot water & 2.38 & 0.63 \\
\hline 9:40:00 PM & 9:41:00 PM & KitchenSinkH & Kitchen Sink hot water & 2.38 & 0.63 \\
\hline 9:43:00 PM & 9:58:00 PM & ShowerMastBathH & $\begin{array}{l}\text { Shower even - Master Bathroom } \\
\text { hot water }\end{array}$ & 53.00 & 14.00 \\
\hline 9:45:00 PM & 10:00:00 PM & Light2ndBath & 2nd Bathroom Lights & & \\
\hline 9:59:00 PM & 10:00:00 PM & SinkMastBathH & $\begin{array}{l}\text { Sink event - Master Bathroom hot } \\
\text { water }\end{array}$ & 2.38 & 0.63 \\
\hline 10:00:00 PM & $\begin{array}{c}12: 00: 00 \\
\mathrm{AM} \\
\end{array}$ & PortableFan & Portable Fan & & \\
\hline 10:00:00 PM & 10:10:00 PM & HeatingPad & Heating Pad & & \\
\hline 10:00:00 PM & 10:30:00 PM & LivingRLights & Living room Lights & & \\
\hline 10:00:00 PM & 11:00:00 PM & LightMastBed & Master Bedroom Lights & & \\
\hline 10:00:00 PM & 11:59:00 PM & SHparentBMBR & $\begin{array}{l}\text { Sensible Heat ParentB Master } \\
\text { Bedroom }\end{array}$ & & \\
\hline 10:05:00 PM & 10:06:00 PM & KitchenSinkH & Kitchen Sink hot water & 2.38 & 0.63 \\
\hline 10:05:00 PM & 10:25:00 PM & LightMastBath & Master Bathroom Lights & & \\
\hline 10:20:00 PM & 10:21:00 PM & SinkMastBathH & $\begin{array}{l}\text { Sink event - Master Bathroom hot } \\
\text { water }\end{array}$ & 2.38 & 0.63 \\
\hline 10:30:00 PM & 10:40:00 PM & LightMastBath & Master Bathroom Lights & & \\
\hline 10:30:00 PM & 11:59:00 PM & SHparentAMBR & $\begin{array}{l}\text { Sensible Heat ParentA Master } \\
\text { Bedroom }\end{array}$ & & \\
\hline 10:35:00 PM & 10:36:00 PM & SinkMastBathH & $\begin{array}{l}\text { Sink event - Master Bathroom hot } \\
\text { water }\end{array}$ & 2.38 & 0.63 \\
\hline
\end{tabular}




\section{Wednesdays}

\begin{tabular}{|c|c|c|c|c|c|c|}
\hline Start time & End time & FixtureID & Description & $\begin{array}{c}\text { Target } \\
\text { volume } \\
\text { / Draw } \\
\text { (liters) }\end{array}$ & $\begin{array}{c}\text { Target } \\
\text { Volume } \\
\text { / Draw } \\
\text { (gallons) }\end{array}$ & $\begin{array}{c}\text { Target } \\
\text { Energy / } \\
\text { Event } \\
\text { (Wh) }\end{array}$ \\
\hline 12:05:00 AM & 6:00:00 AM & SHparentBMBR & $\begin{array}{l}\text { Sensible Heat ParentB Master } \\
\text { Bedroom }\end{array}$ & & & \\
\hline 12:05:00 AM & 6:30:00 AM & SHparentAMBR & $\begin{array}{l}\text { Sensible Heat ParentA Master } \\
\text { Bedroom }\end{array}$ & & & \\
\hline 12:05:00 AM & 7:00:00 AM & SHchildABR2 & Sensible Heat ChildA Bedroom \# 2 & & & \\
\hline 12:05:00 AM & 7:00:00 AM & SHchildBBR3 & Sensible Heat ChildB Bedroom \# 3 & & & \\
\hline 12:05:00 AM & 8:30:00 AM & Latent Load & Latent Load & & & \\
\hline 3:31:00 AM & 3:34:00 AM & LightMastBath & Master Bathroom Lights & & & \\
\hline 3:33:00 AM & 3:34:00 AM & SinkMastBathH & $\begin{array}{l}\text { Sink event - Master Bathroom hot } \\
\text { water }\end{array}$ & 2.38 & 0.63 & \\
\hline 4:00:00 AM & 4:03:00 AM & LightMastBath & Master Bathroom Lights & & & \\
\hline 4:02:00 AM & 4:03:00 AM & SinkMastBathH & $\begin{array}{l}\text { Sink event - Master Bathroom hot } \\
\text { water }\end{array}$ & 2.38 & 0.63 & \\
\hline 6:00:00 AM & 6:01:00 AM & KitchenSinkH & Kitchen Sink hot water & 2.38 & 0.63 & \\
\hline 6:00:00 AM & 6:15:00 AM & LightMastBath & Master Bathroom Lights & & & \\
\hline 6:00:00 AM & 6:30:00 AM & SHparentBDR & $\begin{array}{l}\text { Sensible Heat ParentB Dining } \\
\text { Room }\end{array}$ & & & \\
\hline 6:00:00 AM & $8: 25: 00 \mathrm{AM}$ & KitchenLights & Kitchen Lights & & & \\
\hline 6:00:00 AM & & MicrowaveCLR & $\begin{array}{l}\text { Clear Microwave (equivalent to } \\
\text { opening and closing the door) }\end{array}$ & & & \\
\hline 6:01:00 AM & & MicrowaveON & Turn Microwave ON & & & \\
\hline 6:03:00 AM & 6:13:00 AM & ShowerMastBathH & $\begin{array}{l}\text { Shower even - Master Bathroom } \\
\text { hot water }\end{array}$ & 33.12 & 8.75 & \\
\hline 6:05:00 AM & $6: 15: 00 \mathrm{AM}$ & Blender & Blender & & & 19.20 \\
\hline 6:09:00 AM & & MicrowaveCLR & $\begin{array}{l}\text { Clear Microwave (equivalent to } \\
\text { opening and closing the door) }\end{array}$ & & & \\
\hline 6:10:00 AM & $6: 40: 00$ AM & CoffeeMaker & Coffee Maker & & & 168.12 \\
\hline 6:14:00 AM & 6:15:00 AM & SinkMastBathH & $\begin{array}{l}\text { Sink event - Master Bathroom hot } \\
\text { water }\end{array}$ & 2.38 & 0.63 & \\
\hline 6:15:00 AM & 6:25:00 AM & ToasterOven & Toaster Oven & & & 88.80 \\
\hline 6:15:00 AM & 6:30:00 AM & LightMastBed & Master Bedroom Lights & & & \\
\hline 6:15:00 AM & 7:00:00 AM & MastBedATV & Master Bedroom Active TV & & & \\
\hline 6:20:00 AM & 6:35:00 AM & Toaster & Toaster & & & 126.00 \\
\hline $6: 25: 00 \mathrm{AM}$ & 6:26:00 AM & KitchenSinkH & Kitchen Sink hot water & 2.38 & 0.63 & \\
\hline 6:30:00 AM & 6:40:00 AM & Light2ndBath & 2nd Bathroom Lights & & & \\
\hline 6:30:00 AM & $6: 45: 00 \mathrm{AM}$ & LightMastBath & Master Bathroom Lights & & & \\
\hline 6:30:00 AM & 7:00:00 AM & SHparentBMBR & $\begin{array}{l}\text { Sensible Heat ParentB Master } \\
\text { Bedroom }\end{array}$ & & & \\
\hline 6:30:00 AM & $8: 25: 00 \mathrm{AM}$ & LivingRATV & Living room - Active TV & & & \\
\hline 6:30:00 AM & 8:30:00 AM & SHparentAK & Sensible Heat ParentA Kitchen & & & \\
\hline 6:31:00 AM & 6:41:00 AM & ShowerMastBathH & $\begin{array}{l}\text { Shower even - Master Bathroom } \\
\text { hot water }\end{array}$ & 33.12 & 8.75 & \\
\hline
\end{tabular}




\begin{tabular}{|c|c|c|c|c|c|c|}
\hline $6: 40: 00 \mathrm{AM}$ & $6: 50: 00 \mathrm{AM}$ & HairDryer & Hair Dryer & & & 115.70 \\
\hline $6: 40: 00 \mathrm{AM}$ & 7:00:00 AM & Light2ndBed & 2nd Bedroom Lights & & & \\
\hline $6: 42: 00 \mathrm{AM}$ & $6: 43: 00 \mathrm{AM}$ & SinkMastBathH & $\begin{array}{l}\text { Sink event - Master Bathroom hot } \\
\text { water }\end{array}$ & 2.38 & 0.63 & \\
\hline $6: 44: 00 \mathrm{AM}$ & $6: 45: 00 \mathrm{AM}$ & SinkMastBathH & $\begin{array}{l}\text { Sink event - Master Bathroom hot } \\
\text { water }\end{array}$ & 2.38 & 0.63 & \\
\hline $6: 45: 00 \mathrm{AM}$ & 7:00:00 AM & LightMastBed & Master Bedroom Lights & & & \\
\hline $6: 47: 00 \mathrm{AM}$ & $6: 48: 00 \mathrm{AM}$ & KitchenSinkH & Kitchen Sink hot water & 2.38 & 0.63 & \\
\hline 6:50:00 AM & 7:00:00 AM & Light3rdBed & 3rd Bedroom Lights & & & \\
\hline 7:00:00 AM & 8:00:00 AM & DiningRLights & Dining Room Lights & & & \\
\hline 7:00:00 AM & 8:00:00 AM & SHchildALR & $\begin{array}{l}\text { Sensible Heat ChildA Living } \\
\text { Room }\end{array}$ & & & \\
\hline 7:00:00 AM & 8:00:00 AM & SHchildBDR & $\begin{array}{l}\text { Sensible Heat ChildB Dining } \\
\text { Room }\end{array}$ & & & \\
\hline 7:00:00 AM & 8:30:00 AM & SHparentBDR & $\begin{array}{l}\text { Sensible Heat ParentB Dining } \\
\text { Room }\end{array}$ & & & \\
\hline 7:05:00 AM & 7:06:00 AM & KitchenSinkH & Kitchen Sink hot water & 2.38 & 0.63 & \\
\hline 7:30:00 AM & 7:31:00 AM & KitchenSinkH & Kitchen Sink hot water & 2.38 & 0.63 & \\
\hline 7:40:00 AM & 7:45:00 AM & Light1stBath & 1st Bathroom Lights & & & \\
\hline 7:42:00 AM & 7:43:00 AM & KitchenSinkH & Kitchen Sink hot water & 2.38 & 0.63 & \\
\hline 7:45:00 AM & 7:46:00 AM & KitchenSinkH & Kitchen Sink hot water & 2.38 & 0.63 & \\
\hline 8:00:00 AM & $8: 25: 00 \mathrm{AM}$ & LivingRLights & Living room Lights & & & \\
\hline 8:02:00 AM & 8:03:00 AM & KitchenSinkH & Kitchen Sink hot water & 2.38 & 0.63 & \\
\hline 8:10:00 AM & 8:11:00 AM & KitchenSinkH & Kitchen Sink hot water & 2.38 & 0.63 & \\
\hline $8: 20: 00 \mathrm{AM}$ & $8: 21: 00$ AM & KitchenSinkH & Kitchen Sink hot water & 2.38 & 0.63 & \\
\hline 8:28:00 AM & 8:29:00 AM & KitchenSinkH & Kitchen Sink hot water & 2.38 & 0.63 & \\
\hline 12:00:00 PM & 12:10:00 PM & MBA Tub Cold & Master Bathroom cold water & & & \\
\hline 12:00:00 PM & 1:00:00 PM & MBA Drain & $\begin{array}{l}\text { Master Bathroom Drain Tank } \\
\text { Solenoid }\end{array}$ & & & \\
\hline 4:00:00 PM & 11:59:00 PM & Latent Load & Latent Load & & & \\
\hline 6:00:00 PM & 6:06:00 PM & LightMastBath & Master Bathroom Lights & & & \\
\hline 6:00:00 PM & 6:30:00 PM & KitchenLights & Kitchen Lights & & & \\
\hline 6:00:00 PM & 6:30:00 PM & LivingRLights & Living room Lights & & & \\
\hline 6:00:00 PM & 6:30:00 PM & SHchildBDR & $\begin{array}{l}\text { Sensible Heat ChildB Dining } \\
\text { Room }\end{array}$ & & & \\
\hline 6:00:00 PM & 6:30:00 PM & SHparentAMBR & $\begin{array}{l}\text { Sensible Heat ParentA Master } \\
\text { Bedroom }\end{array}$ & & & \\
\hline 6:00:00 PM & 7:30:00 PM & SHchildABR2 & Sensible Heat ChildA Bedroom \# 2 & & & \\
\hline 6:00:00 PM & 10:00:00 PM & SHparentBDR & $\begin{array}{l}\text { Sensible Heat ParentB Dining } \\
\text { Room }\end{array}$ & & & \\
\hline 6:02:00 PM & 7:02:00 PM & CookTops & Cooktops & & & 408.04 \\
\hline 6:05:00 PM & 6:06:00 PM & SinkMastBathH & $\begin{array}{l}\text { Sink event - Master Bathroom hot } \\
\text { water }\end{array}$ & 2.38 & 0.63 & \\
\hline 6:07:00 PM & 6:19:00 PM & ShowerMastBathH & $\begin{array}{l}\text { Shower even - Master Bathroom } \\
\text { hot water }\end{array}$ & 33.12 & 8.75 & \\
\hline 6:07:00 PM & 6:30:00 PM & LightMastBed & Master Bedroom Lights & & & \\
\hline 6:08:00 PM & 6:18:00 PM & Light2ndBath & 2nd Bathroom Lights & & & \\
\hline 6:10:00 PM & 8:30:00 PM & LivingRATV & Living room - Active TV & & & \\
\hline
\end{tabular}




\begin{tabular}{|c|c|c|c|c|c|c|}
\hline 6:10:00 PM & & MicrowaveON & Turn Microwave ON & & & \\
\hline 6:20:00 PM & 6:21:00 PM & SinkMastBathH & $\begin{array}{l}\text { Sink event - Master Bathroom hot } \\
\text { water }\end{array}$ & 2.38 & 0.63 & \\
\hline 6:20:00 PM & 10:00:00 PM & Light2ndBed & 2nd Bedroom Lights & & & \\
\hline 6:25:00 PM & 6:26:00 PM & KitchenSinkH & Kitchen Sink hot water & 2.38 & 0.63 & \\
\hline 6:30:00 PM & 7:30:00 PM & SHchildBBR3 & Sensible Heat ChildB Bedroom \# 3 & & & \\
\hline 6:30:00 PM & 8:15:00 PM & ComputerACB & Bedroom \# 3 - Laptop & & & \\
\hline 6:30:00 PM & 8:30:00 PM & Light3rdBed & 3rd Bedroom Lights & & & \\
\hline 6:30:00 PM & 10:00:00 PM & ComputerACA & Bedroom \# 2 - Laptop & & & \\
\hline 6:30:00 PM & 10:30:00 PM & DesktopCA & Desktop PC and Monitor & & & 342.60 \\
\hline 6:30:00 PM & 10:30:00 PM & SHparentAK & Sensible Heat ParentA Kitchen & & & \\
\hline 6:30:00 PM & & WashingM & Clothes Washer & & & \\
\hline 6:40:00 PM & 6:41:00 PM & KitchenSinkH & Kitchen Sink hot water & 2.38 & 0.63 & \\
\hline 6:40:00 PM & 6:47:04 PM & CanOpener & Can Opener & & & \\
\hline 6:40:00 PM & 6:50:00 PM & HandMixer & Hand Mixer & & & 5.50 \\
\hline 6:45:00 PM & 6:46:00 PM & KitchenSinkH & Kitchen Sink hot water & 2.38 & 0.63 & \\
\hline 6:55:00 PM & 6:56:00 PM & KitchenSinkH & Kitchen Sink hot water & 2.38 & 0.63 & \\
\hline 7:00:00 PM & 7:15:00 PM & KitchenLights & Kitchen Lights & & & \\
\hline 7:00:00 PM & 7:15:00 PM & LivingRLights & Living room Lights & & & \\
\hline 7:05:00 PM & 7:06:00 PM & KitchenSinkH & Kitchen Sink hot water & 2.38 & 0.63 & \\
\hline 7:10:00 PM & 7:11:00 PM & KitchenSinkH & Kitchen Sink hot water & 2.38 & 0.63 & \\
\hline 7:15:00 PM & 8:30:00 PM & DiningRLights & Dining Room Lights & & & \\
\hline 7:30:00 PM & 8:15:00 PM & KitchenLights & Kitchen Lights & & & \\
\hline 7:30:00 PM & 8:15:00 PM & SHchildALR & $\begin{array}{l}\text { Sensible Heat ChildA Living } \\
\text { Room }\end{array}$ & & & \\
\hline 7:30:00 PM & 8:15:00 PM & SHchildBDR & $\begin{array}{l}\text { Sensible Heat ChildB Dining } \\
\text { Room }\end{array}$ & & & \\
\hline 7:30:00 PM & 10:30:00 PM & LivingRLights & Living room Lights & & & \\
\hline 7:35:00 PM & 7:36:00 PM & KitchenSinkH & Kitchen Sink hot water & 2.38 & 0.63 & \\
\hline 8:00:00 PM & 8:01:00 PM & KitchenSinkH & Kitchen Sink hot water & 2.38 & 0.63 & \\
\hline 8:11:00 PM & 8:12:00 PM & KitchenSinkH & Kitchen Sink hot water & 2.38 & 0.63 & \\
\hline 8:13:00 PM & $8: 25: 00$ PM & MBA Tub & Master Bathroom Tub & 113.56 & 30.00 & \\
\hline 8:15:00 PM & 8:25:00 PM & Light2ndBath & 2nd Bathroom Lights & & & \\
\hline 8:15:00 PM & 11:59:00 PM & SHchildABR2 & Sensible Heat ChildA Bedroom \# 2 & & & \\
\hline 8:15:00 PM & 11:59:00 PM & SHchildBBR3 & Sensible Heat ChildB Bedroom \# 3 & & & \\
\hline $8: 25: 00$ PM & & WashingM & Clothes Washer & & & \\
\hline $8: 26: 00 \mathrm{PM}$ & 8:27:00 PM & KitchenSinkH & Kitchen Sink hot water & 2.38 & 0.63 & \\
\hline 8:28:00 PM & 8:29:00 PM & SinkMastBathH & $\begin{array}{l}\text { Sink event - Master Bathroom hot } \\
\text { water }\end{array}$ & 2.38 & 0.63 & \\
\hline 8:29:00 PM & & Dishwasher & Dishwasher & & & \\
\hline 8:30:00 PM & 10:30:00 PM & KitchenLights & Kitchen Lights & & & \\
\hline 8:30:00 PM & & ClothDryer & Clothes Dryer & & & \\
\hline 8:35:00 PM & 8:36:00 PM & KitchenSinkH & Kitchen Sink hot water & 2.38 & 0.63 & \\
\hline 8:50:00 PM & 8:51:00 PM & KitchenSinkH & Kitchen Sink hot water & 2.38 & 0.63 & \\
\hline
\end{tabular}




\begin{tabular}{|c|c|c|c|c|c|}
\hline 9:05:00 PM & 9:06:00 PM & KitchenSinkH & Kitchen Sink hot water & 2.38 & 0.63 \\
\hline 9:10:00 PM & 9:11:00 PM & KitchenSinkH & Kitchen Sink hot water & 2.38 & 0.63 \\
\hline 9:35:00 PM & 9:36:00 PM & KitchenSinkH & Kitchen Sink hot water & 2.38 & 0.63 \\
\hline 9:38:00 PM & 9:43:00 PM & Light1stBath & 1st Bathroom Lights & & \\
\hline 9:40:00 PM & 9:41:00 PM & KitchenSinkH & Kitchen Sink hot water & 2.38 & 0.63 \\
\hline 9:45:00 PM & 10:00:00 PM & Light2ndBath & 2nd Bathroom Lights & & \\
\hline 9:55:00 PM & 9:56:00 PM & SinkMastBathH & $\begin{array}{l}\text { Sink event - Master Bathroom hot } \\
\text { water }\end{array}$ & 2.38 & 0.63 \\
\hline 10:00:00 PM & 10:15:00 PM & HeatingPad & Heating Pad & & \\
\hline 10:00:00 PM & 11:00:00 PM & LightMastBed & Master Bedroom Lights & & \\
\hline 10:00:00 PM & 11:30:00 PM & BlueRayM & Master Bedroom - BlueRay & & \\
\hline 10:00:00 PM & 11:30:00 PM & MastBedATV & Master Bedroom Active TV & & \\
\hline 10:00:00 PM & 11:59:00 PM & PortableFan & Portable Fan & & \\
\hline 10:00:00 PM & 11:59:00 PM & SHparentBMBR & $\begin{array}{l}\text { Sensible Heat ParentB Master } \\
\text { Bedroom }\end{array}$ & & \\
\hline 10:05:00 PM & 10:06:00 PM & KitchenSinkH & Kitchen Sink hot water & 2.38 & 0.63 \\
\hline 10:05:00 PM & 10:25:00 PM & LightMastBath & Master Bathroom Lights & & \\
\hline 10:10:00 PM & 10:11:00 PM & KitchenSinkH & Kitchen Sink hot water & 2.38 & 0.63 \\
\hline 10:20:00 PM & 10:21:00 PM & SinkMastBathH & $\begin{array}{l}\text { Sink event - Master Bathroom hot } \\
\text { water }\end{array}$ & 2.38 & 0.63 \\
\hline 10:30:00 PM & 10:40:00 PM & LightMastBath & Master Bathroom Lights & & \\
\hline 10:30:00 PM & 11:59:00 PM & SHparentAMBR & $\begin{array}{l}\text { Sensible Heat ParentA Master } \\
\text { Bedroom }\end{array}$ & & \\
\hline 10:40:00 PM & 10:41:00 PM & SinkMastBathH & $\begin{array}{l}\text { Sink event - Master Bathroom hot } \\
\text { water }\end{array}$ & 2.38 & 0.63 \\
\hline
\end{tabular}




\section{Thursdays}

\begin{tabular}{|c|c|c|c|c|c|c|}
\hline Start time & End time & FixtureID & Description & $\begin{array}{c}\text { Target } \\
\text { Volume } \\
\text { / Draw } \\
\text { (liters) }\end{array}$ & $\begin{array}{l}\text { Target } \\
\text { Volume } \\
\text { / Draw } \\
\text { (gallons) }\end{array}$ & $\begin{array}{c}\text { Target } \\
\text { Energy } \\
\text { / Event } \\
\text { (Wh) } \\
\end{array}$ \\
\hline 12:05:00 AM & 6:00:00 AM & SHparentBMBR & $\begin{array}{l}\text { Sensible Heat ParentB Master } \\
\text { Bedroom }\end{array}$ & & & \\
\hline 12:05:00 AM & 6:30:00 AM & SHparentAMBR & $\begin{array}{l}\text { Sensible Heat ParentA Master } \\
\text { Bedroom }\end{array}$ & & & \\
\hline 12:05:00 AM & 7:00:00 AM & SHchildABR2 & Sensible Heat ChildA Bedroom \# 2 & & & \\
\hline 12:05:00 AM & 7:00:00 AM & SHchildBBR3 & Sensible Heat ChildB Bedroom \# 3 & & & \\
\hline 12:05:00 AM & 8:30:00 AM & Latent Load & Latent Load & & & \\
\hline 3:31:00 AM & $3: 34: 00 \mathrm{AM}$ & LightMastBath & Master Bathroom Lights & & & \\
\hline 3:33:00 AM & 3:34:00 AM & SinkMastBathH & $\begin{array}{l}\text { Sink event - Master Bathroom hot } \\
\text { water }\end{array}$ & 2.38 & 0.63 & \\
\hline 4:00:00 AM & 4:03:00 AM & LightMastBath & Master Bathroom Lights & & & \\
\hline 4:02:00 AM & 4:03:00 AM & SinkMastBathH & $\begin{array}{l}\text { Sink event - Master Bathroom hot } \\
\text { water }\end{array}$ & 2.38 & 0.63 & \\
\hline 6:00:00 AM & 6:01:00 AM & KitchenSinkH & Kitchen Sink hot water & 2.38 & 0.63 & \\
\hline 6:00:00 AM & $6: 15: 00 \mathrm{AM}$ & LightMastBath & Master Bathroom Lights & & & \\
\hline 6:00:00 AM & 6:30:00 AM & SHparentBDR & $\begin{array}{l}\text { Sensible Heat ParentB Dining } \\
\text { Room }\end{array}$ & & & \\
\hline 6:00:00 AM & 8:25:00 AM & KitchenLights & Kitchen Lights & & & \\
\hline 6:00:00 AM & & MicrowaveCLR & $\begin{array}{l}\text { Clear Microwave (equivalent to } \\
\text { opening and closing the door) }\end{array}$ & & & \\
\hline 6:01:00 AM & & MicrowaveON & Turn Microwave ON & & & \\
\hline $6: 02: 00 \mathrm{AM}$ & 6:03:00 AM & KitchenSinkH & Kitchen Sink hot water & 2.38 & 0.63 & \\
\hline 6:04:00 AM & 6:14:00 AM & ShowerMastBathH & $\begin{array}{l}\text { Shower even - Master Bathroom } \\
\text { hot water }\end{array}$ & 33.12 & 8.75 & \\
\hline 6:05:00 AM & $6: 15: 00 \mathrm{AM}$ & Blender & Blender & & & 19.20 \\
\hline $6: 10: 00 \mathrm{AM}$ & 6:40:00 AM & CoffeeMaker & Coffee Maker & & & 168.12 \\
\hline $6: 15: 00 \mathrm{AM}$ & $6: 16: 00 \mathrm{AM}$ & SinkMastBathH & $\begin{array}{l}\text { Sink event - Master Bathroom hot } \\
\text { water }\end{array}$ & 2.38 & 0.63 & \\
\hline 6:15:00 AM & 6:25:00 AM & ToasterOven & Toaster Oven & & & 88.80 \\
\hline $6: 15: 00 \mathrm{AM}$ & 6:30:00 AM & LightMastBed & Master Bedroom Lights & & & \\
\hline 6:15:00 AM & 7:00:00 AM & MastBedATV & Master Bedroom Active TV & & & \\
\hline 6:20:00 AM & 6:35:00 AM & Toaster & Toaster & & & 126.00 \\
\hline $6: 25: 00 \mathrm{AM}$ & $6: 26: 00 \mathrm{AM}$ & KitchenSinkH & Kitchen Sink hot water & 2.38 & 0.63 & \\
\hline $6: 30: 00 \mathrm{AM}$ & $6: 40: 00 \mathrm{AM}$ & ShowerMastBathH & $\begin{array}{l}\text { Shower even - Master Bathroom } \\
\text { hot water }\end{array}$ & 33.12 & 8.75 & \\
\hline 6:30:00 AM & 6:45:00 AM & LightMastBath & Master Bathroom Lights & & & \\
\hline 6:30:00 AM & $6: 50: 00 \mathrm{AM}$ & Light2ndBath & 2nd Bathroom Lights & & & \\
\hline 6:30:00 AM & 7:00:00 AM & SHparentBMBR & $\begin{array}{l}\text { Sensible Heat ParentB Master } \\
\text { Bedroom }\end{array}$ & & & \\
\hline 6:30:00 AM & $8: 25: 00 \mathrm{AM}$ & LivingRATV & Living room - Active TV & & & \\
\hline 6:30:00 AM & 8:30:00 AM & SHparentAK & Sensible Heat ParentA Kitchen & & & \\
\hline
\end{tabular}




\begin{tabular}{|c|c|c|c|c|c|c|}
\hline $6: 40: 00 \mathrm{AM}$ & $6: 50: 00 \mathrm{AM}$ & HairDryer & Hair Dryer & & & 115.70 \\
\hline 6:40:00 AM & 7:00:00 AM & Light2ndBed & 2nd Bedroom Lights & & & \\
\hline 6:41:00 AM & 6:42:00 AM & SinkMastBathH & $\begin{array}{l}\text { Sink event - Master Bathroom hot } \\
\text { water }\end{array}$ & 2.38 & 0.63 & \\
\hline 6:43:00 AM & $6: 44: 00 \mathrm{AM}$ & KitchenSinkH & Kitchen Sink hot water & 2.38 & 0.63 & \\
\hline 6:45:00 AM & 6:55:00 AM & ShowerMastBathH & $\begin{array}{l}\text { Shower even - Master Bathroom } \\
\text { hot water }\end{array}$ & 33.12 & 8.75 & \\
\hline 6:45:00 AM & 7:00:00 AM & LightMastBed & Master Bedroom Lights & & & \\
\hline $6: 50: 00 \mathrm{AM}$ & 7:00:00 AM & Light3rdBed & 3rd Bedroom Lights & & & \\
\hline $6: 56: 00 \mathrm{AM}$ & $6: 57: 00 \mathrm{AM}$ & SinkMastBathH & $\begin{array}{l}\text { Sink event - Master Bathroom hot } \\
\text { water }\end{array}$ & 2.38 & 0.63 & \\
\hline 6:58:00 AM & 6:59:00 AM & SinkMastBathH & $\begin{array}{l}\text { Sink event - Master Bathroom hot } \\
\text { water }\end{array}$ & 2.38 & 0.63 & \\
\hline 7:00:00 AM & 8:00:00 AM & DiningRLights & Dining Room Lights & & & \\
\hline 7:00:00 AM & 8:00:00 AM & SHchildALR & Sensible Heat ChildA Living Room & & & \\
\hline 7:00:00 AM & 8:00:00 AM & SHchildBDR & Sensible Heat ChildB Dining Room & & & \\
\hline 7:00:00 AM & 8:30:00 AM & SHparentBDR & $\begin{array}{l}\text { Sensible Heat ParentB Dining } \\
\text { Room }\end{array}$ & & & \\
\hline 7:05:00 AM & 7:06:00 AM & KitchenSinkH & Kitchen Sink hot water & 2.38 & 0.63 & \\
\hline 7:30:00 AM & 7:31:00 AM & KitchenSinkH & Kitchen Sink hot water & 2.38 & 0.63 & \\
\hline 7:35:00 AM & 7:36:00 AM & KitchenSinkH & Kitchen Sink hot water & 2.38 & 0.63 & \\
\hline 8:00:00 AM & 8:25:00 AM & LivingRLights & Living room Lights & & & \\
\hline 8:02:00 AM & 8:03:00 AM & KitchenSinkH & Kitchen Sink hot water & 2.38 & 0.63 & \\
\hline 8:10:00 AM & 8:11:00 AM & KitchenSinkH & Kitchen Sink hot water & 2.38 & 0.63 & \\
\hline $8: 20: 00$ AM & $8: 21: 00 \mathrm{AM}$ & KitchenSinkH & Kitchen Sink hot water & 2.38 & 0.63 & \\
\hline 8:26:00 AM & $8: 27: 00$ AM & KitchenSinkH & Kitchen Sink hot water & 2.38 & 0.63 & \\
\hline 4:00:00 PM & 4:30:00 PM & SHchildALR & Sensible Heat ChildA Living Room & & & \\
\hline 4:00:00 PM & 11:59:00 PM & Latent Load & Latent Load & & & \\
\hline 4:01:00 PM & 4:06:00 PM & Light1stBath & 1st Bathroom Lights & & & \\
\hline 4:04:00 PM & 4:05:00 PM & KitchenSinkH & Kitchen Sink hot water & 2.38 & 0.63 & \\
\hline 4:10:00 PM & 4:11:00 PM & KitchenSinkH & Kitchen Sink hot water & 2.38 & 0.63 & \\
\hline 4:25:00 PM & 4:26:00 PM & KitchenSinkH & Kitchen Sink hot water & 2.38 & 0.63 & \\
\hline 4:30:00 PM & 6:00:00 PM & Light2ndBed & 2nd Bedroom Lights & & & \\
\hline 4:30:00 PM & 6:00:00 PM & SHchildABR2 & Sensible Heat ChildA Bedroom \# 2 & & & \\
\hline 6:00:00 PM & 6:30:00 PM & KitchenLights & Kitchen Lights & & & \\
\hline 6:00:00 PM & 6:30:00 PM & LivingRLights & Living room Lights & & & \\
\hline 6:00:00 PM & 6:30:00 PM & SHchildALR & Sensible Heat ChildA Living Room & & & \\
\hline 6:00:00 PM & 6:30:00 PM & SHchildBDR & Sensible Heat ChildB Dining Room & & & \\
\hline 6:00:00 PM & 6:30:00 PM & SHparentAMBR & $\begin{array}{l}\text { Sensible Heat ParentA Master } \\
\text { Bedroom }\end{array}$ & & & \\
\hline 6:00:00 PM & 10:00:00 PM & SHparentBDR & $\begin{array}{l}\text { Sensible Heat ParentB Dining } \\
\text { Room }\end{array}$ & & & \\
\hline 6:01:00 PM & 6:06:00 PM & LightMastBath & Master Bathroom Lights & & & \\
\hline 6:02:00 PM & 6:06:00 PM & Light1stBath & 1st Bathroom Lights & & & \\
\hline 6:02:00 PM & 6:08:49 PM & RangeHood & Range-hood & & & \\
\hline 6:02:00 PM & 7:02:00 PM & CookTops & Cooktops & & & 408.04 \\
\hline
\end{tabular}




\begin{tabular}{|c|c|c|c|c|c|c|}
\hline 6:05:00 PM & 6:06:00 PM & SinkMastBathH & $\begin{array}{l}\text { Sink event - Master Bathroom hot } \\
\text { water }\end{array}$ & 2.38 & 0.63 & \\
\hline 6:07:00 PM & 6:30:00 PM & LightMastBed & Master Bedroom Lights & & & \\
\hline 6:09:00 PM & & MicrowaveCLR & $\begin{array}{l}\text { Clear Microwave (equivalent to } \\
\text { opening and closing the door) }\end{array}$ & & & \\
\hline $6: 10: 00 \mathrm{PM}$ & 8:30:00 PM & LivingRATV & Living room - Active TV & & & \\
\hline 6:10:00 PM & & MicrowaveON & Turn Microwave ON & & & \\
\hline 6:30:00 PM & 7:30:00 PM & SHchildABR2 & Sensible Heat ChildA Bedroom \# 2 & & & \\
\hline 6:30:00 PM & 7:30:00 PM & SHchildBBR3 & Sensible Heat ChildB Bedroom \# 3 & & & \\
\hline 6:30:00 PM & 8:15:00 PM & ComputerACB & Bedroom \# 3 - Laptop & & & \\
\hline 6:30:00 PM & 8:30:00 PM & Light3rdBed & 3rd Bedroom Lights & & & \\
\hline 6:30:00 PM & 10:00:00 PM & ComputerACA & Bedroom \# 2 - Laptop & & & \\
\hline 6:30:00 PM & 10:00:00 PM & Light2ndBed & 2nd Bedroom Lights & & & \\
\hline 6:30:00 PM & 10:30:00 PM & DesktopCA & Desktop PC and Monitor & & & 342.60 \\
\hline 6:30:00 PM & 10:30:00 PM & SHparentAK & Sensible Heat ParentA Kitchen & & & \\
\hline 6:40:00 PM & $6: 41: 00 \mathrm{PM}$ & KitchenSinkH & Kitchen Sink hot water & 2.38 & 0.63 & \\
\hline 6:40:00 PM & $6: 47: 04 \mathrm{PM}$ & CanOpener & Can Opener & & & \\
\hline 6:40:00 PM & 6:50:00 PM & HandMixer & Hand Mixer & & & 5.50 \\
\hline 6:45:00 PM & 6:46:00 PM & KitchenSinkH & Kitchen Sink hot water & 2.38 & 0.63 & \\
\hline 6:55:00 PM & 6:56:00 PM & KitchenSinkH & Kitchen Sink hot water & 2.38 & 0.63 & \\
\hline 7:00:00 PM & 7:15:00 PM & KitchenLights & Kitchen Lights & & & \\
\hline 7:00:00 PM & 7:15:00 PM & LivingRLights & Living room Lights & & & \\
\hline 7:10:00 PM & 7:11:00 PM & KitchenSinkH & Kitchen Sink hot water & 2.38 & 0.63 & \\
\hline 7:15:00 PM & 8:30:00 PM & DiningRLights & Dining Room Lights & & & \\
\hline 7:30:00 PM & 8:15:00 PM & KitchenLights & Kitchen Lights & & & \\
\hline 7:30:00 PM & 8:15:00 PM & SHchildALR & Sensible Heat ChildA Living Room & & & \\
\hline 7:30:00 PM & 8:15:00 PM & SHchildBDR & Sensible Heat ChildB Dining Room & & & \\
\hline 7:30:00 PM & 9:30:00 PM & LivingRLights & Living room Lights & & & \\
\hline 7:35:00 PM & 7:36:00 PM & KitchenSinkH & Kitchen Sink hot water & 2.38 & 0.63 & \\
\hline 8:00:00 PM & 8:01:00 PM & KitchenSinkH & Kitchen Sink hot water & 2.38 & 0.63 & \\
\hline 8:15:00 PM & 8:16:00 PM & KitchenSinkH & Kitchen Sink hot water & 2.38 & 0.63 & \\
\hline 8:15:00 PM & 8:25:00 PM & Light2ndBath & 2nd Bathroom Lights & & & \\
\hline 8:15:00 PM & 11:59:00 PM & SHchildABR2 & Sensible Heat ChildA Bedroom \# 2 & & & \\
\hline $8: 15: 00$ PM & 11:59:00 PM & SHchildBBR3 & Sensible Heat ChildB Bedroom \# 3 & & & \\
\hline 8:20:00 PM & 8:21:00 PM & SinkMastBathH & $\begin{array}{l}\text { Sink event - Master Bathroom hot } \\
\text { water }\end{array}$ & 2.38 & 0.63 & \\
\hline $8: 25: 00 \mathrm{PM}$ & 8:26:00 PM & KitchenSinkH & Kitchen Sink hot water & 2.38 & 0.63 & \\
\hline 8:30:00 PM & 10:30:00 PM & KitchenLights & Kitchen Lights & & & \\
\hline 8:35:00 PM & 8:36:00 PM & KitchenSinkH & Kitchen Sink hot water & 2.38 & 0.63 & \\
\hline 8:50:00 PM & 8:51:00 PM & KitchenSinkH & Kitchen Sink hot water & 2.38 & 0.63 & \\
\hline 9:05:00 PM & 9:06:00 PM & KitchenSinkH & Kitchen Sink hot water & 2.38 & 0.63 & \\
\hline 9:10:00 PM & 9:11:00 PM & KitchenSinkH & Kitchen Sink hot water & 2.38 & 0.63 & \\
\hline 9:30:00 PM & 9:31:00 PM & KitchenSinkH & Kitchen Sink hot water & 2.38 & 0.63 & \\
\hline
\end{tabular}




\begin{tabular}{|c|c|c|c|c|c|}
\hline 9:40:00 PM & 9:41:00 PM & KitchenSinkH & Kitchen Sink hot water & 2.38 & 0.63 \\
\hline 9:43:00 PM & 9:58:00 PM & ShowerMastBathH & $\begin{array}{l}\text { Shower even - Master Bathroom } \\
\text { hot water }\end{array}$ & 53.00 & 14.00 \\
\hline 9:45:00 PM & 10:00:00 PM & Light2ndBath & 2nd Bathroom Lights & & \\
\hline 9:59:00 PM & 10:00:00 PM & SinkMastBathH & $\begin{array}{l}\text { Sink event - Master Bathroom hot } \\
\text { water }\end{array}$ & 2.38 & 0.63 \\
\hline 10:00:00 PM & 12:00:00 AM & PortableFan & Portable Fan & & \\
\hline 10:00:00 PM & 10:10:00 PM & HeatingPad & Heating Pad & & \\
\hline 10:00:00 PM & 10:30:00 PM & LivingRLights & Living room Lights & & \\
\hline 10:00:00 PM & 11:00:00 PM & LightMastBed & Master Bedroom Lights & & \\
\hline 10:00:00 PM & 11:59:00 PM & SHparentBMBR & $\begin{array}{l}\text { Sensible Heat ParentB Master } \\
\text { Bedroom }\end{array}$ & & \\
\hline 10:05:00 PM & 10:06:00 PM & KitchenSinkH & Kitchen Sink hot water & 2.38 & 0.63 \\
\hline 10:05:00 PM & 10:25:00 PM & LightMastBath & Master Bathroom Lights & & \\
\hline 10:20:00 PM & 10:21:00 PM & SinkMastBathH & $\begin{array}{l}\text { Sink event - Master Bathroom hot } \\
\text { water }\end{array}$ & 2.38 & 0.63 \\
\hline 10:30:00 PM & 10:40:00 PM & LightMastBath & Master Bathroom Lights & & \\
\hline 10:30:00 PM & 11:59:00 PM & SHparentAMBR & $\begin{array}{l}\text { Sensible Heat ParentA Master } \\
\text { Bedroom }\end{array}$ & & \\
\hline 10:35:00 PM & 10:36:00 PM & SinkMastBathH & $\begin{array}{l}\text { Sink event - Master Bathroom hot } \\
\text { water }\end{array}$ & 2.38 & 0.63 \\
\hline
\end{tabular}




\section{Fridays}

\begin{tabular}{|c|c|c|c|c|c|c|}
\hline Start time & End time & FixtureID & Description & $\begin{array}{c}\text { Target } \\
\text { Volume } \\
\text { / Draw } \\
\text { (liters) }\end{array}$ & $\begin{array}{c}\text { Target } \\
\text { Volume } \\
\text { / Draw } \\
\text { (gallons) }\end{array}$ & $\begin{array}{c}\text { Target } \\
\text { Energy / } \\
\text { Event } \\
\text { (Wh) }\end{array}$ \\
\hline 12:05:00 AM & 6:00:00 AM & SHparentBMBR & $\begin{array}{l}\text { Sensible Heat ParentB Master } \\
\text { Bedroom }\end{array}$ & & & \\
\hline 12:05:00 AM & 6:30:00 AM & SHparentAMBR & $\begin{array}{l}\text { Sensible Heat ParentA Master } \\
\text { Bedroom }\end{array}$ & & & \\
\hline 12:05:00 AM & 7:00:00 AM & SHchildABR2 & Sensible Heat ChildA Bedroom \# 2 & & & \\
\hline 12:05:00 AM & 7:00:00 AM & SHchildBBR3 & Sensible Heat ChildB Bedroom \# 3 & & & \\
\hline 12:05:00 AM & 8:30:00 AM & Latent Load & Latent Load & & & \\
\hline 3:31:00 AM & 3:34:00 AM & LightMastBath & Master Bathroom Lights & & & \\
\hline 3:33:00 AM & 3:34:00 AM & SinkMastBathH & $\begin{array}{l}\text { Sink event - Master Bathroom hot } \\
\text { water }\end{array}$ & 2.38 & 0.63 & \\
\hline 4:00:00 AM & 4:03:00 AM & LightMastBath & Master Bathroom Lights & & & \\
\hline 4:02:00 AM & 4:03:00 AM & SinkMastBathH & $\begin{array}{l}\text { Sink event - Master Bathroom hot } \\
\text { water }\end{array}$ & 2.38 & 0.63 & \\
\hline 6:00:00 AM & 6:15:00 AM & LightMastBath & Master Bathroom Lights & & & \\
\hline 6:00:00 AM & 6:30:00 AM & SHparentBDR & $\begin{array}{l}\text { Sensible Heat ParentB Dining } \\
\text { Room }\end{array}$ & & & \\
\hline 6:00:00 AM & 8:25:00 AM & KitchenLights & Kitchen Lights & & & \\
\hline 6:00:00 AM & & MicrowaveCLR & $\begin{array}{l}\text { Clear Microwave (equivalent to } \\
\text { opening and closing the door) }\end{array}$ & & & \\
\hline 6:01:00 AM & & MicrowaveON & Turn Microwave ON & & & \\
\hline 6:04:00 AM & 6:05:00 AM & KitchenSinkH & Kitchen Sink hot water & 2.38 & 0.63 & \\
\hline 6:05:00 AM & $6: 15: 00$ AM & Blender & Blender & & & 19.20 \\
\hline 6:06:00 AM & 6:17:00 AM & ShowerMastBathH & $\begin{array}{l}\text { Shower even - Master Bathroom } \\
\text { hot water }\end{array}$ & 33.12 & 8.75 & \\
\hline 6:10:00 AM & $6: 40: 00 \mathrm{AM}$ & CoffeeMaker & Coffee Maker & & & 168.12 \\
\hline 6:15:00 AM & 6:25:00 AM & ToasterOven & Toaster Oven & & & 88.80 \\
\hline 6:15:00 AM & 6:30:00 AM & LightMastBed & Master Bedroom Lights & & & \\
\hline $6: 15: 00$ AM & 7:00:00 AM & MastBedATV & Master Bedroom Active TV & & & \\
\hline 6:18:00 AM & 6:19:00 AM & SinkMastBathH & $\begin{array}{l}\text { Sink event - Master Bathroom hot } \\
\text { water }\end{array}$ & 2.38 & 0.63 & \\
\hline 6:20:00 AM & $6: 35: 00 \mathrm{AM}$ & Toaster & Toaster & & & 126.00 \\
\hline 6:27:00 AM & 6:28:00 AM & SinkMastBathH & $\begin{array}{l}\text { Sink event - Master Bathroom hot } \\
\text { water }\end{array}$ & 2.38 & 0.63 & \\
\hline 6:29:00 AM & 6:30:00 AM & KitchenSinkH & Kitchen Sink hot water & 2.38 & 0.63 & \\
\hline 6:30:00 AM & $6: 45: 00$ AM & LightMastBath & Master Bathroom Lights & & & \\
\hline 6:30:00 AM & 6:50:00 AM & Light2ndBath & 2nd Bathroom Lights & & & \\
\hline 6:30:00 AM & 7:00:00 AM & SHparentBMBR & $\begin{array}{l}\text { Sensible Heat ParentB Master } \\
\text { Bedroom }\end{array}$ & & & \\
\hline 6:30:00 AM & 8:30:00 AM & SHparentAK & Sensible Heat ParentA Kitchen & & & \\
\hline 6:31:00 AM & 6:41:00 AM & ShowerMastBathH & $\begin{array}{l}\text { Shower even - Master Bathroom } \\
\text { hot water }\end{array}$ & 33.12 & 8.75 & \\
\hline $6: 40: 00$ AM & 6:50:00 AM & HairDryer & Hair Dryer & & & 115.70 \\
\hline
\end{tabular}




\begin{tabular}{|c|c|c|c|c|c|c|}
\hline 6:40:00 AM & 7:00:00 AM & Light2ndBed & 2nd Bedroom Lights & & & \\
\hline 6:42:00 AM & 6:43:00 AM & SinkMastBathH & $\begin{array}{l}\text { Sink event - Master Bathroom hot } \\
\text { water }\end{array}$ & 2.38 & 0.63 & \\
\hline 6:44:00 AM & $6: 54: 00 \mathrm{AM}$ & ShowerMastBathH & $\begin{array}{l}\text { Shower even - Master Bathroom } \\
\text { hot water }\end{array}$ & 33.12 & 8.75 & \\
\hline 6:45:00 AM & 7:00:00 AM & LightMastBed & Master Bedroom Lights & & & \\
\hline 6:50:00 AM & 7:00:00 AM & Light3rdBed & 3rd Bedroom Lights & & & \\
\hline 6:55:00 AM & 6:56:00 AM & SinkMastBathH & $\begin{array}{l}\text { Sink event - Master Bathroom hot } \\
\text { water }\end{array}$ & 2.38 & 0.63 & \\
\hline 7:00:00 AM & 8:00:00 AM & DiningRLights & Dining Room Lights & & & \\
\hline 7:00:00 AM & 8:00:00 AM & SHchildALR & $\begin{array}{l}\text { Sensible Heat ChildA Living } \\
\text { Room }\end{array}$ & & & \\
\hline 7:00:00 AM & 8:00:00 AM & SHchildBDR & $\begin{array}{l}\text { Sensible Heat ChildB Dining } \\
\text { Room }\end{array}$ & & & \\
\hline 7:00:00 AM & 8:30:00 AM & SHparentBDR & $\begin{array}{l}\text { Sensible Heat ParentB Dining } \\
\text { Room }\end{array}$ & & & \\
\hline 7:05:00 AM & 7:06:00 AM & KitchenSinkH & Kitchen Sink hot water & 2.38 & 0.63 & \\
\hline 7:30:00 AM & 7:31:00 AM & KitchenSinkH & Kitchen Sink hot water & 2.38 & 0.63 & \\
\hline 8:00:00 AM & $8: 25: 00 \mathrm{AM}$ & LivingRLights & Living room Lights & & & \\
\hline 8:02:00 AM & 8:03:00 AM & KitchenSinkH & Kitchen Sink hot water & 2.38 & 0.63 & \\
\hline 8:10:00 AM & 8:11:00 AM & KitchenSinkH & Kitchen Sink hot water & 2.38 & 0.63 & \\
\hline 8:26:00 AM & 8:27:00 AM & KitchenSinkH & Kitchen Sink hot water & 2.38 & 0.63 & \\
\hline 8:28:00 AM & 8:29:00 AM & KitchenSinkH & Kitchen Sink hot water & 2.38 & 0.63 & \\
\hline 4:00:00 PM & 11:59:00 PM & Latent Load & Latent Load & & & \\
\hline 6:00:00 PM & 6:30:00 PM & KitchenLights & Kitchen Lights & & & \\
\hline 6:00:00 PM & 6:30:00 PM & SHchildBDR & $\begin{array}{l}\text { Sensible Heat ChildB Dining } \\
\text { Room }\end{array}$ & & & \\
\hline 6:00:00 PM & 6:30:00 PM & SHparentAMBR & $\begin{array}{l}\text { Sensible Heat ParentA Master } \\
\text { Bedroom }\end{array}$ & & & \\
\hline 6:00:00 PM & 7:30:00 PM & SHchildABR2 & Sensible Heat ChildA Bedroom \# 2 & & & \\
\hline 6:00:00 PM & 11:30:00 PM & SHparentBDR & $\begin{array}{l}\text { Sensible Heat ParentB Dining } \\
\text { Room }\end{array}$ & & & \\
\hline 6:01:00 PM & 6:06:00 PM & LightMastBath & Master Bathroom Lights & & & \\
\hline 6:01:00 PM & 6:30:00 PM & LivingRLights & Living room Lights & & & \\
\hline 6:02:00 PM & 7:02:00 PM & CookTops & Cooktops & & & 408.04 \\
\hline 6:05:00 PM & 6:06:00 PM & SinkMastBathH & $\begin{array}{l}\text { Sink event - Master Bathroom hot } \\
\text { water }\end{array}$ & 2.38 & 0.63 & \\
\hline 6:07:00 PM & 6:30:00 PM & LightMastBed & Master Bedroom Lights & & & \\
\hline 6:08:00 PM & 6:09:00 PM & KitchenSinkH & Kitchen Sink hot water & 2.38 & 0.63 & \\
\hline 6:08:00 PM & 6:18:00 PM & Light2ndBath & 2nd Bathroom Lights & & & \\
\hline 6:09:00 PM & & MicrowaveCLR & $\begin{array}{l}\text { Clear Microwave (equivalent to } \\
\text { opening and closing the door) }\end{array}$ & & & \\
\hline 6:10:00 PM & $6: 25: 00 \mathrm{PM}$ & ShowerMastBathH & $\begin{array}{l}\text { Shower even - Master Bathroom } \\
\text { hot water }\end{array}$ & 53.00 & 14.00 & \\
\hline 6:10:00 PM & 10:25:00 PM & LivingRATV & Living room - Active TV & & & \\
\hline 6:10:00 PM & & MicrowaveON & Turn Microwave ON & & & \\
\hline 6:20:00 PM & 9:00:00 PM & Light2ndBed & 2nd Bedroom Lights & & & \\
\hline $6: 26: 00 \mathrm{PM}$ & $6: 27: 00 \mathrm{PM}$ & KitchenSinkH & Kitchen Sink hot water & 2.38 & 0.63 & \\
\hline 6:28:00 PM & 6:29:00 PM & SinkMastBathH & $\begin{array}{l}\text { Sink event - Master Bathroom hot } \\
\text { water }\end{array}$ & 2.38 & 0.63 & \\
\hline
\end{tabular}




\begin{tabular}{|c|c|c|c|c|c|c|}
\hline 6:30:00 PM & 7:30:00 PM & SHchildBBR3 & Sensible Heat ChildB Bedroom \# 3 & & & \\
\hline 6:30:00 PM & 9:00:00 PM & ComputerACA & Bedroom \# 2 - Laptop & & & \\
\hline 6:30:00 PM & 9:00:00 PM & ComputerACB & Bedroom \# 3 - Laptop & & & \\
\hline 6:30:00 PM & 9:00:00 PM & Light 3 rdBed & 3rd Bedroom Lights & & & \\
\hline 6:30:00 PM & 10:30:00 PM & DesktopCA & Desktop PC and Monitor & & & 342.60 \\
\hline 6:30:00 PM & 11:30:00 PM & SHparentAK & Sensible Heat ParentA Kitchen & & & \\
\hline 6:40:00 PM & 6:47:04 PM & CanOpener & Can Opener & & & \\
\hline 6:40:00 PM & 6:50:00 PM & HandMixer & Hand Mixer & & & 5.50 \\
\hline $6: 55: 00 \mathrm{PM}$ & $6: 56: 00 \mathrm{PM}$ & KitchenSinkH & Kitchen Sink hot water & 2.38 & 0.63 & \\
\hline 7:00:00 PM & 7:15:00 PM & KitchenLights & Kitchen Lights & & & \\
\hline 7:00:00 PM & 7:15:00 PM & LivingRLights & Living room Lights & & & \\
\hline 7:05:00 PM & 7:06:00 PM & KitchenSinkH & Kitchen Sink hot water & 2.38 & 0.63 & \\
\hline 7:10:00 PM & 7:11:00 PM & KitchenSinkH & Kitchen Sink hot water & 2.38 & 0.63 & \\
\hline 7:15:00 PM & 9:00:00 PM & DiningRLights & Dining Room Lights & & & \\
\hline 7:30:00 PM & $8: 15: 00 \mathrm{PM}$ & KitchenLights & Kitchen Lights & & & \\
\hline 7:30:00 PM & 8:15:00 PM & SHchildALR & $\begin{array}{l}\text { Sensible Heat ChildA Living } \\
\text { Room }\end{array}$ & & & \\
\hline 7:30:00 PM & 8:15:00 PM & SHchildBDR & $\begin{array}{l}\text { Sensible Heat ChildB Dining } \\
\text { Room }\end{array}$ & & & \\
\hline 7:30:00 PM & 11:30:00 PM & LivingRLights & Living room Lights & & & \\
\hline 7:35:00 PM & 7:36:00 PM & KitchenSinkH & Kitchen Sink hot water & 2.38 & 0.63 & \\
\hline 8:00:00 PM & 9:00:00 PM & Light2ndBath & 2nd Bathroom Lights & & & \\
\hline 8:00:00 PM & 8:01:00 PM & KitchenSinkH & Kitchen Sink hot water & 2.38 & 0.63 & \\
\hline 8:15:00 PM & 9:00:00 PM & SHchildABR2 & Sensible Heat ChildA Bedroom \# 2 & & & \\
\hline 8:15:00 PM & 9:00:00 PM & SHchildBBR3 & Sensible Heat ChildB Bedroom \# 3 & & & \\
\hline $8: 15: 00$ PM & & Dishwasher & Dishwasher & & & \\
\hline 8:25:00 PM & 8:26:00 PM & KitchenSinkH & Kitchen Sink hot water & 2.38 & 0.63 & \\
\hline 9:00:00 PM & 10:00:00 PM & SHchildBDR & $\begin{array}{l}\text { Sensible Heat ChildB Dining } \\
\text { Room }\end{array}$ & & & \\
\hline 9:00:00 PM & 10:00:00 PM & VideoAGame & Video Game Active (Turned ON) & & & \\
\hline 9:00:00 PM & 11:00:00 PM & SHchildALR & $\begin{array}{l}\text { Sensible Heat ChildA Living } \\
\text { Room }\end{array}$ & & & \\
\hline 9:00:00 PM & 11:30:00 PM & KitchenLights & Kitchen Lights & & & \\
\hline 9:05:00 PM & 9:06:00 PM & KitchenSinkH & Kitchen Sink hot water & 2.38 & 0.63 & \\
\hline 9:10:00 PM & 9:11:00 PM & KitchenSinkH & Kitchen Sink hot water & 2.38 & 0.63 & \\
\hline 9:30:00 PM & 9:31:00 PM & KitchenSinkH & Kitchen Sink hot water & 2.38 & 0.63 & \\
\hline 9:40:00 PM & 9:41:00 PM & KitchenSinkH & Kitchen Sink hot water & 2.38 & 0.63 & \\
\hline 10:00:00 PM & 10:01:00 PM & KitchenSinkH & Kitchen Sink hot water & 2.38 & 0.63 & \\
\hline 10:00:00 PM & 10:15:00 PM & Light2ndBath & 2nd Bathroom Lights & & & \\
\hline 10:00:00 PM & 11:59:00 PM & SHchildBBR3 & Sensible Heat ChildB Bedroom \# 3 & & & \\
\hline 10:05:00 PM & 10:06:00 PM & KitchenSinkH & Kitchen Sink hot water & 2.38 & 0.63 & \\
\hline 10:10:00 PM & 10:11:00 PM & SinkMastBathH & $\begin{array}{l}\text { Sink event - Master Bathroom hot } \\
\text { water }\end{array}$ & 2.38 & 0.63 & \\
\hline 10:15:00 PM & 10:16:00 PM & KitchenSinkH & Kitchen Sink hot water & 2.38 & 0.63 & \\
\hline
\end{tabular}




\begin{tabular}{|c|c|c|c|c|c|}
\hline 10:18:00 PM & 10:22:00 PM & Light1stBath & 1st Bathroom Lights & & \\
\hline 10:20:00 PM & 10:21:00 PM & KitchenSinkH & Kitchen Sink hot water & 2.38 & 0.63 \\
\hline 10:30:00 PM & 10:31:00 PM & KitchenSinkH & Kitchen Sink hot water & 2.38 & 0.63 \\
\hline 10:40:00 PM & 10:41:00 PM & KitchenSinkH & Kitchen Sink hot water & 2.38 & 0.63 \\
\hline 11:00:00 PM & 11:15:00 PM & Light2ndBath & 2nd Bathroom Lights & & \\
\hline 11:00:00 PM & 11:59:00 PM & SHchildABR2 & Sensible Heat ChildA Bedroom \# 2 & & \\
\hline 11:10:00 PM & 11:11:00 PM & SinkMastBathH & $\begin{array}{l}\text { Sink event - Master Bathroom hot } \\
\text { water }\end{array}$ & 2.38 & 0.63 \\
\hline 11:18:00 PM & $11: 22: 00 \mathrm{PM}$ & Light1stBath & 1st Bathroom Lights & & \\
\hline 11:20:00 PM & 11:21:00 PM & KitchenSinkH & Kitchen Sink hot water & 2.38 & 0.63 \\
\hline 11:25:00 PM & 11:26:00 PM & KitchenSinkH & Kitchen Sink hot water & 2.38 & 0.63 \\
\hline 11:30:00 PM & 11:45:00 PM & HeatingPad & Heating Pad & & \\
\hline 11:30:00 PM & 11:45:00 PM & LightMastBath & Master Bathroom Lights & & \\
\hline 11:30:00 PM & 11:59:00 PM & LightMastBed & Master Bedroom Lights & & \\
\hline 11:30:00 PM & 11:59:00 PM & PortableFan & Portable Fan & & \\
\hline 11:30:00 PM & 11:59:00 PM & SHparentAMBR & $\begin{array}{l}\text { Sensible Heat ParentA Master } \\
\text { Bedroom }\end{array}$ & & \\
\hline 11:30:00 PM & 11:59:00 PM & SHparentBMBR & $\begin{array}{l}\text { Sensible Heat ParentB Master } \\
\text { Bedroom }\end{array}$ & & \\
\hline 11:40:00 PM & 11:41:00 PM & SinkMastBathH & $\begin{array}{l}\text { Sink event - Master Bathroom hot } \\
\text { water }\end{array}$ & 2.38 & 0.63 \\
\hline 11:50:00 PM & 11:51:00 PM & SinkMastBathH & $\begin{array}{l}\text { Sink event - Master Bathroom hot } \\
\text { water }\end{array}$ & 2.38 & 0.63 \\
\hline
\end{tabular}




\section{Saturdays}

\begin{tabular}{|c|c|c|c|c|c|c|}
\hline Start time & End time & FixtureID & Description & $\begin{array}{c}\text { Target } \\
\text { Volume } \\
\text { / Draw } \\
\text { (liters) }\end{array}$ & $\begin{array}{l}\text { Target } \\
\text { Volume } \\
\text { / Draw } \\
\text { (gallons) }\end{array}$ & $\begin{array}{c}\text { Target } \\
\text { Energy } \\
\text { / Event } \\
\text { (Wh) }\end{array}$ \\
\hline 12:05:00 AM & 8:15:00 AM & SHparentAMBR & $\begin{array}{l}\text { Sensible Heat ParentA Master } \\
\text { Bedroom }\end{array}$ & & & \\
\hline 12:05:00 AM & 8:15:00 AM & SHparentBMBR & $\begin{array}{l}\text { Sensible Heat ParentB Master } \\
\text { Bedroom }\end{array}$ & & & \\
\hline 12:05:00 AM & 9:00:00 AM & SHchildBBR3 & Sensible Heat ChildB Bedroom \# 3 & & & \\
\hline 12:05:00 AM & 9:30:00 AM & SHchildABR2 & Sensible Heat ChildA Bedroom \# 2 & & & \\
\hline 12:05:00 AM & 11:59:00 AM & Latent Load & Latent Load & & & \\
\hline 8:00:00 AM & $8: 15: 00$ AM & LightMastBath & Master Bathroom Lights & & & \\
\hline 8:04:00 AM & 8:05:00 AM & SinkMastBathH & $\begin{array}{l}\text { Sink event - Master Bathroom hot } \\
\text { water }\end{array}$ & 2.38 & 0.63 & \\
\hline 8:10:00 AM & 8:11:00 AM & SinkMastBathH & $\begin{array}{l}\text { Sink event - Master Bathroom hot } \\
\text { water }\end{array}$ & 2.38 & 0.63 & \\
\hline 8:14:00 AM & 8:15:00 AM & KitchenSinkH & Kitchen Sink hot water & 2.38 & 0.63 & \\
\hline 8:15:00 AM & 9:15:00 AM & CookTops & Cooktops & & & 408.04 \\
\hline 8:15:00 AM & 10:00:00 AM & KitchenLights & Kitchen Lights & & & \\
\hline 8:15:00 AM & 10:00:00 AM & SHparentAK & Sensible Heat ParentA Kitchen & & & \\
\hline 8:15:00 AM & 10:00:00 AM & SHparentBDR & $\begin{array}{l}\text { Sensible Heat ParentB Dining } \\
\text { Room }\end{array}$ & & & \\
\hline $8: 15: 00 \mathrm{AM}$ & 11:15:00 AM & Oven & Oven & & & 1946.79 \\
\hline $8: 16: 00 \mathrm{AM}$ & $8: 17: 00$ AM & SinkMastBathH & $\begin{array}{l}\text { Sink event - Master Bathroom hot } \\
\text { water }\end{array}$ & 2.38 & 0.63 & \\
\hline 8:20:00 AM & 8:21:00 AM & KitchenSinkH & Kitchen Sink hot water & 2.38 & 0.63 & \\
\hline 8:30:00 AM & 8:31:00 AM & KitchenSinkH & Kitchen Sink hot water & 2.38 & 0.63 & \\
\hline 8:30:00 AM & 11:00:00 AM & LivingRATV & Living room - Active TV & & & \\
\hline 8:30:00 AM & 7:00:00 PM & DesktopCA & Desktop PC and Monitor & & & 899.30 \\
\hline 8:40:00 AM & $8: 41: 00 \mathrm{AM}$ & KitchenSinkH & Kitchen Sink hot water & 2.38 & 0.63 & \\
\hline $8: 45: 00 \mathrm{AM}$ & 9:15:00 AM & Light2ndBath & 2nd Bathroom Lights & & & \\
\hline 8:50:00 AM & 8:51:00 AM & SinkMastBathH & $\begin{array}{l}\text { Sink event - Master Bathroom hot } \\
\text { water }\end{array}$ & 2.38 & 0.63 & \\
\hline 8:59:00 AM & 9:11:00 AM & $\begin{array}{c}\text { ShowerMastBath } \\
\text { H } \\
\end{array}$ & $\begin{array}{l}\text { Shower even - Master Bathroom } \\
\text { hot water }\end{array}$ & 33.12 & 8.75 & \\
\hline 9:00:00 AM & 10:00:00 AM & SHchildBDR & $\begin{array}{l}\text { Sensible Heat ChildB Dining } \\
\text { Room }\end{array}$ & & & \\
\hline 9:10:00 AM & 9:40:00 AM & CoffeeMaker & Coffee Maker & & & 168.12 \\
\hline 9:12:00 AM & 9:13:00 AM & KitchenSinkH & Kitchen Sink hot water & 2.38 & 0.63 & \\
\hline 9:14:00 AM & & MicrowaveCLR & $\begin{array}{l}\text { Clear Microwave (equivalent to } \\
\text { opening and closing the door) }\end{array}$ & & & \\
\hline 9:15:00 AM & 9:25:00 AM & Blender & Blender & & & 19.20 \\
\hline 9:15:00 AM & & MicrowaveON & Turn Microwave ON & & & \\
\hline 9:16:00 AM & 9:17:00 AM & SinkMastBathH & $\begin{array}{l}\text { Sink event - Master Bathroom hot } \\
\text { water }\end{array}$ & 2.38 & 0.63 & \\
\hline 9:20:00 AM & 9:30:00 AM & ToasterOven & Toaster Oven & & & 88.74 \\
\hline 9:20:00 AM & 9:35:00 AM & Toaster & Toaster & & & 126.10 \\
\hline 9:30:00 AM & 10:00:00 AM & DiningRLights & Dining Room Lights & & & \\
\hline
\end{tabular}




\begin{tabular}{|c|c|c|c|c|c|c|}
\hline 9:30:00 AM & 11:00:00 AM & SHchildALR & $\begin{array}{l}\text { Sensible Heat ChildA Living } \\
\text { Room }\end{array}$ & & & \\
\hline 9:32:00 AM & 9:33:00 AM & KitchenSinkH & Kitchen Sink hot water & 2.38 & 0.63 & \\
\hline 9:40:00 AM & 9:41:00 AM & KitchenSinkH & Kitchen Sink hot water & 2.38 & 0.63 & \\
\hline 9:45:00 AM & 8:30:00 PM & SlowCooker & Slow Cooker & & & 153.85 \\
\hline 10:00:00 AM & 10:10:00 AM & $\begin{array}{c}\text { ShowerMastBath } \\
\mathrm{H} \\
\end{array}$ & $\begin{array}{l}\text { Shower even - Master Bathroom } \\
\text { hot water }\end{array}$ & 33.12 & 8.75 & \\
\hline 10:00:00 AM & $10: 15: 00 \mathrm{AM}$ & LightMastBath & Master Bathroom Lights & & & \\
\hline 10:00:00 AM & 11:00:00 AM & SHparentBMBR & $\begin{array}{l}\text { Sensible Heat ParentB Master } \\
\text { Bedroom }\end{array}$ & & & \\
\hline 10:00:00 AM & 11:00:00 AM & VideoAGame & Video Game Active (Turned ON) & & & \\
\hline 10:09:00 AM & 10:19:00 AM & HairDryer & Hair Dryer & & & 115.70 \\
\hline 10:11:00 AM & 10:12:00 AM & SinkMastBathH & $\begin{array}{l}\text { Sink event - Master Bathroom hot } \\
\text { water }\end{array}$ & 2.38 & 0.63 & \\
\hline 10:15:00 AM & 11:00:00 AM & LightMastBed & Master Bedroom Lights & & & \\
\hline 10:30:00 AM & 10:31:00 AM & KitchenSinkH & Kitchen Sink hot water & 2.38 & 0.63 & \\
\hline 11:00:00 AM & 1:00:00 PM & ComputerACA & Bedroom \# 2 - Laptop & & & \\
\hline 11:00:00 AM & 1:00:00 PM & SHchildABR2 & Sensible Heat ChildA Bedroom \# 2 & & & \\
\hline 11:00:00 AM & 2:30:00 PM & SHparentBDR & $\begin{array}{l}\text { Sensible Heat ParentB Dining } \\
\text { Room }\end{array}$ & & & \\
\hline 11:00:00 AM & & WashingM & Clothes Washer & & & \\
\hline 12:00:00 PM & 12:01:00 PM & KitchenSinkH & Kitchen Sink hot water & 2.38 & 0.63 & \\
\hline 12:00:00 PM & 11:59:00 PM & Latent Load & Latent Load & & & \\
\hline 12:02:00 PM & 1:02:00 PM & CookTops & Cooktops & & & 408.04 \\
\hline 12:09:00 PM & & MicrowaveCLR & $\begin{array}{l}\text { Clear Microwave (equivalent to } \\
\text { opening and closing the door) }\end{array}$ & & & \\
\hline 12:10:00 PM & & MicrowaveON & Turn Microwave ON & & & \\
\hline 12:30:00 PM & 12:31:00 PM & KitchenSinkH & Kitchen Sink hot water & 2.38 & 0.63 & \\
\hline 12:30:00 PM & 12:45:00 PM & Light2ndBath & 2nd Bathroom Lights & & & \\
\hline 12:30:00 PM & 1:00:00 PM & SHchildBBR3 & Sensible Heat ChildB Bedroom \# 3 & & & \\
\hline 12:30:00 PM & 6:00:00 PM & SHparentAK & Sensible Heat ParentA Kitchen & & & \\
\hline 12:30:00 PM & & ClothDryer & Clothes Dryer & & & \\
\hline 12:32:00 PM & 12:43:00 PM & MBA Tub & Master Bathroom Tub & 113.56 & 30.00 & \\
\hline 12:44:00 PM & $12: 45: 00 \mathrm{PM}$ & SinkMastBathH & $\begin{array}{l}\text { Sink event - Master Bathroom hot } \\
\text { water }\end{array}$ & 2.38 & 0.63 & \\
\hline $12: 45: 00 \mathrm{PM}$ & 1:00:00 PM & Light2ndBed & 2nd Bedroom Lights & & & \\
\hline 1:00:00 PM & 1:01:00 PM & KitchenSinkH & Kitchen Sink hot water & 2.38 & 0.63 & \\
\hline 1:00:00 PM & 2:30:00 PM & SHchildALR & $\begin{array}{l}\text { Sensible Heat ChildA Living } \\
\text { Room }\end{array}$ & & & \\
\hline 1:00:00 PM & 6:00:00 PM & SHchildBDR & $\begin{array}{l}\text { Sensible Heat ChildB Dining } \\
\text { Room }\end{array}$ & & & \\
\hline 1:05:00 PM & 1:06:00 PM & KitchenSinkH & Kitchen Sink hot water & 2.38 & 0.63 & \\
\hline 2:00:00 PM & 2:01:00 PM & KitchenSinkH & Kitchen Sink hot water & 2.38 & 0.63 & \\
\hline 2:10:00 PM & $2: 11: 00 \mathrm{PM}$ & KitchenSinkH & Kitchen Sink hot water & 2.38 & 0.63 & \\
\hline 2:20:00 PM & 2:21:00 PM & KitchenSinkH & Kitchen Sink hot water & 2.38 & 0.63 & \\
\hline 2:30:00 PM & & WashingM & Clothes Washer & & & \\
\hline 3:00:00 PM & 4:30:00 PM & BlueRayL & Living room - BlueRay & & & \\
\hline
\end{tabular}




\begin{tabular}{|c|c|c|c|c|c|c|}
\hline 3:00:00 PM & 4:30:00 PM & LivingRATV & Living room - Active TV & & & \\
\hline 3:00:00 PM & & ClothDryer & Clothes Dryer & & & \\
\hline 5:00:00 PM & 6:00:00 PM & SHchildALR & $\begin{array}{l}\text { Sensible Heat ChildA Living } \\
\text { Room }\end{array}$ & & & \\
\hline 5:00:00 PM & 6:00:00 PM & SHparentBDR & $\begin{array}{l}\text { Sensible Heat ParentB Dining } \\
\text { Room }\end{array}$ & & & \\
\hline 5:30:00 PM & 5:31:00 PM & KitchenSinkH & Kitchen Sink hot water & 2.38 & 0.63 & \\
\hline 5:30:00 PM & 7:27:00 PM & VacuumC & Vacuum Cleaner & & & 1075.70 \\
\hline 6:00:00 PM & 6:45:00 PM & Iron & Iron & & & 506.70 \\
\hline 6:00:00 PM & 7:00:00 PM & LightMastBed & Master Bedroom Lights & & & \\
\hline 6:00:00 PM & 7:00:00 PM & SHparentBMBR & $\begin{array}{l}\text { Sensible Heat ParentB Master } \\
\text { Bedroom }\end{array}$ & & & \\
\hline 6:00:00 PM & 7:30:00 PM & ComputerACA & Bedroom \# 2 - Laptop & & & \\
\hline 6:00:00 PM & 7:30:00 PM & ComputerACB & Bedroom \# 3 - Laptop & & & \\
\hline 6:00:00 PM & 7:30:00 PM & Light2ndBed & 2nd Bedroom Lights & & & \\
\hline 6:00:00 PM & 7:30:00 PM & Light3rdBed & 3rd Bedroom Lights & & & \\
\hline 6:00:00 PM & 7:30:00 PM & SHchildABR2 & Sensible Heat ChildA Bedroom \# 2 & & & \\
\hline 6:00:00 PM & 8:30:00 PM & SHchildBBR3 & Sensible Heat ChildB Bedroom \# 3 & & & \\
\hline 7:00:00 PM & 7:01:00 PM & KitchenSinkH & Kitchen Sink hot water & 2.38 & 0.63 & \\
\hline 7:00:00 PM & 8:00:00 PM & CookTops & Cooktops & & & 408.04 \\
\hline 7:00:00 PM & 10:00:00 PM & Oven & Oven & & & 1946.79 \\
\hline 7:00:00 PM & 11:30:00 PM & KitchenLights & Kitchen Lights & & & \\
\hline 7:00:00 PM & 11:30:00 PM & SHparentBDR & $\begin{array}{l}\text { Sensible Heat ParentB Dining } \\
\text { Room }\end{array}$ & & & \\
\hline 7:05:00 PM & 7:12:05 PM & CanOpener & Can Opener & & & \\
\hline 7:05:00 PM & 7:15:00 PM & HandMixer & Hand Mixer & & & 5.50 \\
\hline 7:20:00 PM & 7:21:00 PM & KitchenSinkH & Kitchen Sink hot water & 2.38 & 0.63 & \\
\hline 8:00:00 PM & 8:01:00 PM & KitchenSinkH & Kitchen Sink hot water & 2.38 & 0.63 & \\
\hline 8:00:00 PM & $8: 15: 00 \mathrm{PM}$ & LightMastBath & Master Bathroom Lights & & & \\
\hline 8:00:00 PM & 8:30:00 PM & DiningRLights & Dining Room Lights & & & \\
\hline 8:00:00 PM & 8:30:00 PM & SHparentAMBR & $\begin{array}{l}\text { Sensible Heat ParentA Master } \\
\text { Bedroom }\end{array}$ & & & \\
\hline 8:00:00 PM & 11:30:00 PM & LivingRATV & Living room - Active TV & & & \\
\hline 8:05:00 PM & 8:17:00 PM & $\begin{array}{c}\text { ShowerMastBath } \\
\mathrm{H}\end{array}$ & $\begin{array}{l}\text { Shower even - Master Bathroom } \\
\text { hot water }\end{array}$ & 33.12 & 8.75 & \\
\hline 8:15:00 PM & 8:30:00 PM & LightMastBed & Master Bedroom Lights & & & \\
\hline 8:30:00 PM & 10:00:00 PM & SHchildBDR & $\begin{array}{l}\text { Sensible Heat ChildB Dining } \\
\text { Room }\end{array}$ & & & \\
\hline 8:30:00 PM & 11:00:00 PM & SHchildALR & $\begin{array}{l}\text { Sensible Heat ChildA Living } \\
\text { Room }\end{array}$ & & & \\
\hline 8:30:00 PM & 11:30:00 PM & SHparentAK & Sensible Heat ParentA Kitchen & & & \\
\hline 9:00:00 PM & 11:30:00 PM & LivingRLights & Living room Lights & & & \\
\hline 9:00:00 PM & & Dishwasher & Dishwasher & & & \\
\hline 9:10:00 PM & 9:11:00 PM & KitchenSinkH & Kitchen Sink hot water & 2.38 & 0.63 & \\
\hline 9:30:00 PM & 9:31:00 PM & KitchenSinkH & Kitchen Sink hot water & 2.38 & 0.63 & \\
\hline 9:36:00 PM & 9:37:00 PM & KitchenSinkH & Kitchen Sink hot water & 2.38 & 0.63 & \\
\hline
\end{tabular}




\begin{tabular}{|c|c|c|c|c|c|}
\hline 10:00:00 PM & 10:01:00 PM & KitchenSinkH & Kitchen Sink hot water & 2.38 & 0.63 \\
\hline 10:00:00 PM & 10:15:00 PM & Light2ndBath & 2nd Bathroom Lights & & \\
\hline 10:00:00 PM & 11:59:00 PM & SHchildBBR3 & Sensible Heat ChildB Bedroom \# 3 & & \\
\hline 10:05:00 PM & 10:06:00 PM & KitchenSinkH & Kitchen Sink hot water & 2.38 & 0.63 \\
\hline 10:12:00 PM & 10:13:00 PM & SinkMastBathH & $\begin{array}{l}\text { Sink event - Master Bathroom hot } \\
\text { water }\end{array}$ & 2.38 & 0.63 \\
\hline 10:18:00 PM & 10:22:00 PM & Light1stBath & 1st Bathroom Lights & & \\
\hline 10:20:00 PM & 10:21:00 PM & KitchenSinkH & Kitchen Sink hot water & 2.38 & 0.63 \\
\hline 10:30:00 PM & 10:31:00 PM & KitchenSinkH & Kitchen Sink hot water & 2.38 & 0.63 \\
\hline 10:40:00 PM & 10:41:00 PM & KitchenSinkH & Kitchen Sink hot water & 2.38 & 0.63 \\
\hline 11:00:00 PM & 11:15:00 PM & Light2ndBath & 2nd Bathroom Lights & & \\
\hline 11:00:00 PM & 11:59:00 PM & SHchildABR2 & Sensible Heat ChildA Bedroom \# 2 & & \\
\hline 11:10:00 PM & 11:11:00 PM & SinkMastBathH & $\begin{array}{l}\text { Sink event - Master Bathroom hot } \\
\text { water }\end{array}$ & 2.38 & 0.63 \\
\hline 11:18:00 PM & 11:22:00 PM & Light1stBath & 1st Bathroom Lights & & \\
\hline 11:25:00 PM & 11:26:00 PM & KitchenSinkH & Kitchen Sink hot water & 2.38 & 0.63 \\
\hline 11:28:00 PM & 11:29:00 PM & KitchenSinkH & Kitchen Sink hot water & 2.38 & 0.63 \\
\hline 11:30:00 PM & 11:45:00 PM & HeatingPad & Heating Pad & & \\
\hline 11:30:00 PM & 11:45:00 PM & LightMastBath & Master Bathroom Lights & & \\
\hline 11:30:00 PM & 11:59:00 PM & LightMastBed & Master Bedroom Lights & & \\
\hline 11:30:00 PM & 11:59:00 PM & PortableFan & Portable Fan & & \\
\hline 11:30:00 PM & 11:59:00 PM & SHparentAMBR & $\begin{array}{l}\text { Sensible Heat ParentA Master } \\
\text { Bedroom }\end{array}$ & & \\
\hline 11:30:00 PM & 11:59:00 PM & SHparentBMBR & $\begin{array}{l}\text { Sensible Heat ParentB Master } \\
\text { Bedroom }\end{array}$ & & \\
\hline 11:40:00 PM & 11:41:00 PM & SinkMastBathH & $\begin{array}{l}\text { Sink event - Master Bathroom hot } \\
\text { water }\end{array}$ & 2.38 & 0.63 \\
\hline 11:50:00 PM & 11:51:00 PM & SinkMastBathH & $\begin{array}{l}\text { Sink event - Master Bathroom hot } \\
\text { water }\end{array}$ & 2.38 & 0.63 \\
\hline
\end{tabular}




\section{Sundays}

\begin{tabular}{|c|c|c|c|c|c|c|}
\hline Start time & End time & FixtureID & Description & $\begin{array}{c}\text { Target } \\
\text { Volume / } \\
\text { Draw } \\
\text { (liters) }\end{array}$ & $\begin{array}{c}\text { Target } \\
\text { Volume / } \\
\text { Draw } \\
\text { (gallons) }\end{array}$ & $\begin{array}{c}\text { Target } \\
\text { Energy / } \\
\text { Event } \\
(\mathrm{Wh})\end{array}$ \\
\hline 12:05:00 AM & $8: 15: 00$ AM & SHparentAMBR & $\begin{array}{l}\text { Sensible Heat ParentA Master } \\
\text { Bedroom }\end{array}$ & & & \\
\hline 12:05:00 AM & 8:15:00 AM & SHparentBMBR & $\begin{array}{l}\text { Sensible Heat ParentB Master } \\
\text { Bedroom }\end{array}$ & & & \\
\hline 12:05:00 AM & 9:00:00 AM & SHchildABR2 & Sensible Heat ChildA Bedroom \# 2 & & & \\
\hline 12:05:00 AM & 9:00:00 AM & SHchildBBR3 & Sensible Heat ChildB Bedroom \# 3 & & & \\
\hline 12:05:00 AM & 11:59:00 AM & Latent Load & Latent Load & & & \\
\hline 6:09:00 AM & & MicrowaveCLR & $\begin{array}{l}\text { Clear Microwave (equivalent to } \\
\text { opening and closing the door) }\end{array}$ & & & \\
\hline 8:00:00 AM & 8:15:00 AM & LightMastBath & Master Bathroom Lights & & & \\
\hline 8:04:00 AM & 8:05:00 AM & SinkMastBathH & $\begin{array}{l}\text { Sink event - Master Bathroom hot } \\
\text { water }\end{array}$ & 2.38 & 0.63 & \\
\hline 8:10:00 AM & 8:11:00 AM & SinkMastBathH & $\begin{array}{l}\text { Sink event - Master Bathroom hot } \\
\text { water }\end{array}$ & 2.38 & 0.63 & \\
\hline 8:15:00 AM & 8:16:00 AM & KitchenSinkH & Kitchen Sink hot water & 2.38 & 0.63 & \\
\hline 8:15:00 AM & 9:15:00 AM & CookTops & Cooktops & & & 408.04 \\
\hline 8:15:00 AM & 10:00:00 AM & KitchenLights & Kitchen Lights & & & \\
\hline 8:15:00 AM & 10:00:00 AM & SHparentAK & Sensible Heat ParentA Kitchen & & & \\
\hline 8:15:00 AM & 10:00:00 AM & SHparentBDR & $\begin{array}{l}\text { Sensible Heat ParentB Dining } \\
\text { Room }\end{array}$ & & & \\
\hline 8:15:00 AM & $11: 15: 00 \mathrm{AM}$ & Oven & Oven & & & 1946.79 \\
\hline $8: 25: 00 \mathrm{AM}$ & $8: 26: 00$ AM & KitchenSinkH & Kitchen Sink hot water & 2.38 & 0.63 & \\
\hline 8:30:00 AM & 10:30:00 AM & LivingRATV & Living room - Active TV & & & \\
\hline 8:30:00 AM & 7:00:00 PM & DesktopCA & Desktop PC and Monitor & & & 899.3 \\
\hline 8:40:00 AM & 8:41:00 AM & KitchenSinkH & Kitchen Sink hot water & 2.38 & 0.63 & \\
\hline $8: 45: 00 \mathrm{AM}$ & 9:15:00 AM & Light2ndBath & 2nd Bathroom Lights & & & \\
\hline 8:50:00 AM & 8:51:00 AM & SinkMastBathH & $\begin{array}{l}\text { Sink event - Master Bathroom hot } \\
\text { water }\end{array}$ & 2.38 & 0.63 & \\
\hline 8:55:00 AM & 8:56:00 AM & KitchenSinkH & Kitchen Sink hot water & 2.38 & 0.63 & \\
\hline 9:00:00 AM & 9:11:00 AM & ShowerMastBathH & $\begin{array}{l}\text { Shower even - Master Bathroom } \\
\text { hot water }\end{array}$ & 33.12 & 8.75 & \\
\hline 9:00:00 AM & 9:30:00 AM & SHchildBBR3 & Sensible Heat ChildB Bedroom \# 3 & & & \\
\hline 9:00:00 AM & 11:00:00 AM & SHchildALR & $\begin{array}{l}\text { Sensible Heat ChildA Living } \\
\text { Room }\end{array}$ & & & \\
\hline 9:10:00 AM & 9:40:00 AM & CoffeeMaker & Coffee Maker & & & 168.12 \\
\hline 9:12:00 AM & 9:13:00 AM & KitchenSinkH & Kitchen Sink hot water & 2.38 & 0.63 & \\
\hline 9:14:00 AM & 9:15:00 AM & SinkMastBathH & $\begin{array}{l}\text { Sink event - Master Bathroom hot } \\
\text { water }\end{array}$ & 2.38 & 0.63 & \\
\hline 9:14:00 AM & & MicrowaveCLR & $\begin{array}{l}\text { Clear Microwave (equivalent to } \\
\text { opening and closing the door) }\end{array}$ & & & \\
\hline 9:15:00 AM & $9: 25: 00 \mathrm{AM}$ & Blender & Blender & & & 19.20 \\
\hline 9:15:00 AM & & MicrowaveON & Turn Microwave ON & & & \\
\hline
\end{tabular}




\begin{tabular}{|c|c|c|c|c|c|c|}
\hline 9:20:00 AM & 9:30:00 AM & ToasterOven & Toaster Oven & & & 88.80 \\
\hline 9:20:00 AM & 9:35:00 AM & Toaster & Toaster & & & 126.00 \\
\hline 9:30:00 AM & 10:00:00 AM & DiningRLights & Dining Room Lights & & & \\
\hline 9:30:00 AM & 10:00:00 AM & SHchildBDR & $\begin{array}{l}\text { Sensible Heat ChildB Dining } \\
\text { Room }\end{array}$ & & & \\
\hline 9:38:00 AM & 9:39:00 AM & KitchenSinkH & Kitchen Sink hot water & 2.38 & 0.63 & \\
\hline 10:00:00 AM & 10:11:00 AM & ShowerMastBathH & $\begin{array}{l}\text { Shower even - Master Bathroom } \\
\text { hot water }\end{array}$ & 33.12 & 8.75 & \\
\hline 10:00:00 AM & 10:15:00 AM & LightMastBath & Master Bathroom Lights & & & \\
\hline 10:00:00 AM & 11:00:00 AM & SHparentBMBR & $\begin{array}{l}\text { Sensible Heat ParentB Master } \\
\text { Bedroom }\end{array}$ & & & \\
\hline 10:00:00 AM & 11:00:00 AM & VideoAGame & Video Game Active (Turned ON) & & & \\
\hline 10:09:00 AM & 10:19:00 AM & HairDryer & Hair Dryer & & & 115.70 \\
\hline 10:12:00 AM & 10:13:00 AM & SinkMastBathH & $\begin{array}{l}\text { Sink event - Master Bathroom hot } \\
\text { water }\end{array}$ & 2.38 & 0.63 & \\
\hline 10:15:00 AM & 11:00:00 AM & LightMastBed & Master Bedroom Lights & & & \\
\hline 10:30:00 AM & 10:31:00 AM & KitchenSinkH & Kitchen Sink hot water & 2.38 & 0.63 & \\
\hline 10:40:00 AM & 10:41:00 AM & KitchenSinkH & Kitchen Sink hot water & 2.38 & 0.63 & \\
\hline 11:00:00 AM & 1:00:00 PM & ComputerACA & Bedroom \# 2 - Laptop & & & \\
\hline 11:00:00 AM & 1:00:00 PM & SHchildABR2 & Sensible Heat ChildA Bedroom \# 2 & & & \\
\hline 11:00:00 AM & 2:30:00 PM & SHparentBDR & $\begin{array}{l}\text { Sensible Heat ParentB Dining } \\
\text { Room }\end{array}$ & & & \\
\hline 11:00:00 AM & & WashingM & Clothes Washer & & & \\
\hline 12:00:00 PM & 12:01:00 PM & KitchenSinkH & Kitchen Sink hot water & 2.38 & 0.63 & \\
\hline 12:00:00 PM & 11:59:00 PM & Latent Load & Latent Load & & & \\
\hline 12:02:00 PM & 1:02:00 PM & CookTops & Cooktops & & & 408.04 \\
\hline 12:09:00 PM & & MicrowaveCLR & $\begin{array}{l}\text { Clear Microwave (equivalent to } \\
\text { opening and closing the door) }\end{array}$ & & & \\
\hline 12:10:00 PM & & MicrowaveON & Turn Microwave ON & & & \\
\hline 12:30:00 PM & 12:31:00 PM & KitchenSinkH & Kitchen Sink hot water & 2.38 & 0.63 & \\
\hline 12:30:00 PM & 1:00:00 PM & SHchildBBR3 & Sensible Heat ChildB Bedroom \# 3 & & & \\
\hline 12:30:00 PM & 2:00:00 PM & SHparentAK & Sensible Heat ParentA Kitchen & & & \\
\hline 12:30:00 PM & & ClothDryer & Clothes Dryer & & & \\
\hline 12:40:00 PM & 12:41:00 PM & KitchenSinkH & Kitchen Sink hot water & 2.38 & 0.63 & \\
\hline 1:00:00 PM & 1:01:00 PM & KitchenSinkH & Kitchen Sink hot water & 2.38 & 0.63 & \\
\hline 1:00:00 PM & 2:30:00 PM & SHchildALR & $\begin{array}{l}\text { Sensible Heat ChildA Living } \\
\text { Room }\end{array}$ & & & \\
\hline 1:00:00 PM & 6:30:00 PM & SHchildBDR & $\begin{array}{l}\text { Sensible Heat ChildB Dining } \\
\text { Room }\end{array}$ & & & \\
\hline 1:05:00 PM & 1:06:00 PM & KitchenSinkH & Kitchen Sink hot water & 2.38 & 0.63 & \\
\hline 2:00:00 PM & 2:11:00 PM & ShowerMastBathH & $\begin{array}{l}\text { Shower even - Master Bathroom } \\
\text { hot water }\end{array}$ & 33.12 & 8.75 & \\
\hline 2:00:00 PM & 2:15:00 PM & LightMastBath & Master Bathroom Lights & & & \\
\hline 2:00:00 PM & 2:30:00 PM & SHparentAMBR & $\begin{array}{l}\text { Sensible Heat ParentA Master } \\
\text { Bedroom }\end{array}$ & & & \\
\hline 2:12:00 PM & 2:13:00 PM & SinkMastBathH & $\begin{array}{l}\text { Sink event - Master Bathroom hot } \\
\text { water }\end{array}$ & 2.38 & 0.63 & \\
\hline 2:16:00 PM & 3:00:00 PM & Iron & Iron & & & 506.70 \\
\hline
\end{tabular}




\begin{tabular}{|c|c|c|c|c|c|c|}
\hline 2:20:00 PM & 2:21:00 PM & KitchenSinkH & Kitchen Sink hot water & 2.38 & 0.63 & \\
\hline 2:30:00 PM & 6:00:00 PM & SHparentAK & Sensible Heat ParentA Kitchen & & & \\
\hline 2:30:00 PM & & WashingM & Clothes Washer & & & \\
\hline 3:00:00 PM & 4:30:00 PM & BlueRayL & Living room - BlueRay & & & \\
\hline 3:00:00 PM & 4:30:00 PM & LivingRATV & Living room - Active TV & & & \\
\hline 3:00:00 PM & & ClothDryer & Clothes Dryer & & & \\
\hline 5:00:00 PM & 6:00:00 PM & SHchildALR & $\begin{array}{l}\text { Sensible Heat ChildA Living } \\
\text { Room }\end{array}$ & & & \\
\hline 5:00:00 PM & 10:00:00 PM & SHparentBDR & $\begin{array}{l}\text { Sensible Heat ParentB Dining } \\
\text { Room }\end{array}$ & & & \\
\hline 5:30:00 PM & 5:31:00 PM & KitchenSinkH & Kitchen Sink hot water & 2.38 & 0.63 & \\
\hline 5:40:00 PM & 5:41:00 PM & KitchenSinkH & Kitchen Sink hot water & 2.38 & 0.63 & \\
\hline 6:00:00 PM & 6:01:00 PM & KitchenSinkH & Kitchen Sink hot water & 2.38 & 0.63 & \\
\hline 6:00:00 PM & 6:30:00 PM & KitchenLights & Kitchen Lights & & & \\
\hline 6:00:00 PM & 6:30:00 PM & LivingRLights & Living room Lights & & & \\
\hline 6:00:00 PM & 6:30:00 PM & SHparentAMBR & $\begin{array}{l}\text { Sensible Heat ParentA Master } \\
\text { Bedroom }\end{array}$ & & & \\
\hline 6:00:00 PM & 7:30:00 PM & SHchildABR2 & Sensible Heat ChildA Bedroom \# 2 & & & \\
\hline 6:01:00 PM & 6:06:00 PM & LightMastBath & Master Bathroom Lights & & & \\
\hline 6:02:00 PM & 6:06:00 PM & Light1stBath & 1st Bathroom Lights & & & \\
\hline 6:02:00 PM & 7:02:00 PM & CookTops & Cooktops & & & 408.04 \\
\hline 6:05:00 PM & 6:06:00 PM & SinkMastBathH & $\begin{array}{l}\text { Sink event - Master Bathroom hot } \\
\text { water }\end{array}$ & 2.38 & 0.63 & \\
\hline 6:07:00 PM & 6:30:00 PM & LightMastBed & Master Bedroom Lights & & & \\
\hline 6:08:00 PM & 6:18:00 PM & Light2ndBath & 2nd Bathroom Lights & & & \\
\hline 6:09:00 PM & & MicrowaveCLR & $\begin{array}{l}\text { Clear Microwave (equivalent to } \\
\text { opening and closing the door) }\end{array}$ & & & \\
\hline 6:10:00 PM & 6:25:00 PM & ShowerMastBathH & $\begin{array}{l}\text { Shower even - Master Bathroom } \\
\text { hot water }\end{array}$ & 53.00 & 14.00 & \\
\hline 6:10:00 PM & 10:40:00 PM & LivingRATV & Living room - Active TV & & & \\
\hline $6: 10: 00 \mathrm{PM}$ & & MicrowaveON & Turn Microwave ON & & & \\
\hline 6:20:00 PM & 12:00:00 AM & Light2ndBed & 2nd Bedroom Lights & & & \\
\hline 6:26:00 PM & 6:27:00 PM & SinkMastBathH & $\begin{array}{l}\text { Sink event - Master Bathroom hot } \\
\text { water }\end{array}$ & 2.38 & 0.63 & \\
\hline 6:30:00 PM & 7:30:00 PM & SHchildBBR3 & Sensible Heat ChildB Bedroom \# 3 & & & \\
\hline 6:30:00 PM & 8:15:00 PM & ComputerACB & Bedroom \# 3 - Laptop & & & \\
\hline 6:30:00 PM & 8:30:00 PM & Light3rdBed & 3rd Bedroom Lights & & & \\
\hline 6:30:00 PM & 10:00:00 PM & ComputerACA & Bedroom \# 2 - Laptop & & & \\
\hline 6:30:00 PM & 10:30:00 PM & SHparentAK & Sensible Heat ParentA Kitchen & & & \\
\hline 6:40:00 PM & 6:41:00 PM & KitchenSinkH & Kitchen Sink hot water & 2.38 & 0.63 & \\
\hline 6:40:00 PM & 6:47:04 PM & CanOpener & Can Opener & & & \\
\hline 6:40:00 PM & 6:50:00 PM & HandMixer & Hand Mixer & & & 5.50 \\
\hline 6:55:00 PM & 6:56:00 PM & KitchenSinkH & Kitchen Sink hot water & 2.38 & 0.63 & \\
\hline 7:00:00 PM & 7:15:00 PM & KitchenLights & Kitchen Lights & & & \\
\hline 7:00:00 PM & 7:15:00 PM & LivingRLights & Living room Lights & & & \\
\hline
\end{tabular}




\begin{tabular}{|c|c|c|c|c|c|}
\hline 7:05:00 PM & 7:06:00 PM & KitchenSinkH & Kitchen Sink hot water & 2.38 & 0.63 \\
\hline 7:15:00 PM & 8:30:00 PM & DiningRLights & Dining Room Lights & & \\
\hline 7:30:00 PM & $8: 15: 00 \mathrm{PM}$ & KitchenLights & Kitchen Lights & & \\
\hline 7:30:00 PM & 8:15:00 PM & SHchildALR & $\begin{array}{l}\text { Sensible Heat ChildA Living } \\
\text { Room }\end{array}$ & & \\
\hline 7:30:00 PM & 8:15:00 PM & SHchildBDR & $\begin{array}{l}\text { Sensible Heat ChildB Dining } \\
\text { Room }\end{array}$ & & \\
\hline 7:30:00 PM & 10:30:00 PM & LivingRLights & Living room Lights & & \\
\hline 8:15:00 PM & 8:16:00 PM & KitchenSinkH & Kitchen Sink hot water & 2.38 & 0.63 \\
\hline 8:15:00 PM & 8:25:00 PM & Light2ndBath & 2nd Bathroom Lights & & \\
\hline 8:15:00 PM & 11:59:00 PM & SHchildABR2 & Sensible Heat ChildA Bedroom \# 2 & & \\
\hline 8:15:00 PM & 11:59:00 PM & SHchildBBR3 & Sensible Heat ChildB Bedroom \# 3 & & \\
\hline $8: 20: 00$ PM & 8:21:00 PM & SinkMastBathH & $\begin{array}{l}\text { Sink event - Master Bathroom hot } \\
\text { water }\end{array}$ & 2.38 & 0.63 \\
\hline $8: 28: 00 \mathrm{PM}$ & & Dishwasher & Dishwasher & & \\
\hline 8:30:00 PM & 10:30:00 PM & KitchenLights & Kitchen Lights & & \\
\hline $8: 35: 00 \mathrm{PM}$ & 8:36:00 PM & KitchenSinkH & Kitchen Sink hot water & 2.38 & 0.63 \\
\hline 8:50:00 PM & 8:51:00 PM & KitchenSinkH & Kitchen Sink hot water & 2.38 & 0.63 \\
\hline 9:00:00 PM & 9:01:00 PM & KitchenSinkH & Kitchen Sink hot water & 2.38 & 0.63 \\
\hline 9:00:00 PM & 9:15:00 PM & Light2ndBath & 2nd Bathroom Lights & & \\
\hline 9:05:00 PM & 9:06:00 PM & SinkMastBathH & $\begin{array}{l}\text { Sink event - Master Bathroom hot } \\
\text { water }\end{array}$ & 2.38 & 0.63 \\
\hline 9:30:00 PM & 9:31:00 PM & KitchenSinkH & Kitchen Sink hot water & 2.38 & 0.63 \\
\hline 9:40:00 PM & 9:41:00 PM & KitchenSinkH & Kitchen Sink hot water & 2.38 & 0.63 \\
\hline 9:45:00 PM & 10:00:00 PM & Light2ndBath & 2nd Bathroom Lights & & \\
\hline 9:55:00 PM & 9:56:00 PM & SinkMastBathH & $\begin{array}{l}\text { Sink event - Master Bathroom hot } \\
\text { water }\end{array}$ & 2.38 & 0.63 \\
\hline 10:00:00 PM & 10:15:00 PM & HeatingPad & Heating Pad & & \\
\hline 10:00:00 PM & 11:00:00 PM & LightMastBed & Master Bedroom Lights & & \\
\hline 10:00:00 PM & 11:30:00 PM & BlueRayM & Master Bedroom - BlueRay & & \\
\hline 10:00:00 PM & 11:30:00 PM & MastBedATV & Master Bedroom Active TV & & \\
\hline 10:00:00 PM & 11:59:00 PM & PortableFan & Portable Fan & & \\
\hline 10:00:00 PM & 11:59:00 PM & SHparentBMBR & $\begin{array}{l}\text { Sensible Heat ParentB Master } \\
\text { Bedroom }\end{array}$ & & \\
\hline 10:05:00 PM & 10:06:00 PM & KitchenSinkH & Kitchen Sink hot water & 2.38 & 0.63 \\
\hline 10:05:00 PM & $10: 25: 00 \mathrm{PM}$ & LightMastBath & Master Bathroom Lights & & \\
\hline 10:20:00 PM & 10:21:00 PM & SinkMastBathH & $\begin{array}{l}\text { Sink event - Master Bathroom hot } \\
\text { water }\end{array}$ & 2.38 & 0.63 \\
\hline 10:30:00 PM & 10:40:00 PM & LightMastBath & Master Bathroom Lights & & \\
\hline 10:30:00 PM & 11:59:00 PM & SHparentAMBR & $\begin{array}{l}\text { Sensible Heat ParentA Master } \\
\text { Bedroom }\end{array}$ & & \\
\hline 10:40:00 PM & 10:41:00 PM & SinkMastBathH & $\begin{array}{l}\text { Sink event - Master Bathroom hot } \\
\text { water }\end{array}$ & 2.38 & 0.63 \\
\hline
\end{tabular}

